\title{
Delivery and Test of the Digital Hardhat System at U.S. Army Corps of Engineers Fort Worth District Office
}

Annette Stumpf, Liang Y. Liu, Chul-Soo Kim, and Sangyoon Chin

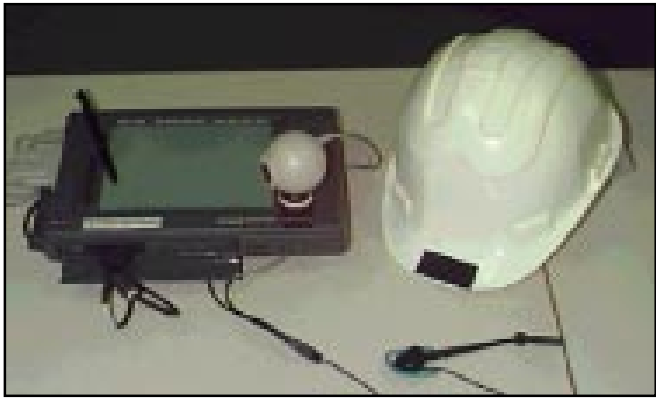

Quality assurance at military construction sites presents a challenge for the Corps of Engineers and other participants. The cost and time required to travel between sites limits the ability of personnel to quickly respond to problems at remote sites and to communicate issues between all necessary decision makers. Also, it is difficult to organize and transmit multimedia project information (digital pictures, video, electronic documents, and audio recordings) so that others can access current project information in an intuitive and timely manner.

The Digital Hardhat (DHH) technology enables dispersed users to capture and communicate multimedia field data to collaboratively solve problems, and collect and share information. The DHH is a pen-based personal computer with special Multimedia Facility Reporting System software that allows the field representative to save multimedia information into a project-specific database, which is then accessible to others through the World Wide Web.

Results of the DHH System test show that the system improves the documentation of site conditions by integrating multimedia and database technologies; structured organization of project information provides easy and timely retrieval for fast and accurate decision-making and problem-solving; easy availability of multimedia project information reduces frequent travel and telephone expenses between sites; videoconferencing and whiteboarding on the Internet improved the collaboration of project participants by sharing construction information in multimedia formats.

Although problems still exist, it was proven that the DHH System could enhance the current paradigm in project documentation and collaboration. 


\section{Foreword}

This research was conducted for U.S. Army Corps of Engineers, Fort Worth District under Military Interdepartmental Purchase Request (MIPR) W45XMA 72708807. The report summarizes the research activities under contracts between the University of Illinois and USACERL (DACA88-96-D-0005-03 and DACA88-96-D-0005-04, 18 February 1997 - 31 J anuary 1998). The Fort Worth District technical monitor was AI Khatena, CESWF-PM-J (MED).

The work was performed by the U.S. Army Construction Engineering Research Laboratories (USACERL), Planning and Management Laboratory (PL), Engineering Processes Division (PL-E). The principal investigator for the project was Annette Stumpf (PL-E). Michael P. Case is Chief, PL-E, and L. Michael Golish is Operations Chief, PL. Liang Y. Liu is an Assistant Professor in the Department of Civil Engineering, University of Illinois at Urbana-Champaign. Acknowledgements are also due to Sangyoon Chin and Chul-Soo Kim at the University of Illinois for their outstanding contribution while developing and field testing the Digital Hardhat System. The USACERL technical editor was Linda L. Wheatley, Technical Information Team.

Dr. Michael J . O'Connor is Director of USACE RL. 


\section{Contents}

SF 298..................................................................................... Error! Bookmark not defined.

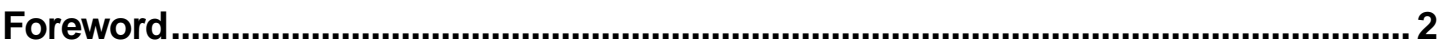

List of Figures and Tables ............................................................................................. 5

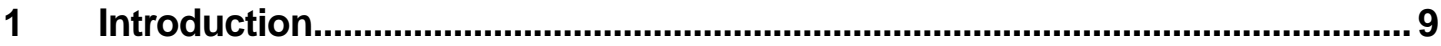

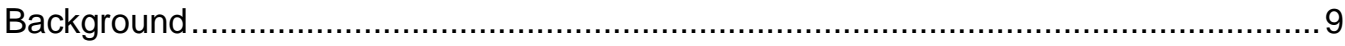

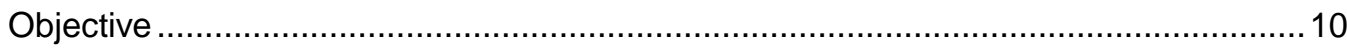

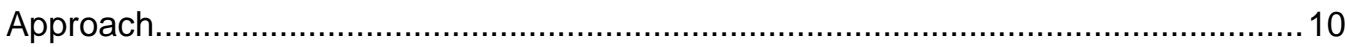

2 The Digital Hardhat System .............................................................................. 12

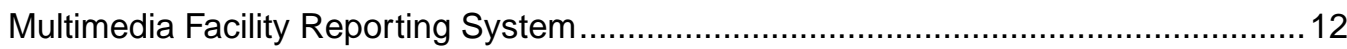

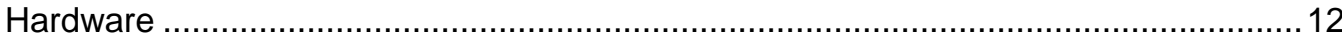

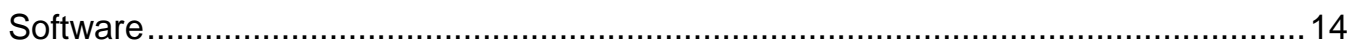

3 Operation of the Digital Hardhat System ......................................................... 18

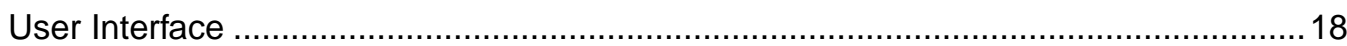

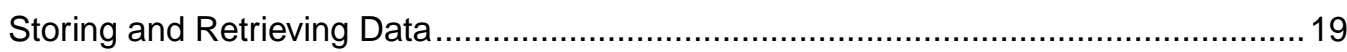

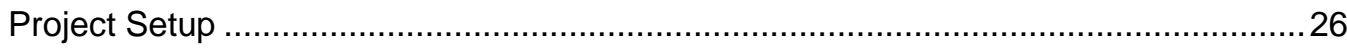

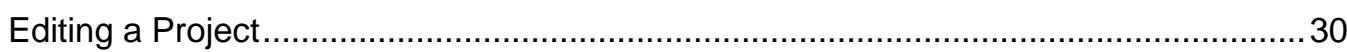

Setting Camera Capture Properties..................................................................... 34

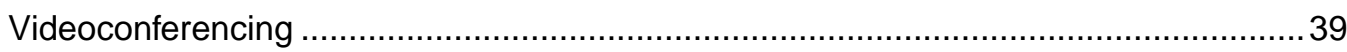

Retrieving Data Through a WWW Browser ........................................................... 44

$4 \quad$ Digital Hardhat System Field Test and Results................................................ 48

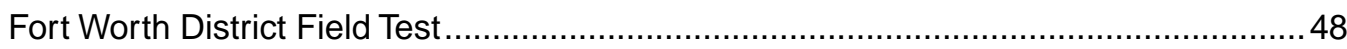

Lessons Learned During the Fort Worth Field Test ............................................... 51

USACERL Field Test and Lessons Learned .......................................................53

5 Summary and Future Development of the Digital Hardhat Technology ......... 65

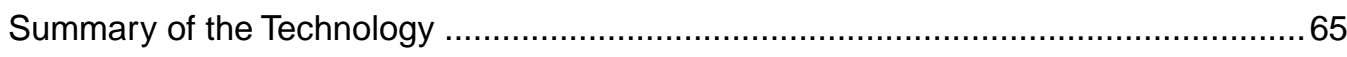

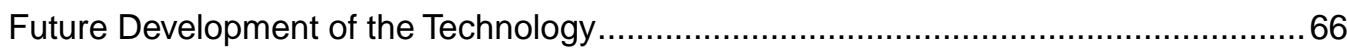




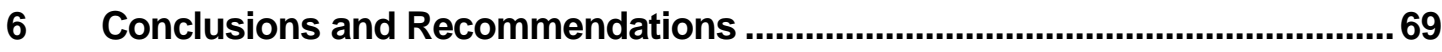

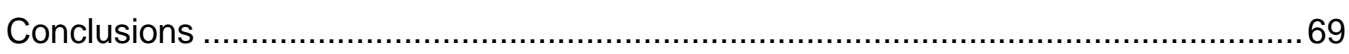

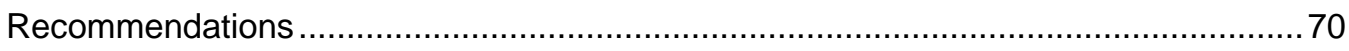

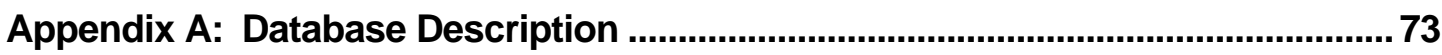

Appendix B: Project File and Data Source Naming Conventions.............................. 76

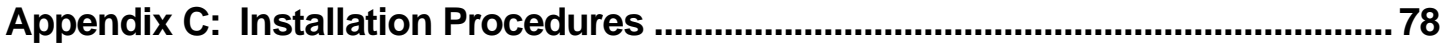

Distribution 


\section{List of Figures and Tables}

\section{Figures}

\begin{tabular}{|c|c|}
\hline 1 & 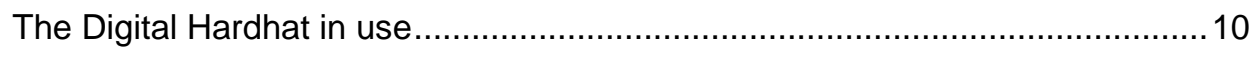 \\
\hline 2 & Hardware components. \\
\hline 3 & The server unit ... \\
\hline 4 & The mobile unit and a hardhat... \\
\hline 5 & The MFR main user interface......... \\
\hline 6 & Select a Project ......................... \\
\hline 7 & 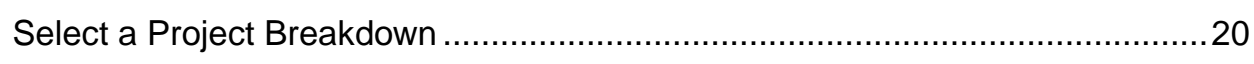 \\
\hline 8 & User Selection Reminder ..................................... \\
\hline 9 & 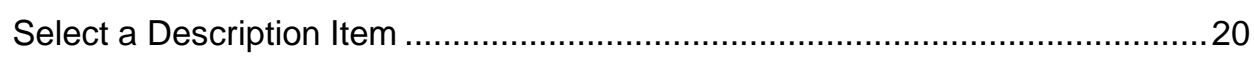 \\
\hline 10 & Preview/Capture buttons ..................................... \\
\hline 11 & 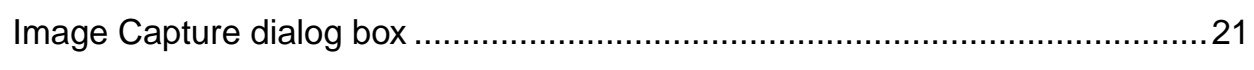 \\
\hline 12 & Captured Still Image dialog box .................................... \\
\hline 13 & 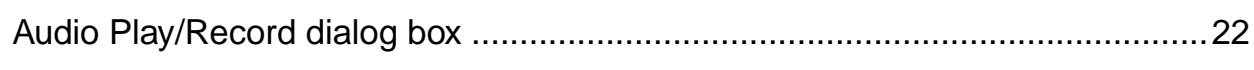 \\
\hline 14 & Capturing a video clip........................................... \\
\hline 15 & Import Image button \\
\hline 16 & Select a File to import ............................ \\
\hline 17 & 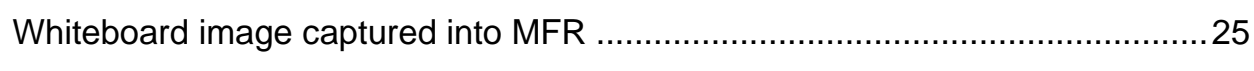 \\
\hline 18 & Select an Image Name to display........... \\
\hline 19 & Create Project menu \\
\hline 20 & Input Project Information to Create ......... \\
\hline 21 & Archive Multimedia menu ...................... \\
\hline 22 & Select a Project to archive................ \\
\hline 23 & Transfer Data menu ........................ \\
\hline 24 & The main dialog box for data transfer ..................... \\
\hline 25 & Delete Project menu.... \\
\hline 26 & Confirm to delete each file ................................. \\
\hline 2 & Define Project Information menu.......... \\
\hline 28 & Edit Project Information-Location and Description ............................................ 31 \\
\hline & Define Project Breakdown menu..... \\
\hline
\end{tabular}


30 Define Project Breakdown dialog box ......................................................... 32

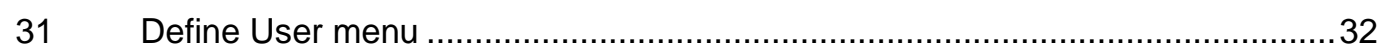

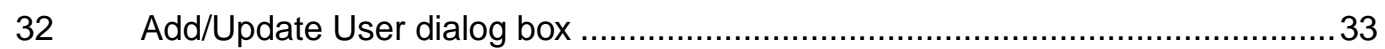

33 Right-Click an Image Name to delete.......................................................... 33

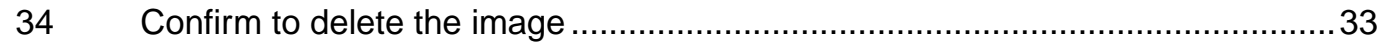

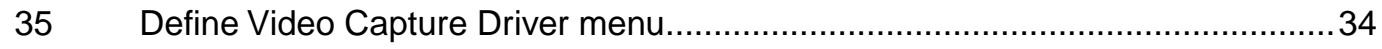

36 Select a Driver for the Installed Video Capture Device.......................................34

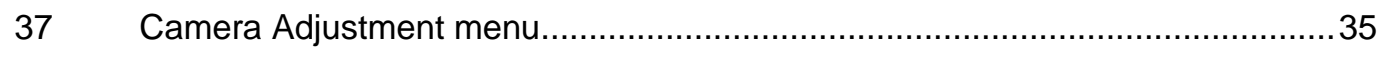

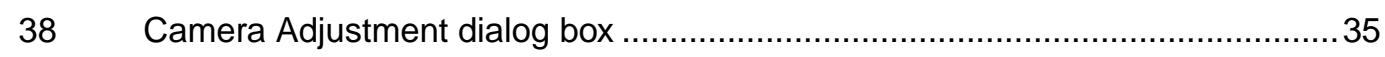

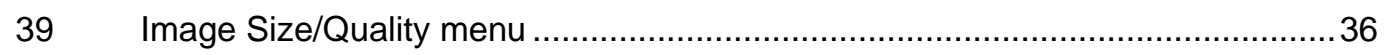

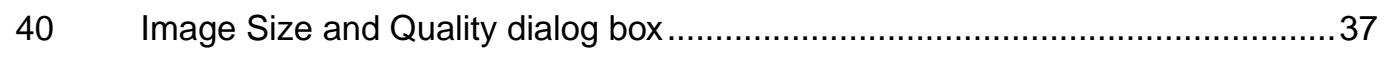

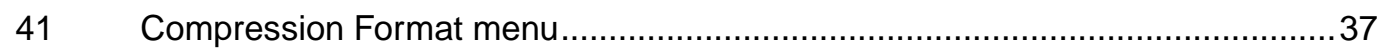

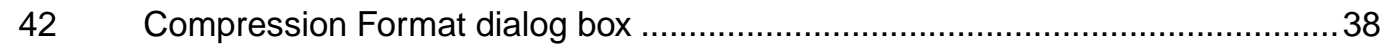

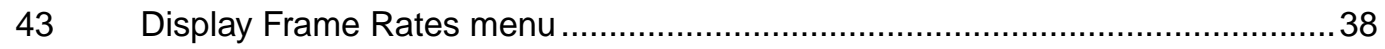

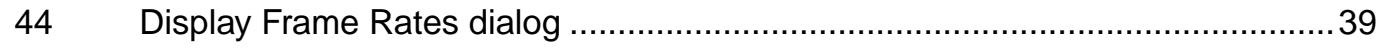

$45 \quad$ Internet Phone 4.0

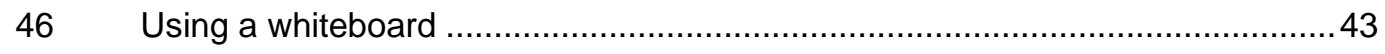

$47 \quad$ The home page of the MFR WWW server .................................................. 44

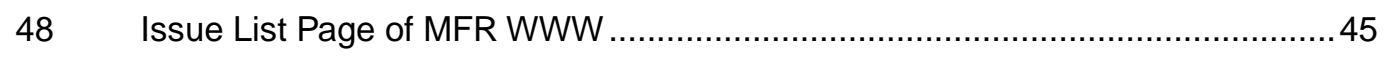

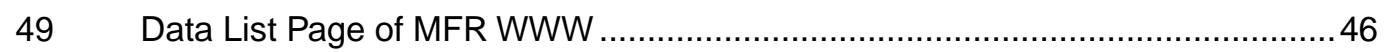

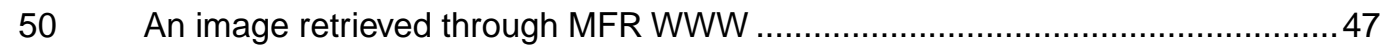

$51 \quad$ Video/audio clips retrieved through MFR WWW ............................................. 47

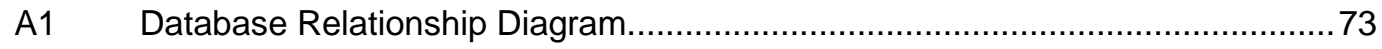

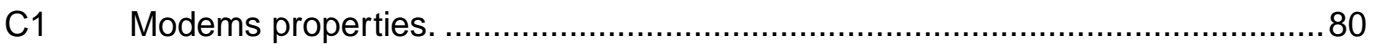

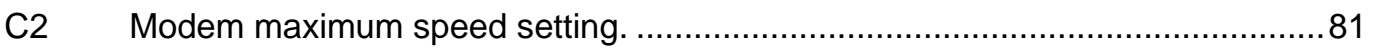

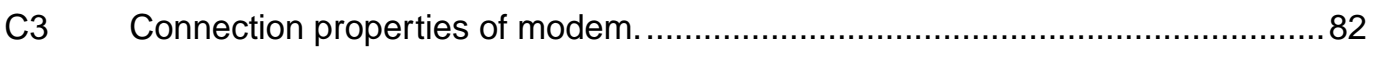

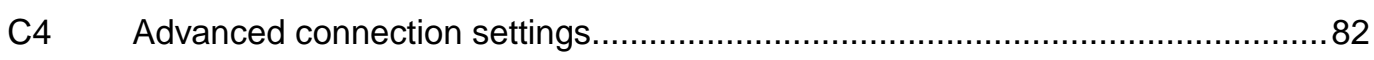

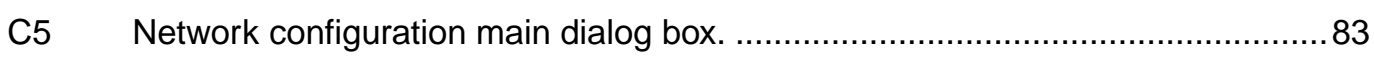

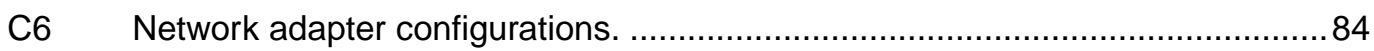

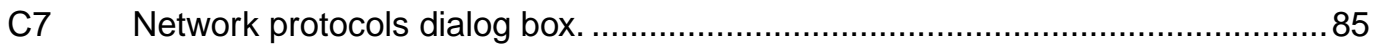

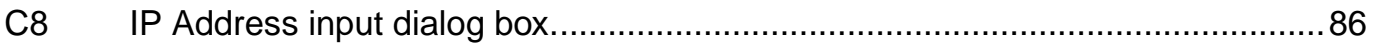

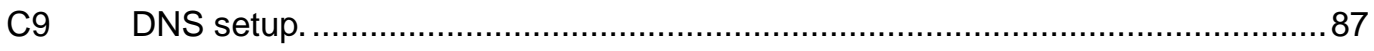

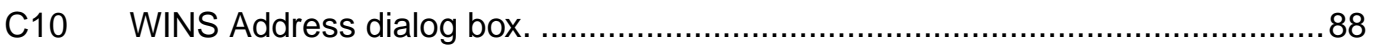

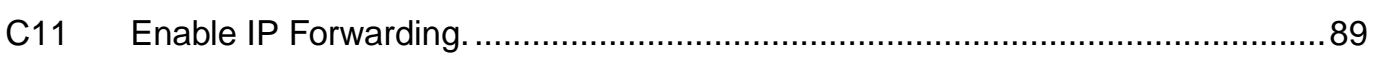

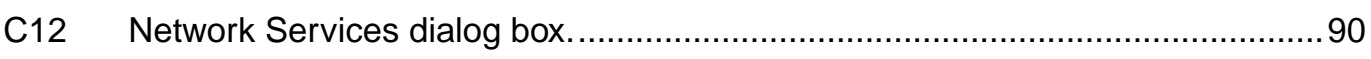

C13 Remote Access Setup dialog box. …..................................................... 90 
C14 Set Dial out and Receive calls................................................................. 91

C15 Allow remote clients running NetBEUI. ..........................................................92

C16 Allow remote NetBEUI clients to access the entire network. ...........................92

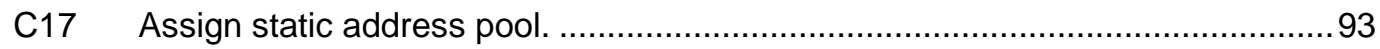

\section{Tables}

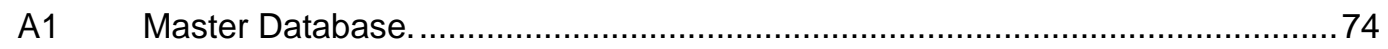

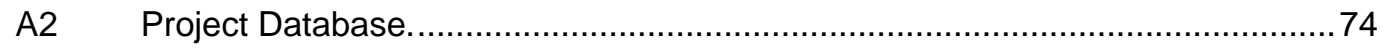

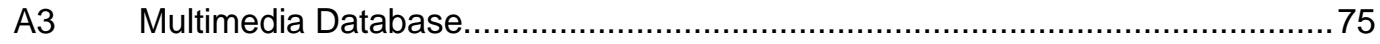

\section{Trademarks}

Conference Card is a trademark of Nogatech, Inc.

Etherlink is a registered trademark of 3Com Corporation.

Internet Phone is a registered trademark of Vocaltec Communications Ltd.

$\mathrm{Jaz}$ is a registered trademark of lomega Corporation.

SlimSCSI is a trademark of Adaptec, Inc.

Stylistic is a trademark of Fujitsu, Inc.

U.S. Robotics and Sportster are trademarks of 3Com Corporation.

QuickCam is a trademark of Connectix Corporation.

Wavepoint is a trademark of Lucent Technologies.

Windows 95, Windows NT, Windows CE, NetMeeting, and Access are trademarks of Microsoft Corporation. 


\section{Introduction}

\section{Background}

Quality assurance at military construction sites presents a challenge for the Corps of Engineers and other participants. The cost and time required to travel between District, area, installation, and field offices limits the ability of personnel to quickly respond to problems at remote sites. Field decisions often require input from people at other locations. Communication of issues between all necessary decision makers requires time, travel, and accurate documentation of field conditions. Also, it is difficult to organize and transmit multimedia project information (digital pictures, video, electronic documents, and audio recordings) so that others can access current project information in an intuitive and timely manner.

The Digital Hardhat ( $\mathrm{DHH}$ ) technology enables dispersed users to capture and communicate multimedia field data to collaboratively solve problems, and collect and share information. The $\mathrm{DHH}$ is a pen-based personal computer (PC) running Windows 95. It is used to collect multimedia information (text, sound, video, and images). Special software called Multimedia Facility Reporting System (MF R) al lows the field representative to save multimedia information into a project-specific database, which is then accessible to others through the World Wide Web (WWW). The pen-based computer can also be used to communicate between the construction site and other locations using a direct network connection, a wireless network connection, an Integrated Services Digital Network (ISDN) line and modem, a POTS (Plain Old Telephone System) analog line and modem (28.8 kps minimum recommended), or any means of cellular communications and associated modem compatible with the computer. If the field representative is using $\mathrm{DHH}$ with a wireless network or modem, s/he will be able to roam around the site and video teleconference live with others to solve problems collaboratively. The project information collected using $\mathrm{DHH}$ will help document site conditions, progress, and problems in an organized manner so the information can be retrieved easily as needed by any project participant. The remote user can also access other electronic project information (such as CADD drawings, specifications, or change orders) through a network connection or 
modem. The Digital Hardhat equipment configuration shown in Figure 1 was used in this field test; however, other ways of capturing and sharing multimedia information will work if they can interface with the computer.

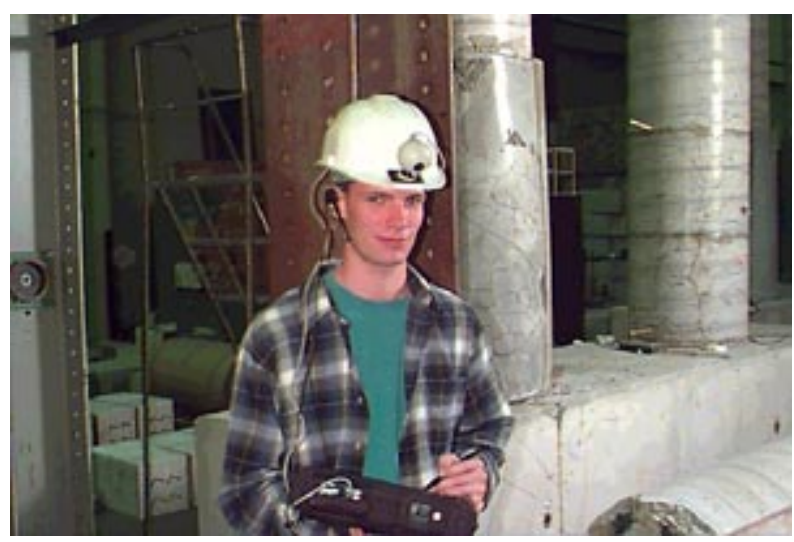

Figure 1. The Digital Hardhat in use.

\section{Objective}

The objective of this research is to improve the usability of DHH hardware and software so that the Fort Worth customer is able to integrate $\mathrm{DHH}$ into current operations successfully.

\section{Approach}

The DHH System (including hardware, software, and communication devices) was installed in J une 1997, so that mobile team members could communicate and share multimedia data between remote facilities, sites, or field and District offices. Web-enabled multimedia database management software was provided so that the mobile team could capture accurate site conditions (text, video, sound, or images) into a multimedia database that can be accessed from a Web site using network connections.

The DHH System is being evaluated to determine the strengths and weaknesses of the technology. Other issues to be evaluated include: (1) time required to resolve outstanding issues, (2) "quality" of decisions versus traditional methods (using both the DHH and multimedia database system), and (3) which kinds of meetings can be effectively conducted using the $\mathrm{DHH}$. 
It is expected that the data-sharing capabilities and improved communication offered by the DHH System will result in a reasonable payback period if the costs of avoided travel and extended meetings are considered. Immediate reductions in travel cost will be the most obvious benefit; however, costs associated with more quickly resolving issues, reducing construction claims, and fewer time delays will be the ultimate benefit of this technology. Improved communication between personnel involved in project planning, design, and construction throughout the life of the project is expected to improve the quality of the completed facility. Additional field testing is necessary, with emphasis on streamlining the procedures for usage, operation, and setup of the $\mathrm{DHH}$ technology. 


\section{The Digital Hardhat System}

\section{Multimedia Facility Reporting System}

DHH supports the management and communication of multimedia construction information using advanced network technologies such as the MFR, developed for facility management tasks of the Corps of Engineers. MFR allows easy capture and retrieval of multimedia construction information based on a userdefined project breakdown. In addition, captured multimedia information is accessible using WWW browsers on the Internet. To support the real-time communication for efficient problem-solving and decision-making, users can discuss the captured information through videoconferencing and white board conferencing between project sites and District offices. For more detailed information on data fields and relationships in the MFR database, see Appendix A. Appendix $B$ describes the database and file naming conventions. Appendix $C$ describes the steps required to set up a new PC as an MFR server.

\section{Hardware}

The components of the DHH System are shown in Figure 2. Separate detailed descriptions of the server and mobile units are given on the next two pages.

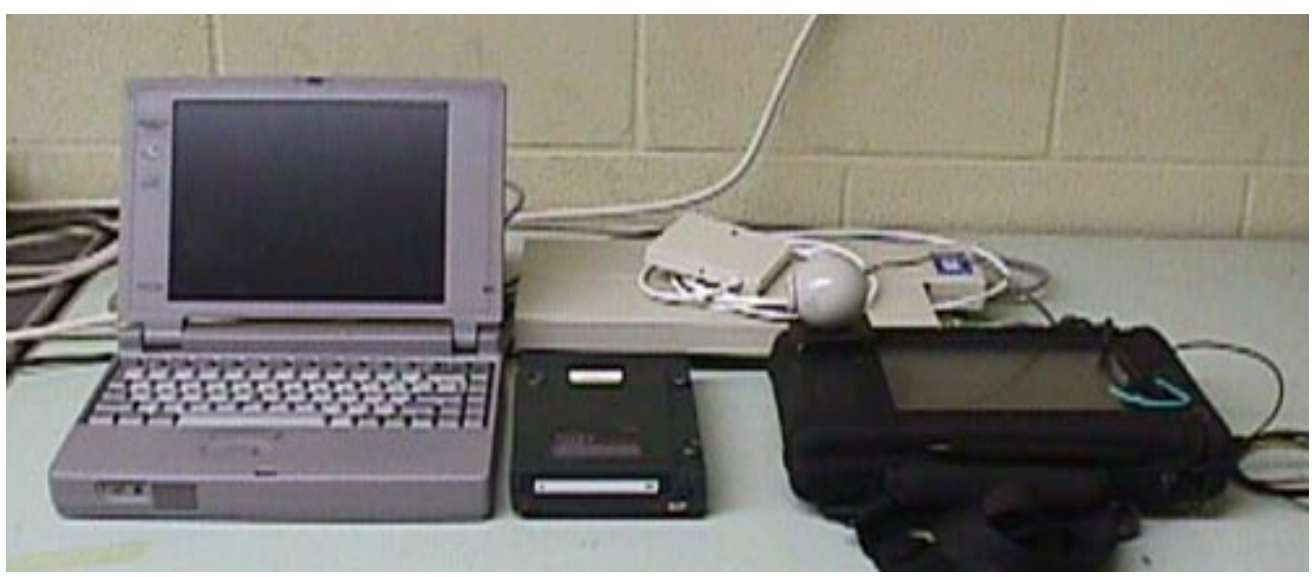

Figure 2. Hardware components. 
Note: The DHH system is just one means of multimedia capture. Any of the hardware can be replaced by other technology that achieves the same objective. Advances in technology are inevitable, so none of the hardware or brand names are mandatory, and users should focus on the software product described in this report-the MFR database system.

\section{Server Unit}

The server unit (Figure 3) is a Pentium-based PC with a Windows NT 4.0 operating system. The unit is also equipped with a SCSI interface external hard disk, a wireless Ethernet device, a high-speed modem, multimedia capabilities, and a digital camera.

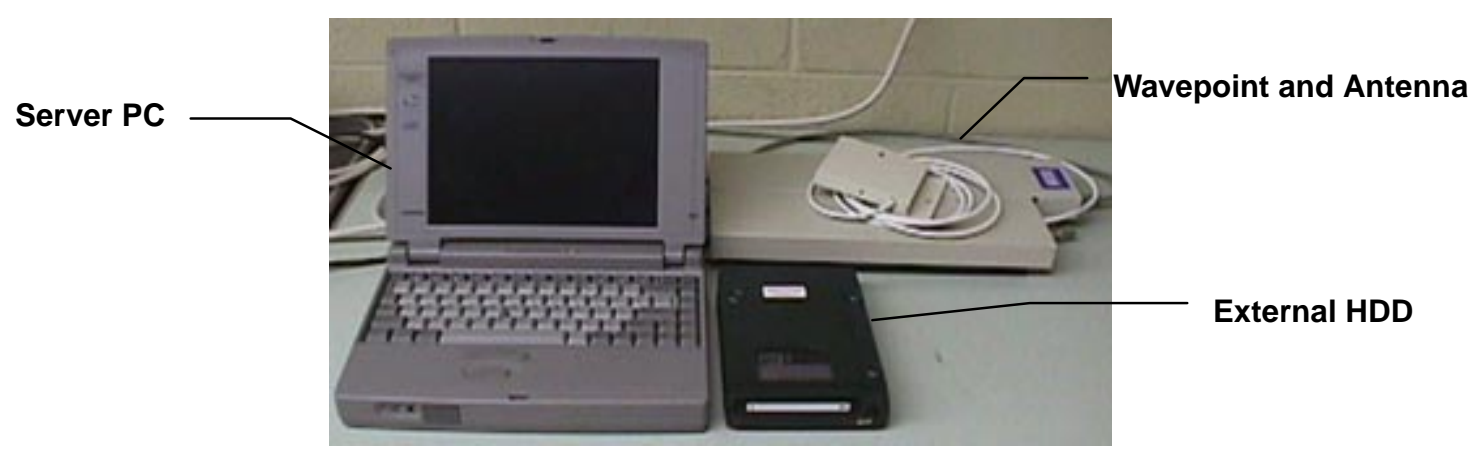

Figure 3. The server unit.

In detail, the server unit consists of:

- Pentium based PC Notebook with 32MB or more of RAM and approximately 1GB of hard disk drive

- Adaptec SlimSCSI PCMCIA SCSI card

- IOMEGA J az Drive with 1GB cartridges

- 3Com Etherlink III (3C562B/3C563B) PCMCIA network card

- QuickCam (Gray Scale) digital camera

- U.S. Robotics Sportster 56K BPS modem

- Lucent Technologies Wavepoint 915MHz

- Hub

\section{Mobile Unit}

The mobile unit (Figure 4) is a 486-100 CPU pen-based PC with a Windows 95 operating system. It has an audio/video card, a wireless Ethernet card, and a digital camera. 


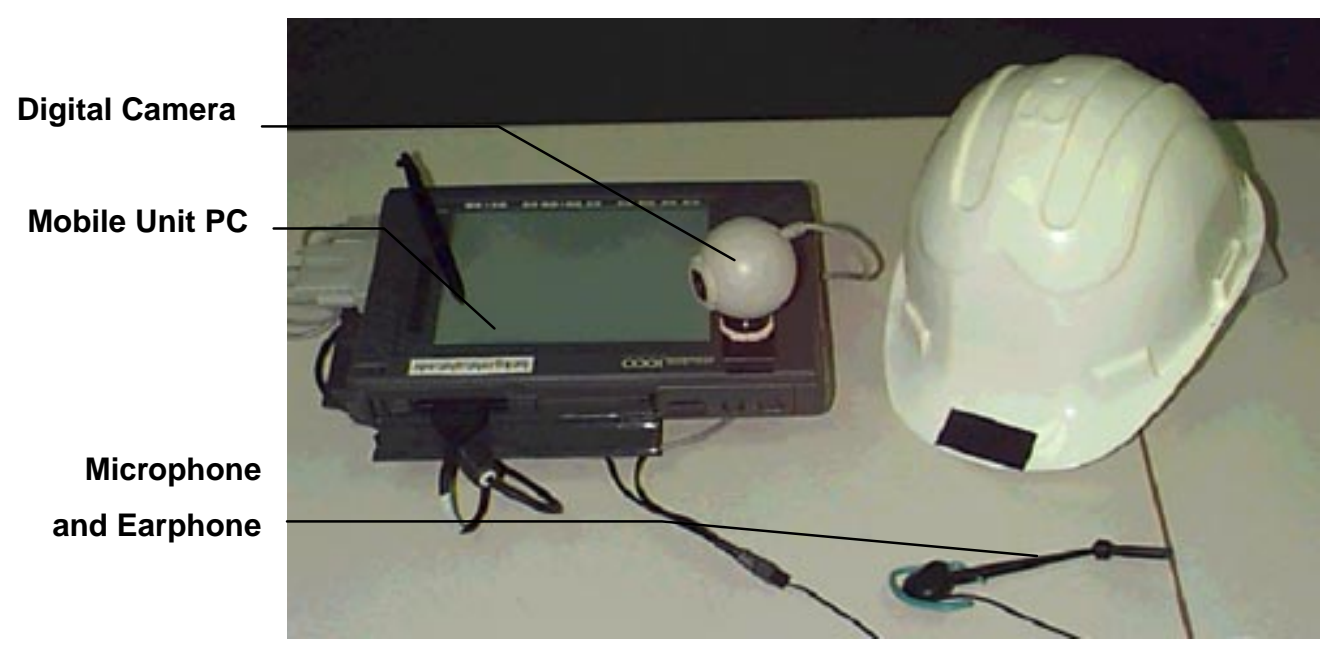

Figure 4. The mobile unit and a hardhat.

The mobile unit has the following hardware items:

- Fujitsu Stylistic Pen-based PC with 16 MB of RAM and 341 MB of hard disk space

- Nogatech Conference Card PCMCIA sound/video card

- Vois Microphone/Earphone

- Lucent Technologies WaveLAN 915 MHz PCMCIA network card

- Color QuickCam.

\section{Software}

Software required for running MFR consists of operating systems, database access system files, image data processing programs, and MFR program files.

\section{Operating Systems}

- Windows NT

The server units use Windows NT Workstation 4.0 as an operating system, primarily because it provides remote access service (RAS).

- Windows 95

The mobile units use Windows 95 as their operating system. Windows 98 has not been tested with the system, but should be as capable as Window 95. 


\section{Database Interface Software}

- 32 bit ODBC (Open Database Connectivity): Version 3.40.2728

- DAO (Data Access Object)

\section{MFR Program Files}

- Program File $\triangleleft$ NSTALLDIR $>*$

MFR.EXE

- System DLL Files<WINSYSDIR $>* *$

MSACAL70.0CX COMCTL32.OCX MFC42.DLL MSVCRT.DLL

MSVCRT40.DLL MSVCIRT.DLL OLEPRO32.DLL

CTL3D32.DLL (for Windows 95 only)

- Registry File $\triangleleft N S T A L L D I R>*$

- Lead Tools Files $\triangleleft$ NSTALLDIR $>*$

LEAD.LIC LEAD32.0CX LFBMP60N.DLL LFCAL60N.DLL

LFCMP60N.DLL LFEPS60N.DLL LFFAX60N.DLL LFGIF60N.DLL

LFICA60N.DLL LFIMG60N.DLL LFLMA60N.DLL LFLMB60N.DLL

LFMAC60N.DLL LFMSP60N.DLL LFPCD60N.DLL LFPCT60N.DLL

LFPCX60N.DLL LFPNG60N.DLL LFPSD60N.DLL LFRAS60N.DLL

LFTGA60N.DLL LFTIF60N.DLL LFWFX60N.DLL FWMF60N.DLL

LFWPG60N.DLL LTFIL60N.DLL LTIMG60N.DLL LTKRN60N.DLL

LTTWN60N.DLL LTWND60N.DLL PCDLIB32.DLL

- OCX Register File $\triangleleft N S T A L L D I R>*$

REGSVR32.EXE

- Template Database Files $\triangleleft$ NSTALLDIR\DATABASE $>^{* * *}$ 
KEYWORDS.MDB MFRMaster.MDB MFRProject.MDB

MFRMultimedia.MDB

$* \triangleleft N S T A L L D I R>$ : The directory where MFR is installed. It would be C:I Program Files\MFR.

**<WINSYSDIR>: The windows system directory. It usually is C:\WINDOWS I SYSTEM for Windows 95 and C:I WINNT\SYSTEM 32 for Windows NT operating system.

*** $\triangleleft N S T A L L D I R \backslash D A T A B A S E>$ : The template and project databases directory. C:\Program Files\MFR\ Database.

Important note: The current version of MFR works best once Microsoft Access 97 has been installed on the computer. Because of the incompatibility between different versions of Microsoft's system files (i.e, DLL files), it is strongly recommended to use the same DLL versions used to devel op MFR. N ote especially that, with Access 97, the proper versions of ODBCJ T32.DLL (Version 3.50.3602.00 or 3.50.3428.00) and MFC42.DLL (Version 6.00.8047.3) should be used. If Access 95 is used, the proper versions are ODBCJ T32.DLL (Version 3.40.27778) and MFC42.DLL (Version 4.2.6068). If you have problems running MFR after loading new software to your computer, check to see what versions of these files are being used.

\section{MFR WWW Server Files (For Server Unit Only)}

- WWW HTML File $\varangle$ netPub\WWWRoot>

MFR.HTM

- WWW CGI-BIN Files $\varangle$ netPub\SCRIPTSI CGI-BIN >

MFRGetProject.EXE MFRGetDate.EXE MFRGetlssue.EXE

- WWW Image Files 4 netPub\ WWWRoot\IMAGES>

Image Files 
- WWW DLL Files $\varangle$ netPubl SCRIPTS>

MFRGetMultimedia.DLL

\section{Communication Software}

- Internet Phone 4.0

- Microsoft NetMeeting is available at no cost over the Internet. This universal availability makes it the preferred means of mobile conferencing. See page 58 for some specific details on working with NetMeeting. 


\section{Operation of the Digital Hardhat System}

\section{User Interface}

MFR is a Windows-based program that operates with graphical user interfaces (GUIS). MFR's main user interface is described in Figure 5. The main user interface of MFR is comprehensive and straightforward. Considering the field use of the pen-based mobile unit, text input using a keyboard is minimized. Most of operations are self-explanatory, and a user can input data and select options as prompted by simply clicking the mouse button.

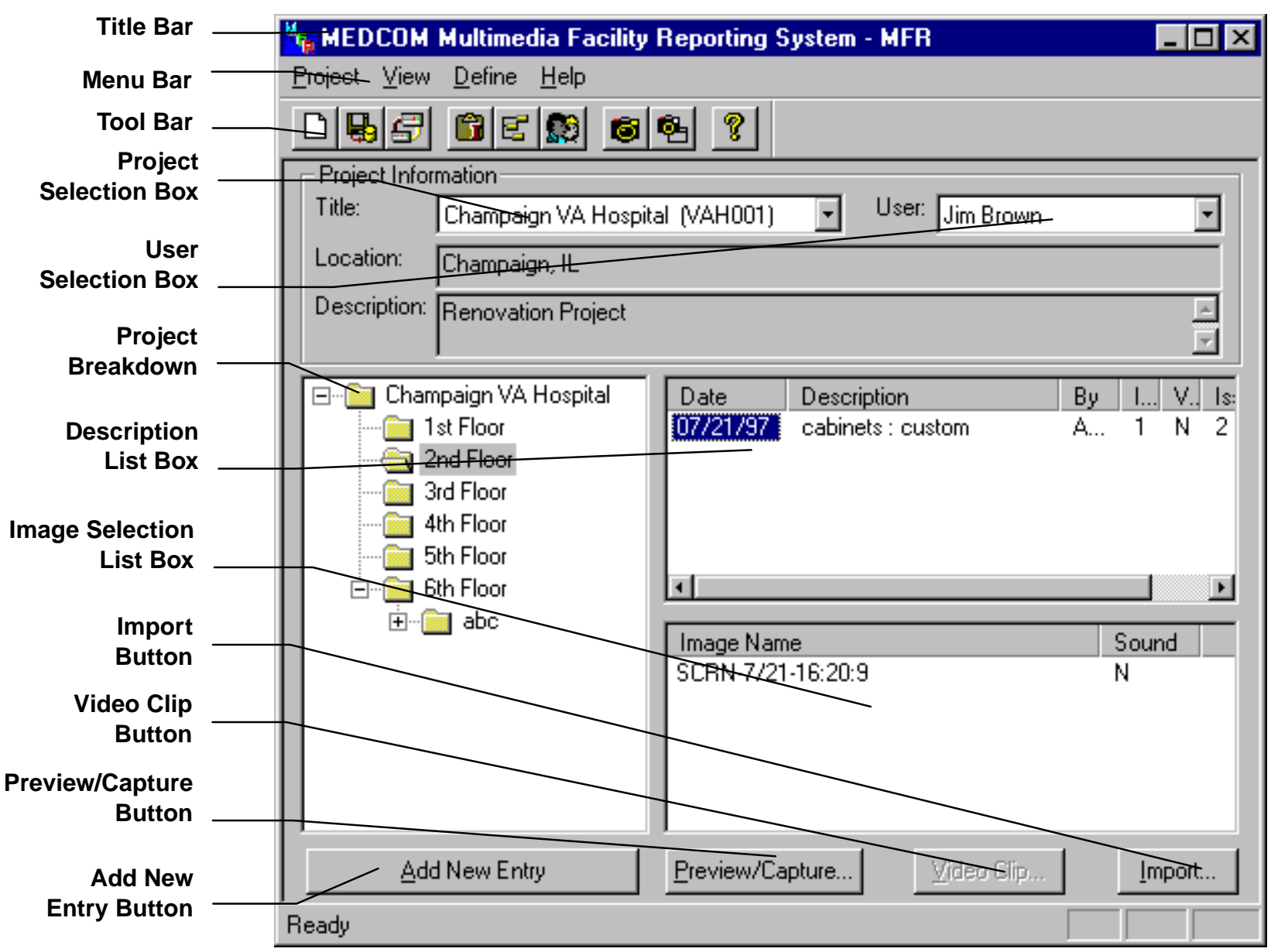

Figure 5. The MFR main user interface. 
Through the following sections, the operation of MFR is described in a step-bystep tutorial manner. A user can follow these steps to store and retrieve data and to setup software. At the end of the tutorial, a method to retrieve stored data using the WWW is also explained.

\section{Storing and Retrieving Data}

\section{Capturing and Storing Multimedia Data}

- Run MFR.

Double click the MFR icon.

- Select a project.

Select a project name from the Title combo box (Figure 6) or create a new project and select it.

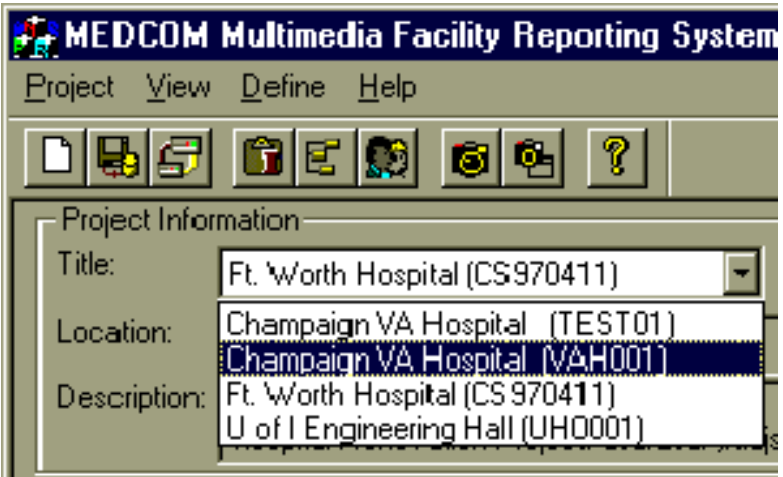

Figure 6. Select a project.

- Select a project breakdown item (Figure 7).

Select a project breakdown item to input to or retrieve data from. 


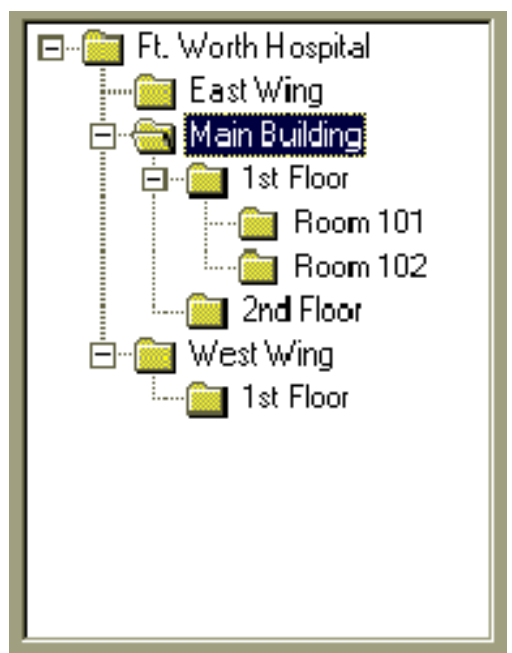

Figure 7. Select a Project Breakdown.

- Reminder - user name selection message box (Figure 8).

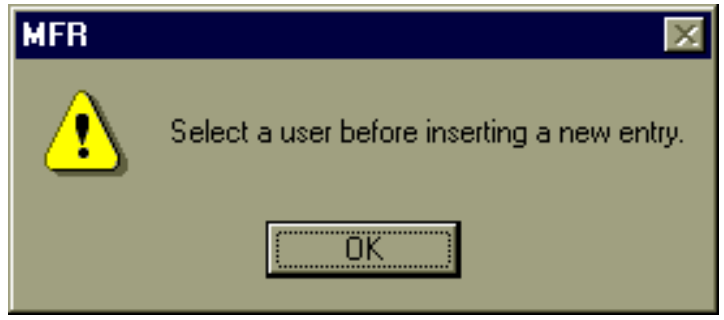

Figure 8. User Selection Reminder.

Note: If a user name has not been selected in the 'User' combo box, MFR recommends you do so. J ust click the OK button. You can still add image, sound, and video to the existing descriptions without selecting a user. However, you need to select a user name to add a new description.

- Select a description item.

Select a description item to which you want to add image/sound or video (Figure 9).

\begin{tabular}{|c|c|c|c|c|}
\hline Date & Description & By & I. & V. 1. \\
\hline $11 / 22 / 96$ & Visual C++ versior & Bi... & 4 & $Y$ \\
\hline $04 / 08 / 97$ & packaged lift stations & M... & 2 & $Y$ \\
\hline $04 / 16 / 97$ & lagging, piling with inter... & Bi... & 1 & $Y$ \\
\hline $04 / 30 / 97$ & cabinet safesllpackage... & Bi... & 0 & $\mathrm{~N}$ \\
\hline $05 / 01 / 97$ & maintenance materials a.. & Bi... & 0 & \\
\hline $15 / 178 / 97$ & ahhreviations ahcr & & & \\
\hline
\end{tabular}

Figure 9. Select a Description Item. 
- Preview/Capture

Click the Preview/Capture button (Figure 10) to display image/video capture window. This action will show a live picture fed through the camera.

Preview/Capture...

Figure 10. Preview/Capture buttons.

- Capture Image/Sound

Select I mage menu, select Capture (F igure 11).

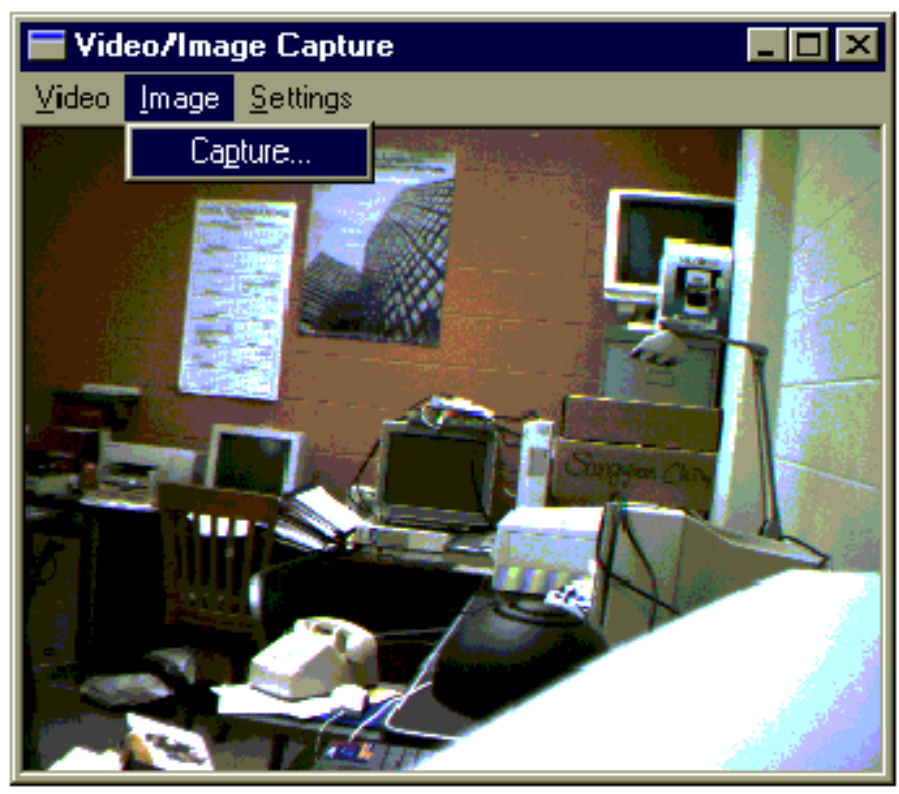

Figure 11. Image Capture dialog box.

The captured image will be displayed in a separate window. Use the default image name in the format of CAM-MM/DD-HH:MM:SS, or type in a new name for the image (Figure 12). 


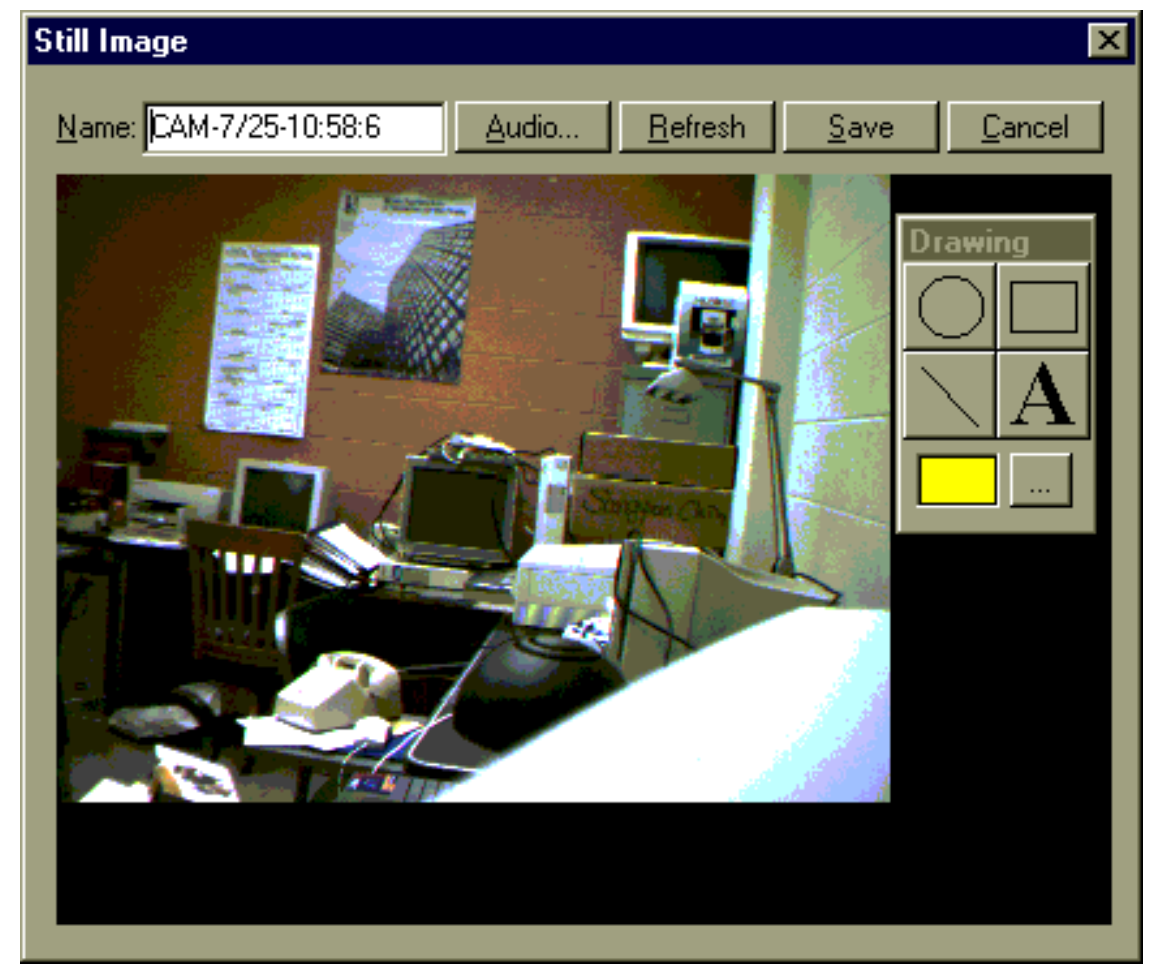

Figure 12. Captured Still Image dialog box.

- To record sound, select the Audio... button to display a window for Audio Play and Record (Figure 13).

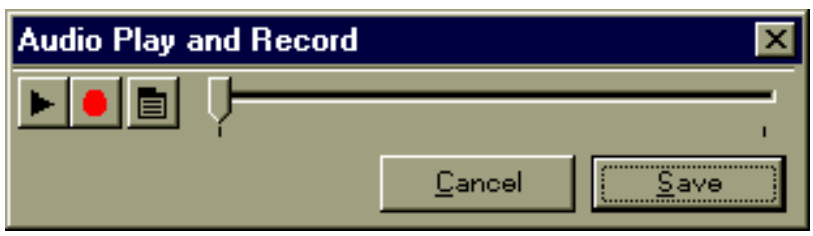

Figure 13. Audio Play/Record dialog box.

- Click the red record button to start recording and the black square button to stop. Click Save to save the sound.

- Click Save in the Still Image window to save the image/sound. Close the window by selecting Close.

- Capturing Video

Select Video and Capture Start to starting video capturing (Figure 14). 


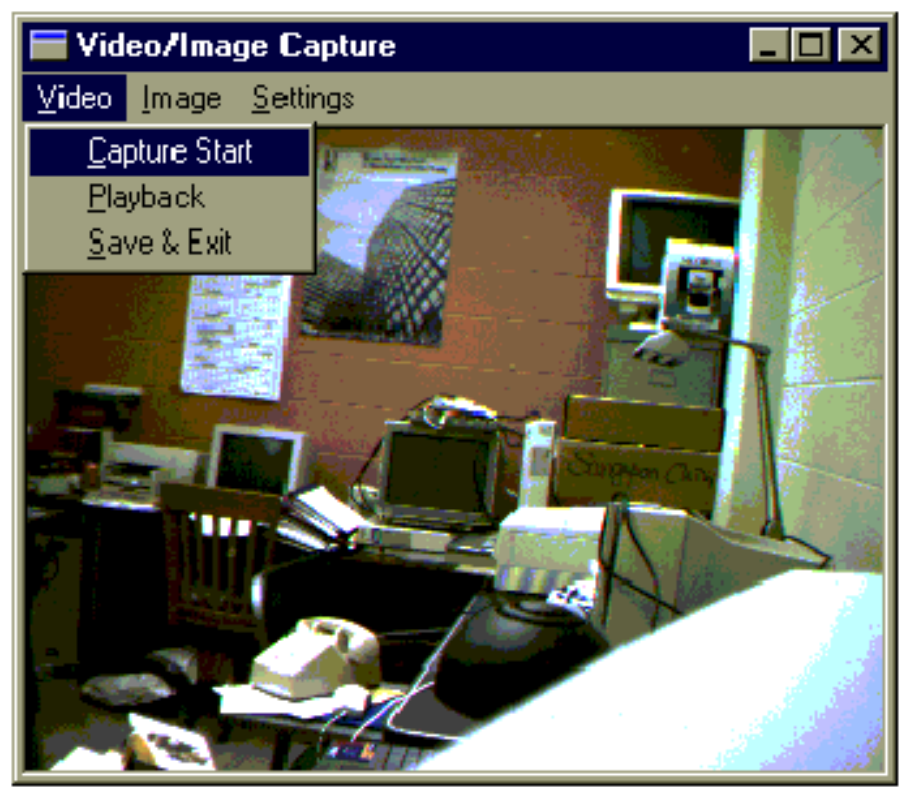

Figure 14. Capturing a video clip.

Double click on the window or hit Esc on the keyboard to stop capturing the video. Select Playback to check if the video is acceptable. Select Save \& Exit to save the video.

- Importing I mage/Video

In the main panel, click Import... and select Image... or Video... from the menu (Figure 15).

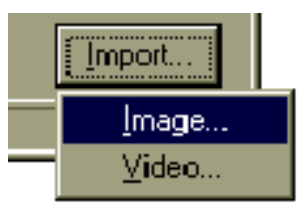

Figure 15. Import Image button.

Select a *.jpg (JPEG) file or a *.wav (WAV) file for image or video, respectively. Click Open to import and save the selected file (Figure 16). 


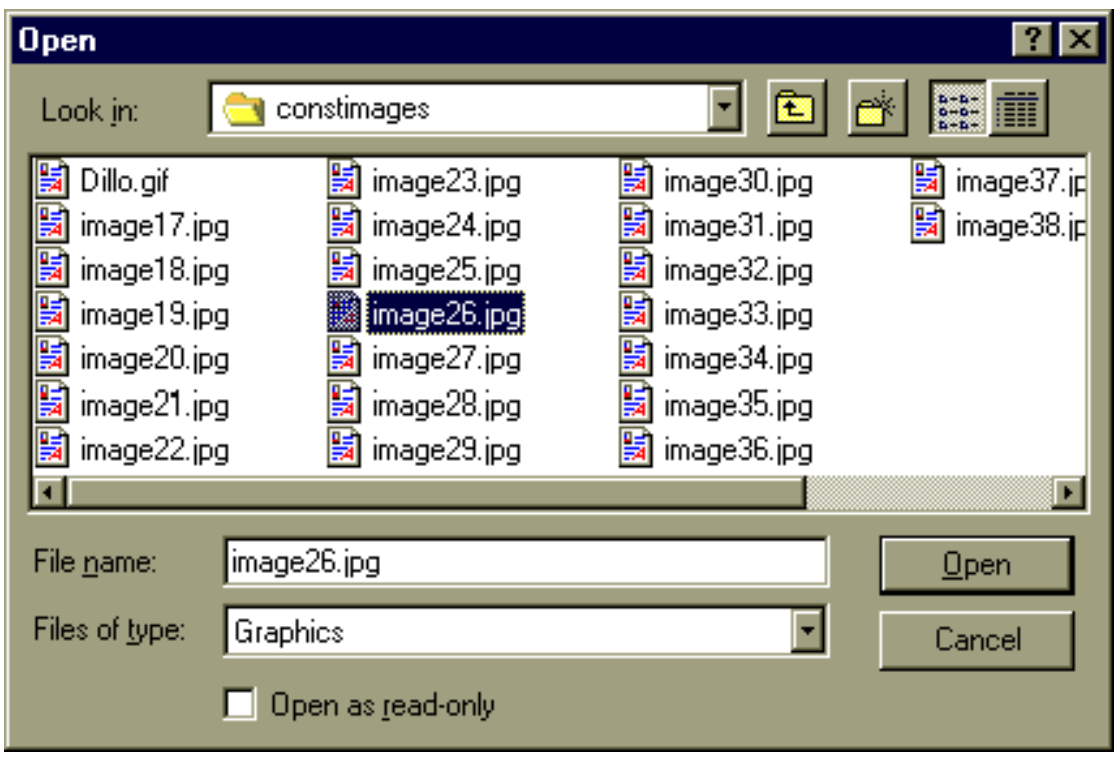

Figure 16. Select a file to import.

- Capturing a Screen

The contents of any window or screen can be captured and saved into MFR. The primary purpose of this feature is to save 'Whiteboard' content. Whiteboard is a module available with most commercial videoconferencing software, such as Internet Phone and NetMeeting. Remote users can share images and annotations on this common discussion board and save the content into the MFR database for later use and reference (Figure 17).

Click on Screen Capture oq. After the MFR main window is minimized, click anywhere inside of the window to capture. Follow the same steps described earlier under Capture Image/Sound to save the image. 


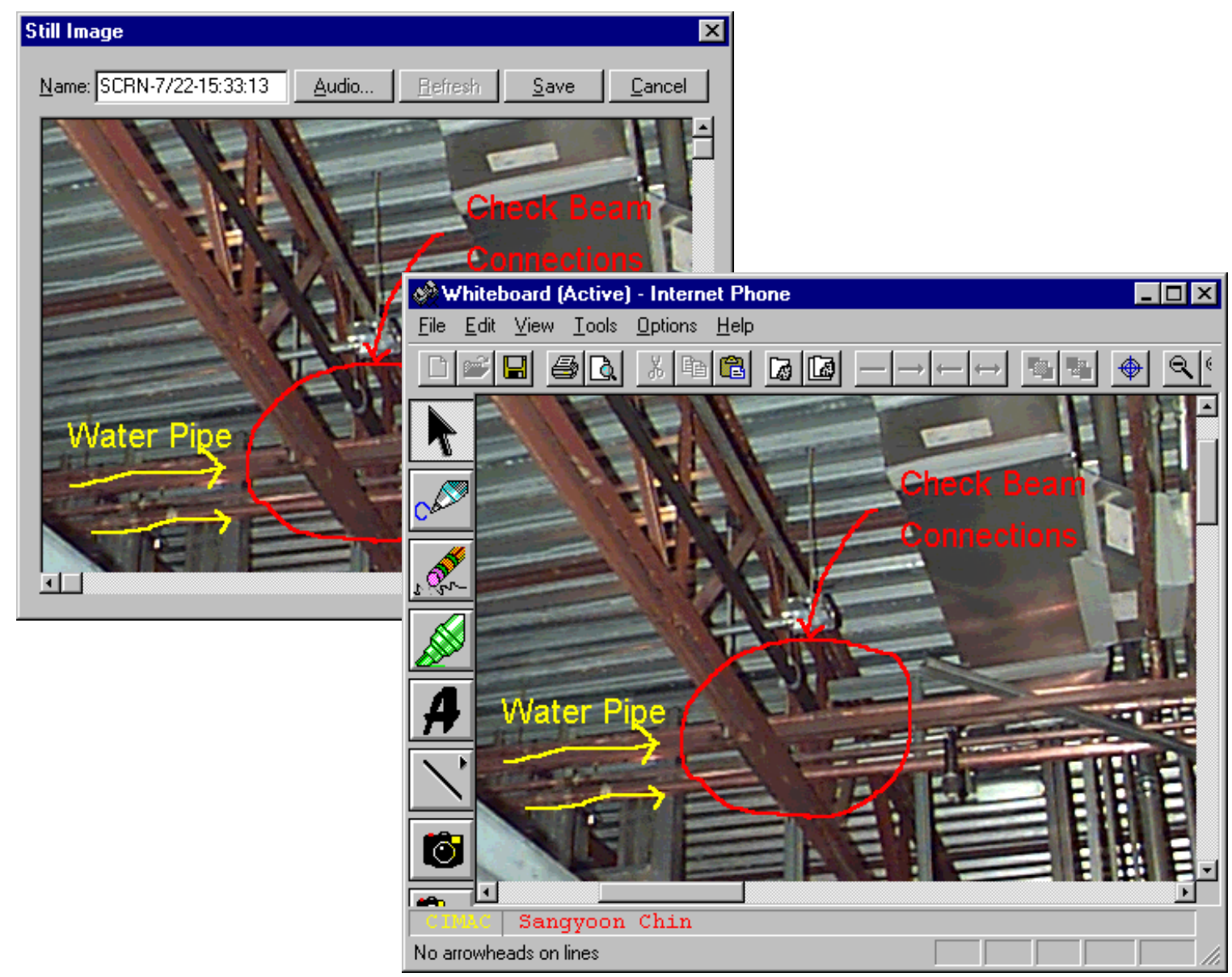

Figure 17. Whiteboard image captured into MFR.

\section{Retrieving Multimedia Data}

- To retrieve a video dip, dick $\underline{\text { Video Clip... }}$ if it is enabled. If it is not enabled, the description does not contain a video dip.

- For retrieving image/sound, click an image name under the Image Name box (Figure 18).

\begin{tabular}{|l|l|}
\hline Image Name & Sound \\
\hline aaa & $Y$ \\
Ebcder: & $Y$ \\
abcodefg & $N$ \\
& \\
& \\
\hline
\end{tabular}

Figure 18. Select an Image Name to display. 


\section{Project Setup}

\section{Creating a new project}

- From the Project menu, select Create Project (Figure 19).

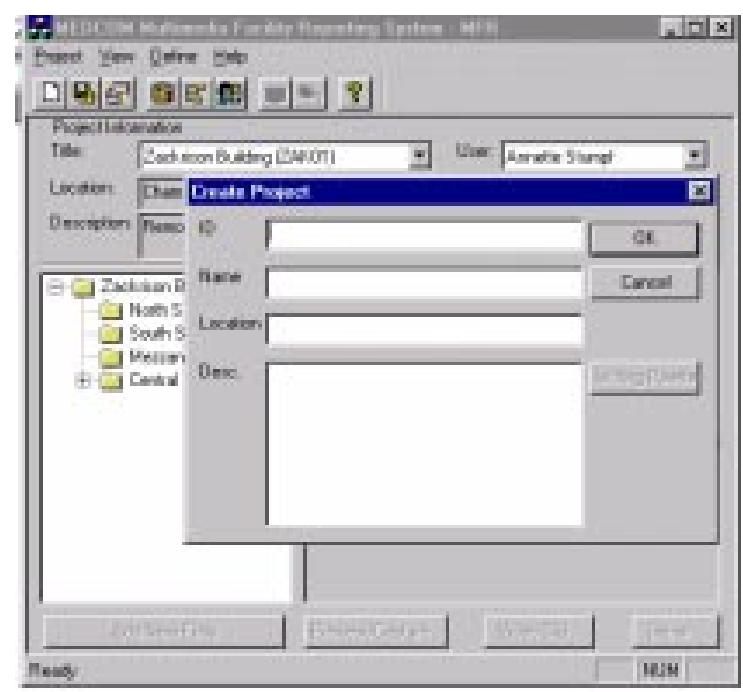

Figure 19. Create Project menu.

- Type in project information on the Create Project screen (Figure 20). ID and Name fields should be typed in. The Location and Desc. fields are not necessary to create a project and can be edited later. Click OK to create a new project. Otherwise, click Cancel.

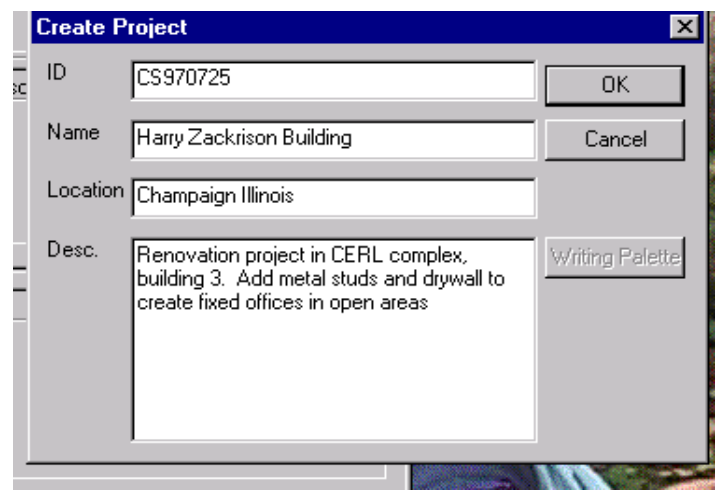

Figure 20. Input Project Information to Create. 


\section{Archiving Multimedia}

Due to the large size of multimedia data (i.e, image, sound, and video), storing all the data onto the hard disk is not feasible. After the user captures data and stores it onto the system's hard disk, the files need to be moved to a permanent storage space so that the system's resources will be available for further uses.

Therefore, it is recommended that multimedia data be archived to a removable storage device MFR provides a mechanism to archive multimedia data to a J AZ drive up to $1 \mathrm{~GB}$ at a time. The archived data can be retrieved for viewing; however, it cannot be edited or deleted using the current version of MFR.

- Select Archive Multimedia from the Project menu (Figure 21).

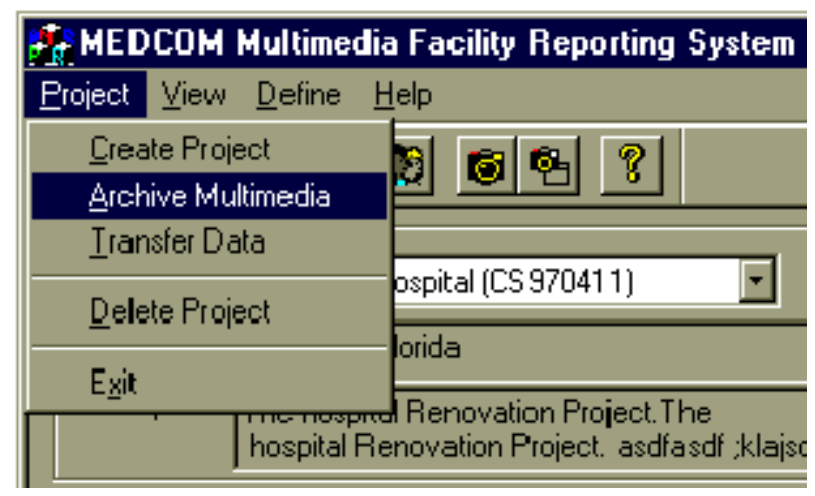

Figure 21. Archive Multimedia menu.

- Select a project you want to archive.

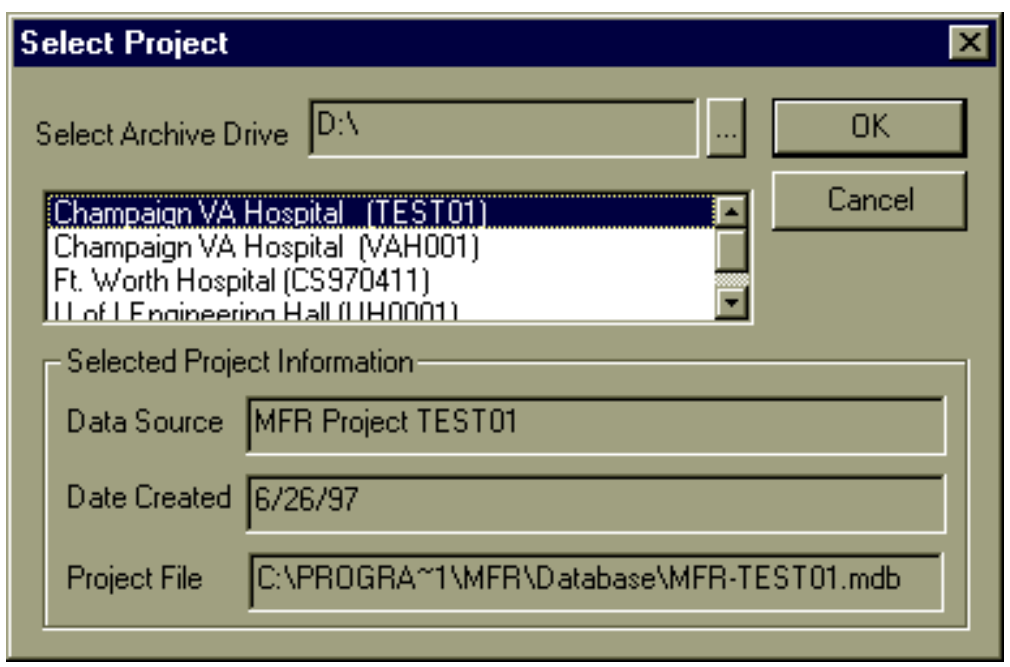

Figure 22. Select a project to archive. 
- Click OK.

Note: Ensure that the selected archive drive is correct. If not, click the '...' button to sel ect the path for the archive drive (i.e., J AZ drive).

\section{Transferring Data}

MFR uses two types of systems-a data server and data collecting units. The data server stores all the data collected by the collecting units. It is recommended that the user periodically upload the data captured by the collecting units (pen-based PC, Fujitsu Stylistic 1000).

On the other hand, when a new project is created in the server, the collecting units need to acquire the project information data so they can collect data for the new project.

Note 1: Transfer Data should only be performed to the server from collecting units referred to as 'Mobile Unit (Local Unit)' in MFR.

Note 2: At your Local Unit, the server's C:\Program Files\MFR\ Database directory should be mapped as X: drive Make sure your computer is a Local Unit (a pen-based PC running Windows 95). Also make sure your $X$ : drive is mapped to the server's $C: \backslash$ Program Files\MFR\Database directory. This can be done using Windows 95 Explorer.

- From the Project menu, select Transfer Data (Figure 23).

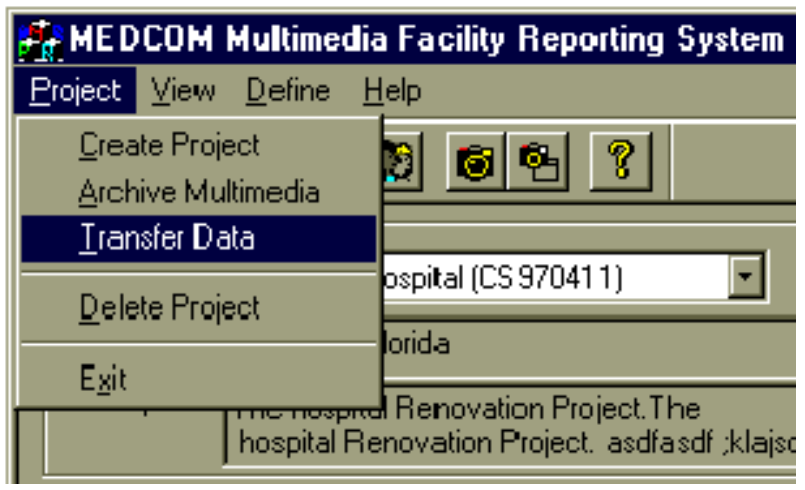

Figure 23. Transfer Data menu.

As mentioned, Transfer Data does two things. It uploads collected data and downloads project information (Project ID, Name, Project Breakdown, etc.) 
To upload data (Figure 24), select the radio button From Local to Server Unit. To download data, select the radio button From Server to Local Unit (General Info. Only).

- Select a source project and a target project. If you want to create a new project using the source project, select $\varangle$ reate A New Project> from the Target Project list.

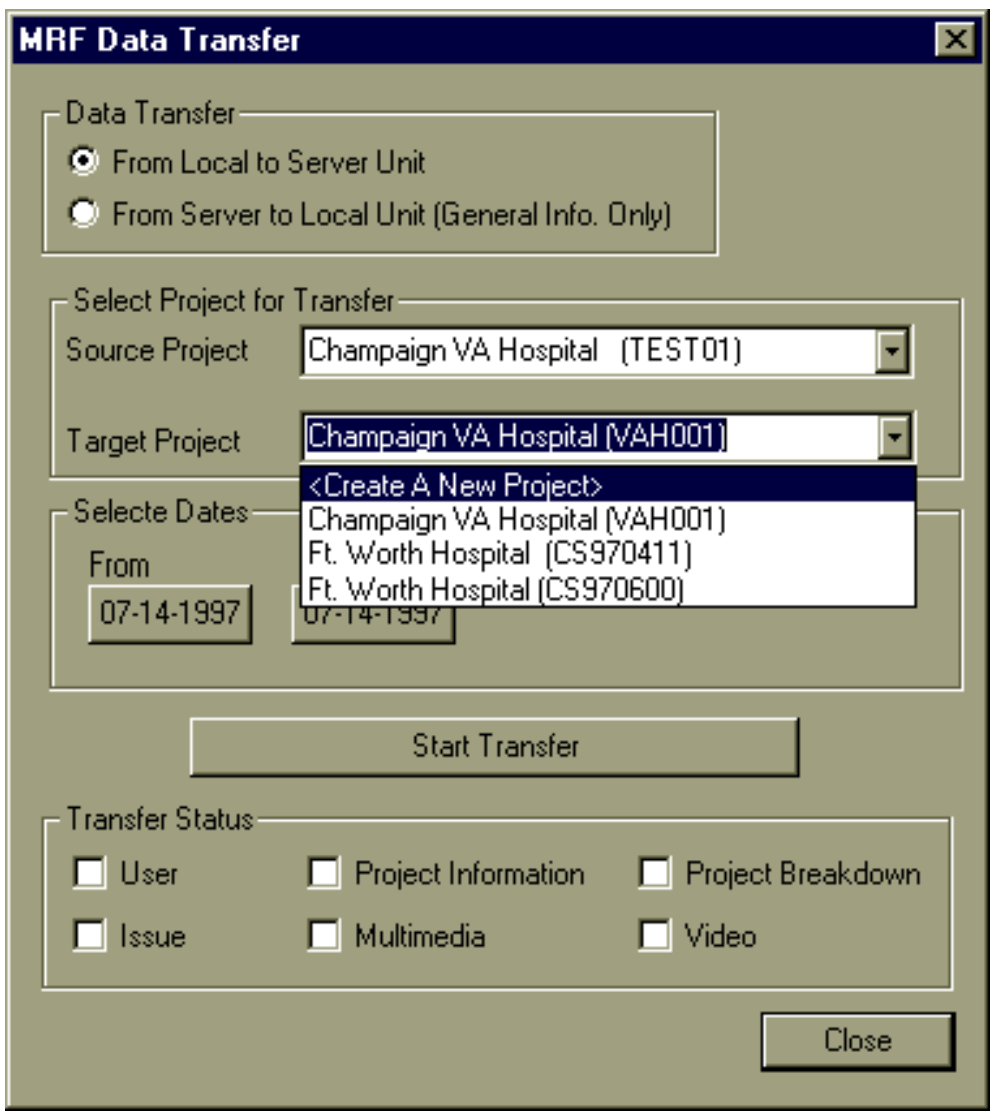

Figure 24. The main dialog box for data transfer.

When you finish selecting a source and a target, the data selection From and To buttons will be enabled. You can selectively choose dates of the data you want to transfer. The Start Transfer button will also be enabled. By clicking it, the data transfer process will execute. As data are being transferred, the transfer status will be displayed in the Transfer Status box.

After the Transfer complete! Message appears at the bottom of the dialog box, click Close to end the transfer session.

Note: When transferring from the server to a local unit, only Project Information and Project Breakdown will becheckmarked. 
Important note: After transferring a new project using \&Create a New Project>, the data will not be noticed by the server until you rerun MFR. Personnel at the Local Unit side should contact the server administrator to close the currently loaded MFR, if it is loaded, and reload it.

\section{Deleting a Project}

- Select Delete Project under the Project menu. The project you want to del ete must be selected before Delete Project can be selected (Figure 25).

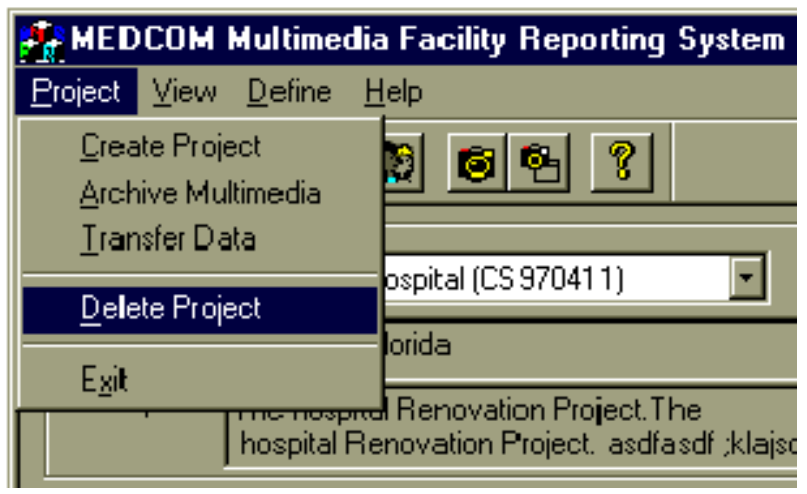

Figure 25. Delete Project menu.

- Click Yes to confirm the deletion (Figure 26). Otherwise, select No.

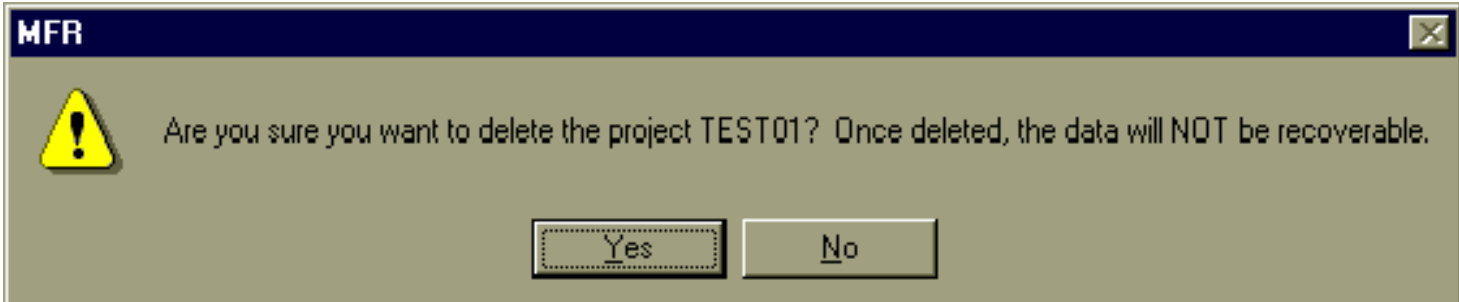

Figure 26. Confirm to delete each file.

\section{Editing a Project}

\section{Editing Project Information}

- Select Project Information under the Define menu (Figure 27). 


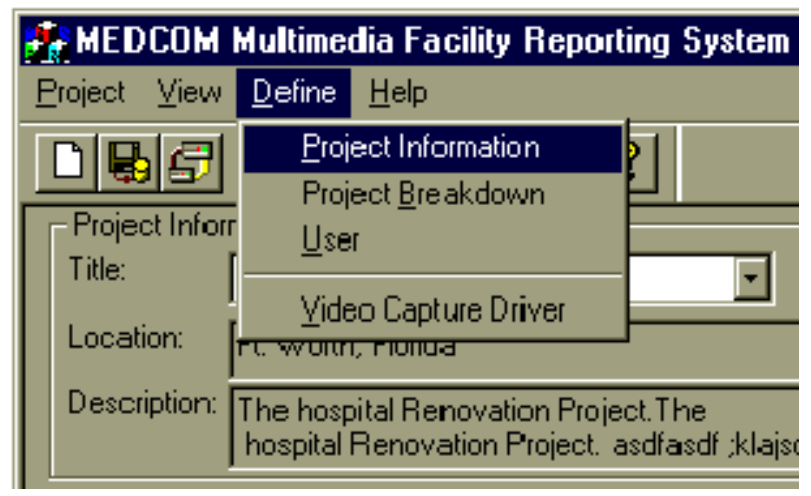

Figure 27. Define Project Information menu.

- Edit the location and description of the project. Click Update to save the changes (Figure 28).

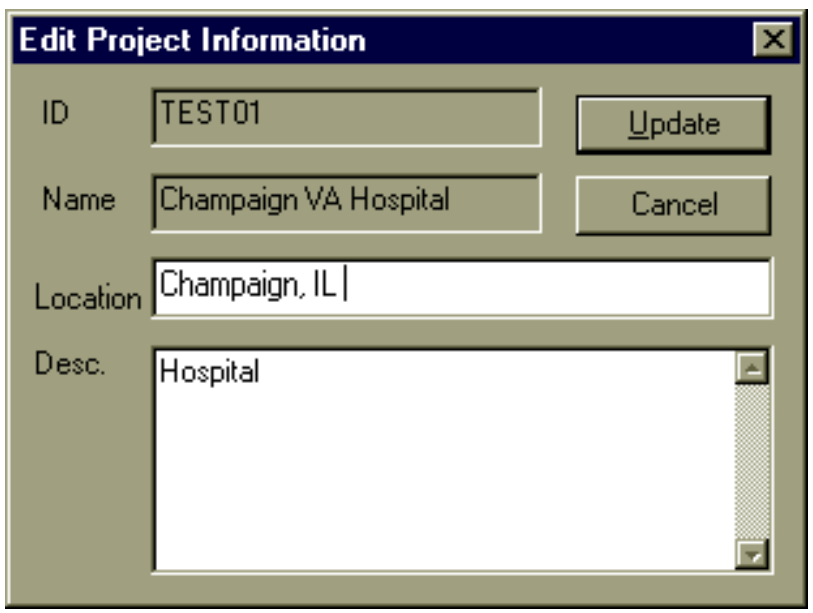

Figure 28. Edit Project Information-Location and Description.

\section{Editing Project Breakdown}

- Select Project Breakdown from the Define menu (Figure 29).

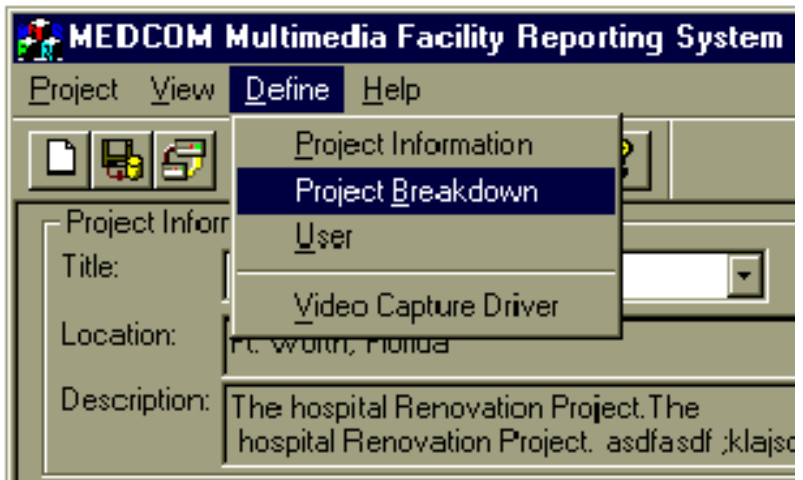

Figure 29. Define Project Breakdown menu. 
- Select a breakdown item (Figure 30). Click Add to add a new item under the selected item. Or, dick Remove to delete the item. An item cannot be deleted if it has data associated with it. To delete such an item, delete the descriptions first. You also cannot delete an item that has subitems. To delete such an item, delete the subitems first.

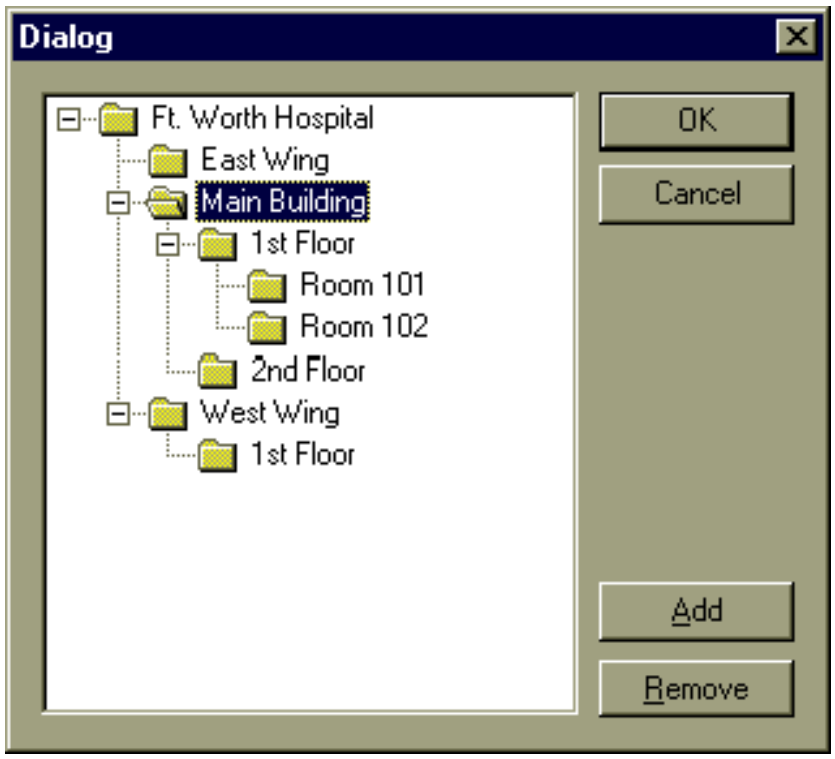

Figure 30. Define Project Breakdown dialog box.

\section{Defining Users}

- Select User from Define menu (Figure 31).

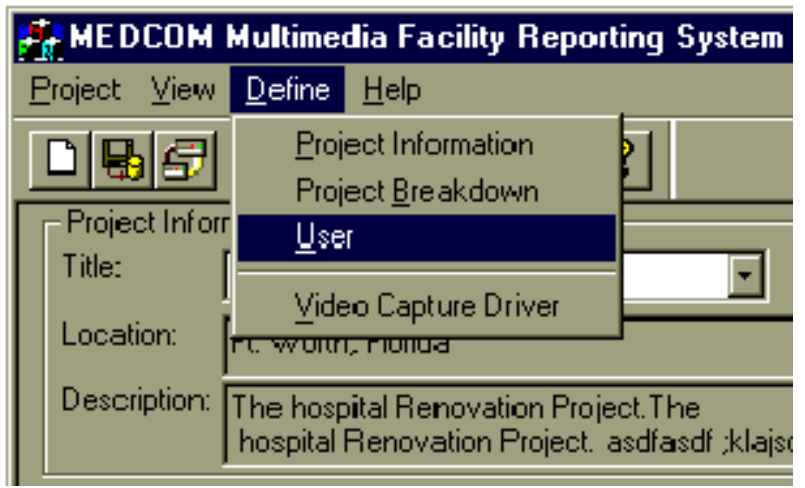

Figure 31. Define User menu.

- Select a user to edit or remove and dick Update or Remove. Or, type in a new user name and dick Add (Figure 32). 


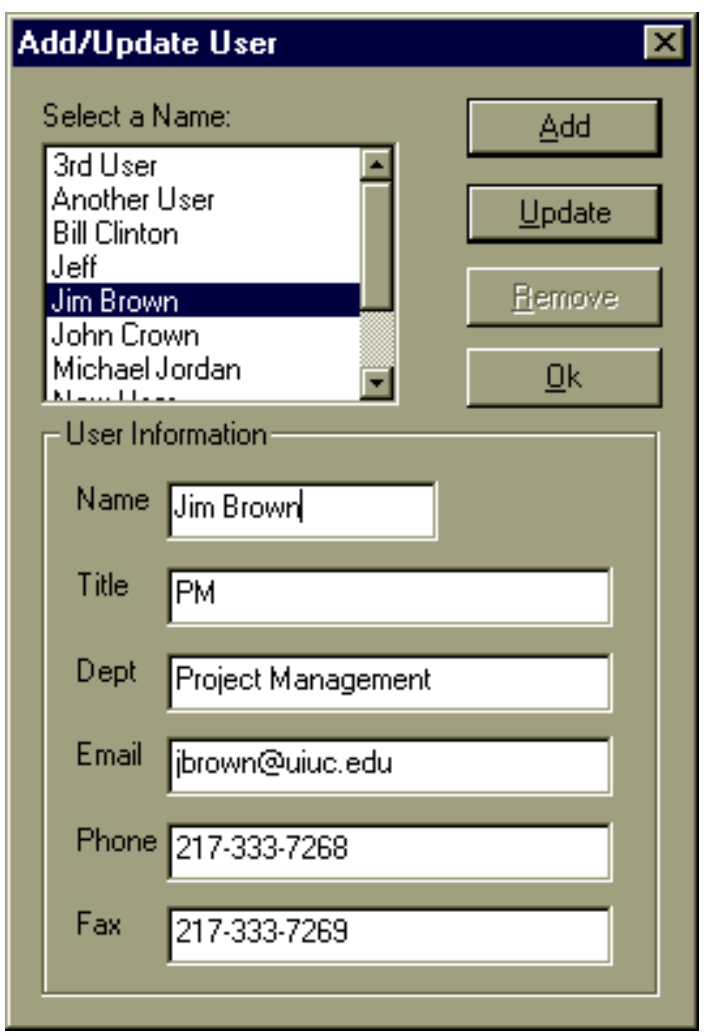

Figure 32. Add/Update User dialog box.

\section{Deleting Multimedia Item}

- Right-dick on the image name you want to delete (F igure 33).

\begin{tabular}{|c|l|}
\hline Image Name & Sound \\
\hline asdfd & $\mathrm{N}$ \\
\hline image35: & $\mathrm{N}$ \\
\hline Show & \\
\hline Delete \\
\hline
\end{tabular}

Figure 33. Right-Click an Image Name to delete.

- Confirm to delete by selecting OK (Figure 34).

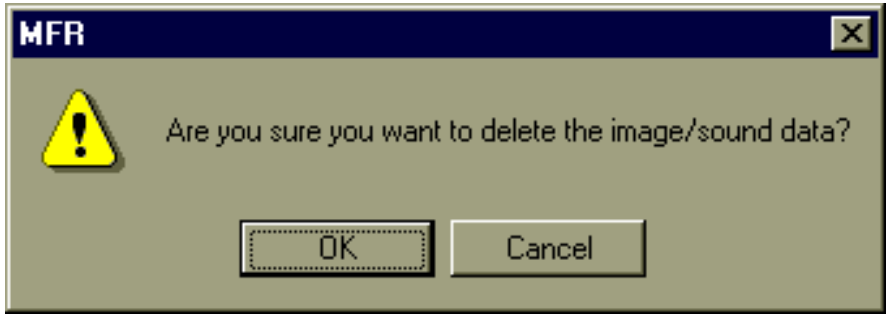

Figure 34. Confirm to delete the image. 


\section{Changing the Video Capture Driver}

- Select Video Capture Driver from the Define menu (Figure 35).

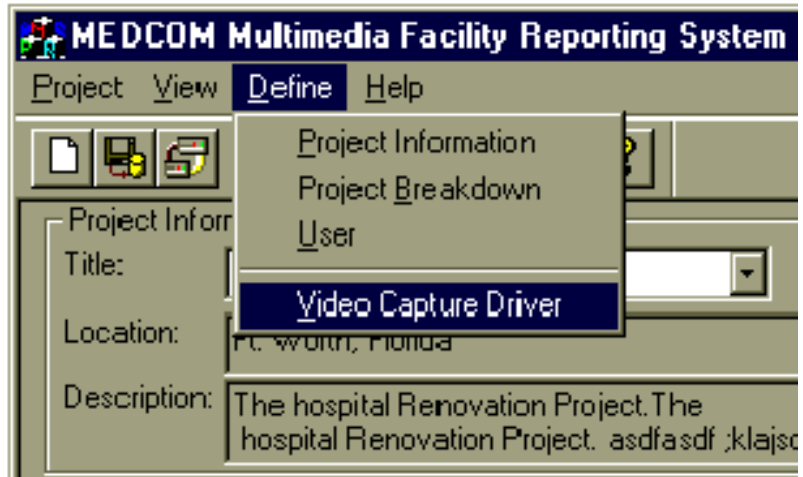

Figure 35. Define Video Capture Driver menu.

- Select a driver from the list (Figure 36). MFR uses Color QuickCam video capture driver as its default driver.

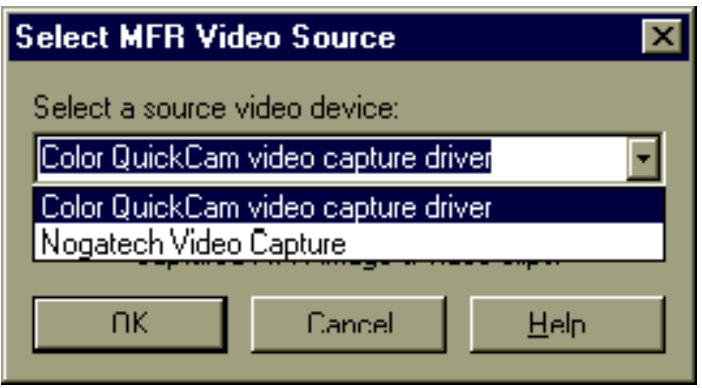

Figure 36. Select a driver for the installed video capture device.

\section{Setting Camera Capture Properties}

\section{Camera Adjustment}

- Select Camera Adjustment from the Settings menu of the Video/lmage Capture window (Figure 37). 


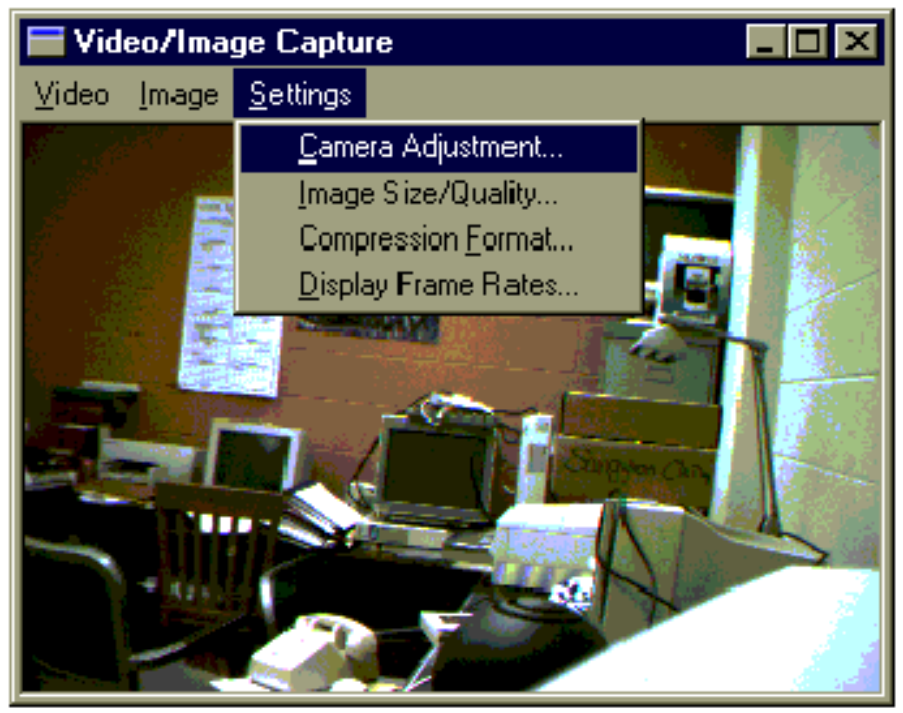

Figure 37. Camera Adjustment menu.

- In the Camera Adjustments dialog box (Figure 38), set brightness, hue, saturation, etc.

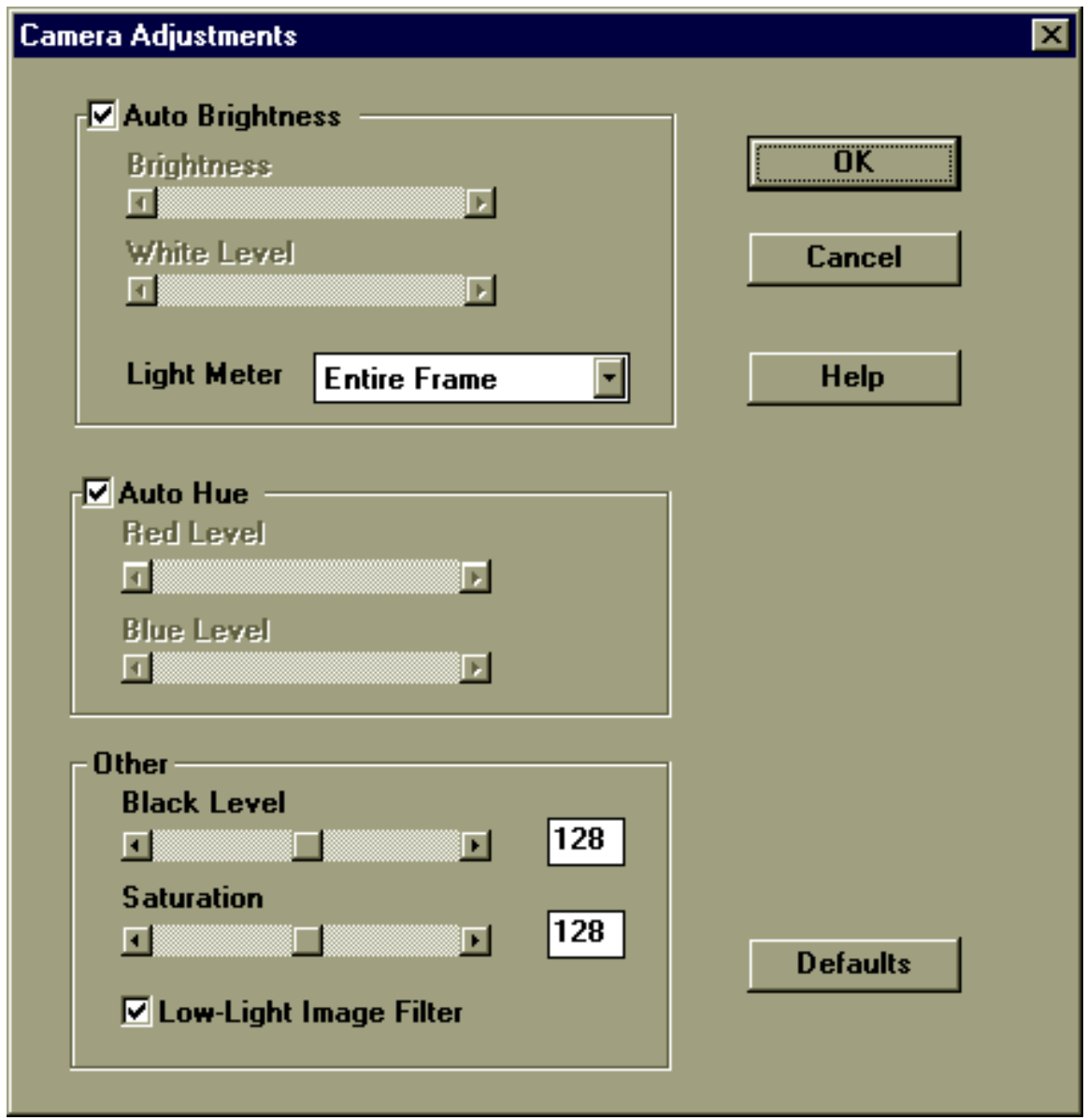

Figure 38. Camera Adjustments dialog box. 


\section{Image Size and Quality}

- Select Image Size/Quality from the Settings menu (Figure 39).

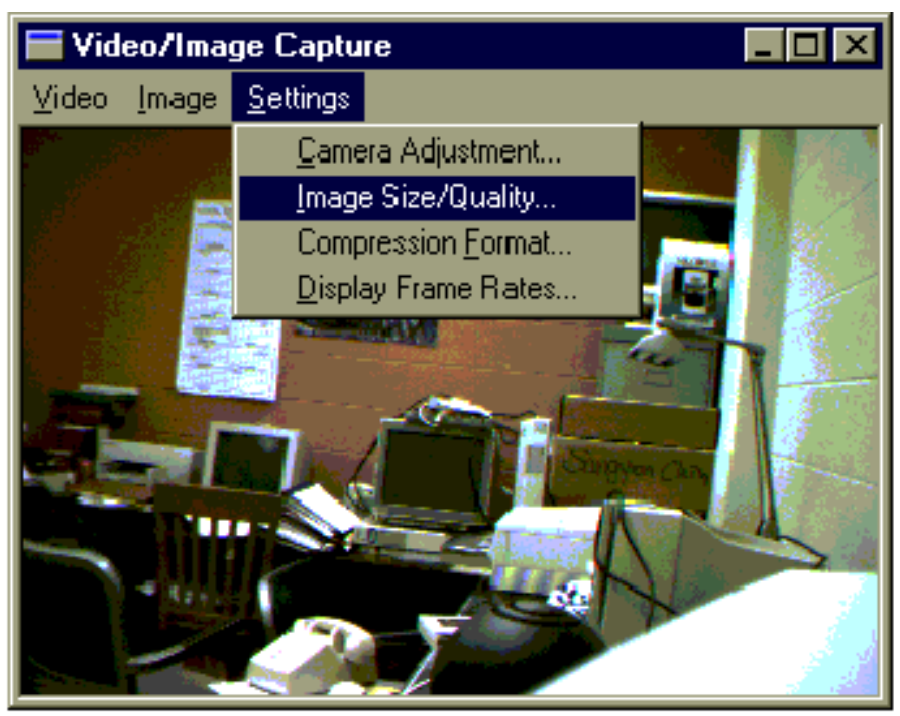

Figure 39. Image size/quality menu.

- Select from Full ( 640 X 480), Half ( 320 X 240), Quarter ( $160 \times 120)$, or Other sizes (Figure 40). You can also set col ors and the sharpness of the image.

Considering the limitations of hardware performance and storage space, Quarter size is recommended for video capturing. For still image capturing, any size can be selected, although Half size would be appropriate in most cases. 


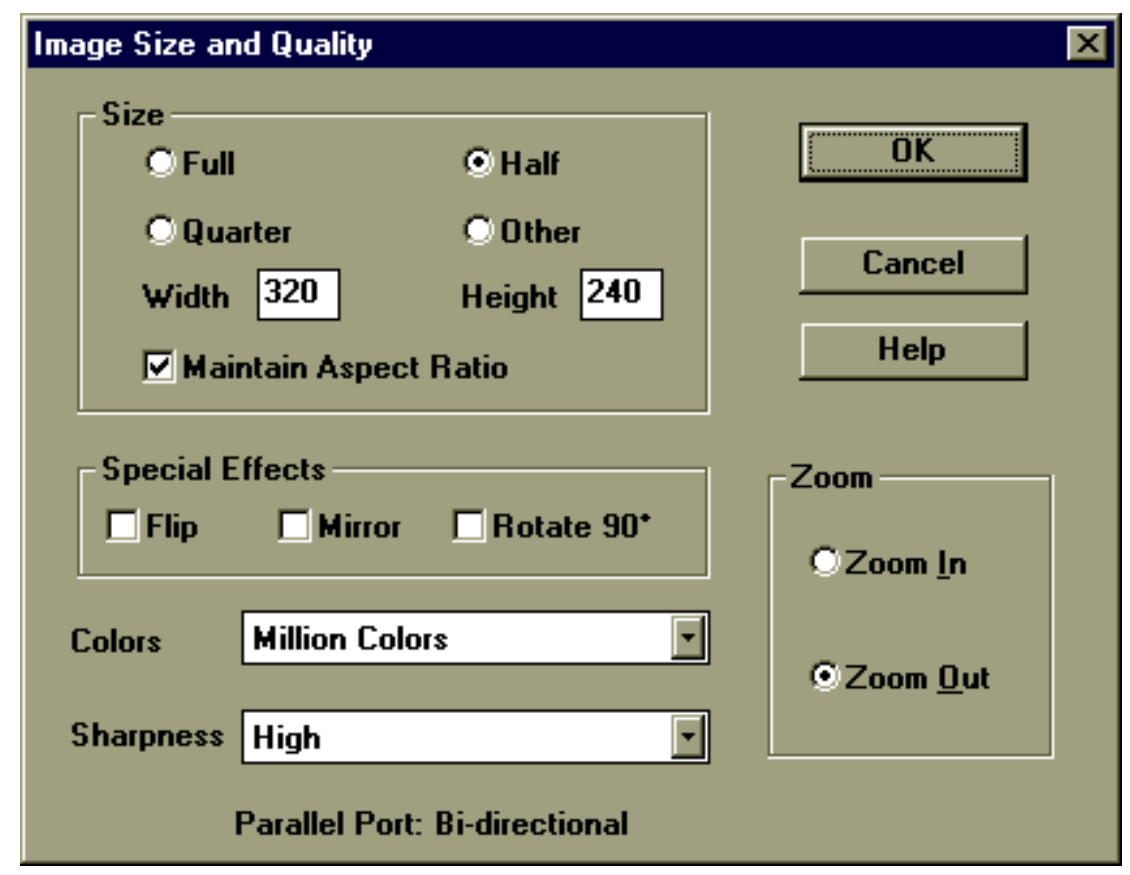

Figure 40. Image Size and Quality dialog box.

\section{Compression Format}

- Select Compression Format from the Settings menu (Figure 41).

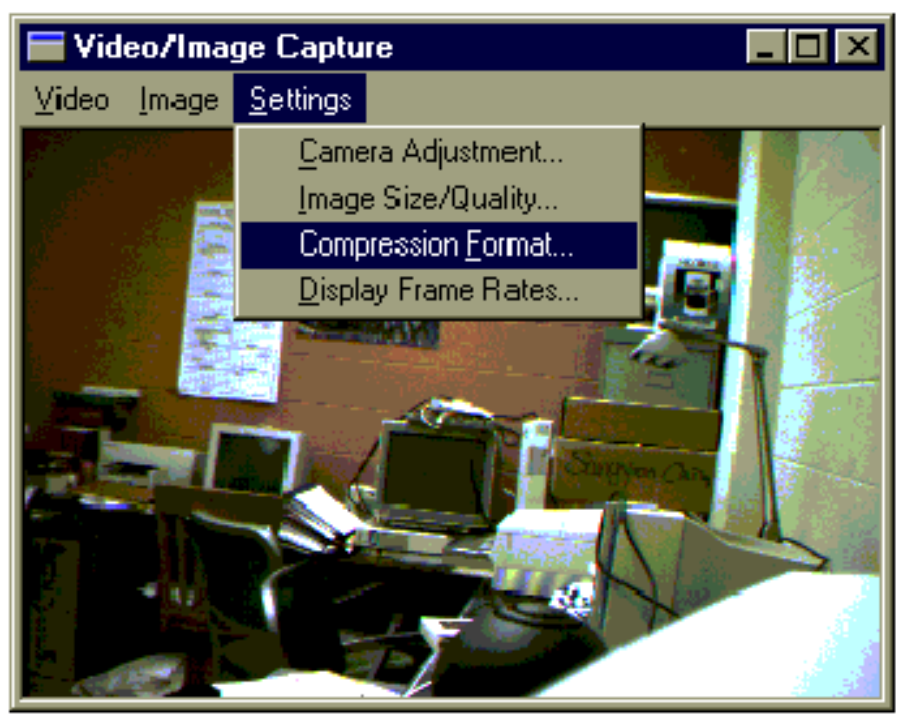

Figure 41. Compression Format menu.

- Select the default compressor and compression quality as in Figure 42. 


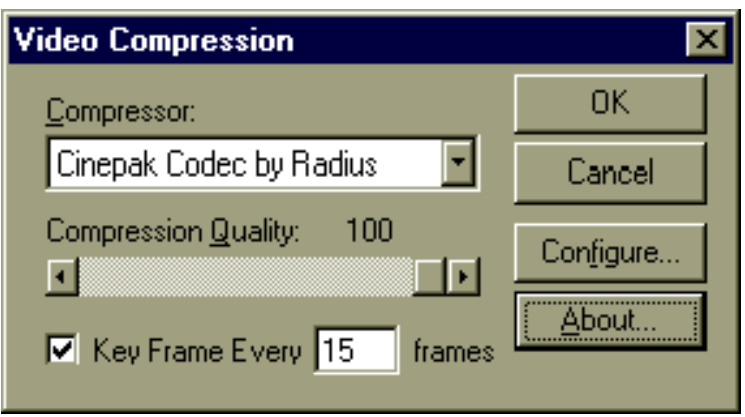

Figure 42. Compression Format dialog box.

\section{Display Frame Rate}

- Select Display Frame Rates from the Settings menu (Figure 43).

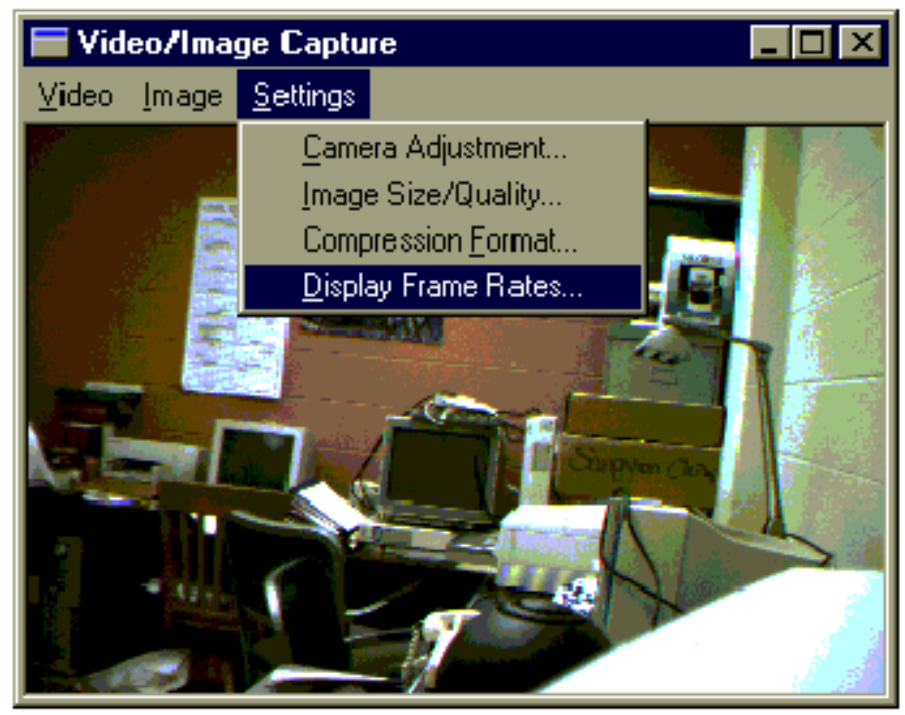

Figure 43. Display Frame Rates menu.

- Select frame rate and time limit for video (Figure 44).

Note: Frame rate represents the number of frames per second. Selting this rate to a higher number increases file size considerably and chances of a hardware crash. The frame rate of $1 \mathrm{frame} /$ second is recommended. For shorter videos (less than 5 seconds at an image size of Quarter), 2 or 3 frames/ second may be used. When Enable Time Limit for Video Capture is enabled, video capturing will be terminated automatically after capturing video for the timelimit specified in the Limit box. 


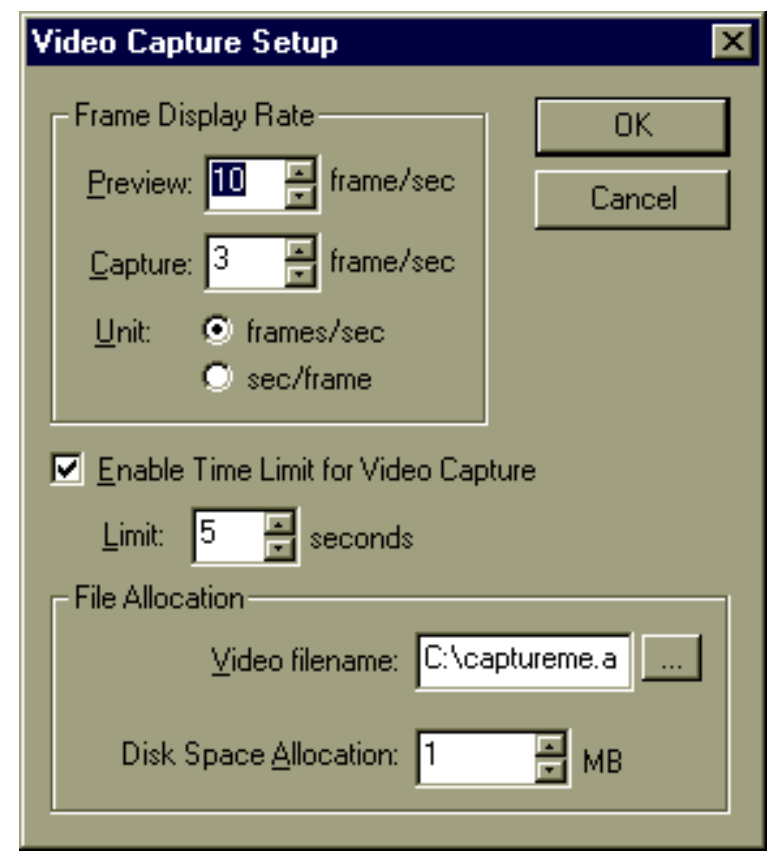

Figure 44. Display Frame Rates dialog box.

\section{Videoconferencing}

Videoconferencing is live, two-way video and audio telecommunications technology capable of linking people locally, nationally, and internationally using a variety of communication channels. The image quality and speed of video transmission depend on the equipment and available bandwidth in the chosen communication channel. Bandwidth is a term used to describe the speed with which information flows, usually given in bits/second. Currently, the fastest communication channels are special digital telephone lines ISDN or a fast connection to the Internet (e.g., a T1 line). ISDN connections deliver $128 \mathrm{Kbps}$, while T1 lines are rated at $1 \mathrm{M}$ bps. Actual transmission rates will depend on the network conditions between the two points and how many other users are transmitting information. During a videoconferencing test, the actual transmission rate was only one quarter of the rated T1 speed. Modems (regular, cell phone, satellite) can also be used while videoconferencing. Again, the transmission rate will depend on the modem speed, traffic, and phone switching equipment between the users. In the future, cable modems are expected to provide connections that are between 4 and 78 times the speed of ISDN connections (500 Kbps to $1 \mathrm{Mbps}$ compared to $128 \mathrm{Kbps}$ ).

It is possible to use either two-way (point-to-point) videoconferencing or multipoint videoconferencing (meeting of more than two sites). Multipoint 
videoconferencing requires either special switching equipment or Internet multicasting capability such as MBONE. MBONE uses the Internet Protocol (IP)-multicast protocols to allow more than two users to share video, audio, and whiteboards over the Internet. A whiteboard enables users to share, communicate, and markup multimedia (graphic, text, audio, and video) information. Using the Internet, modem, or local area network (LAN) connections, users can collaborate on a project more effectively than would be possible using a regular tel ephone, while seeing video views of the other party.

\section{Standards}

Recent telecommunications and videoconferencing standards have been developed to ensure compatibility between different software and equipment. All videoconferencing software and hardware purchased should comply with the relevant standard.

\section{Room-based Videoconferencing}

Room-based videoconferencing systems typically have more expensive equipment, dedicated high speed communication channels, large monitors to display outgoing and incoming video, good quality microphones and videocameras, and additional equipment to allow sharing of computer files, graphics, whiteboards, etc. These systems provide the best quality audio, video, and transmission speed. The Corps of Engineers has an established network of room-based videoconferencing centers for point-to-point and multipoint videoconferencing. Each room can accommodate a reasonably large audience. For more information, see the USACE Video Teleconferencing home page at http://www.usace.army.mil/ inet/functions/cw/cecwe/coexpert/newcoe/doe/vcnm.htm.

\section{Desktop Videoconferencing}

Of the many different types of desktop videoconferencing systems, the more expensive systems typically require a controller board to be installed in each computer. Depending on the communication channel used, these systems provide better quality video and audio transmission. PictureTel, for example, is a system that can be used at an individual desk or in a small conference room. Desktop videoconferencing systems can be configured to use a variety of communication channels, depending on the user requirements. The U.S. Army Corps of Engineers has a network of desktop videoconferencing systems connecting all Commanding Officers. 
Less expensive desktop videoconferencing systems are widely available, and many people are beginning to use them to videoconference from their desktops. Each computer must be configured with the standards-based videoconferencing software, soundcard, speakers or headphones, a microphone, digital videocamera and modem, and ISDN or network connection. Several of the most commonly used videoconferencing software programs are available free on the Internet.

\section{Mobile Videoconferencing}

Users who wish to videoconference from remote sites have special concerns. If they are using a laptop computer, a pen-based computer, or a palmtop computer, there are fewer options for equipment than with a desktop computer. It is typically more difficult to access high speed communications channels from remote sites. Also, if the user is mobile, the fastest and most reliable communication channels will vary from location to location. The DHH System described in this report is considered a mobile videoconferencing system. The best commercially available videoconferencing software and equipment were chosen for this field test. New commercial developments are watched closely, so that technology improvements can be incorporated into the DHH System.

\section{The Digital Hardhat Mobile Videoconferencing System}

Currently, commercially available videoconferencing software include CU-See Me, Video Phone, NetMeeting, and Internet Phone. After several tests, VocalTec's Internet Phone 4.0 was found to suit our needs the best in terms of provided features, performance, and stability. Quite simple and easy to operate, Internet Phone 4.0 is included in $\mathrm{DHH}$ as a communication feature (Figure 45). Using Internet Phone, a field inspector can communicate with an engineer at a remote office while running the MFR program. Inputting the other party's IP address makes the call and the rest of the operation is similar to regular phone calls (refer to Internet Phone's user manual for details). 


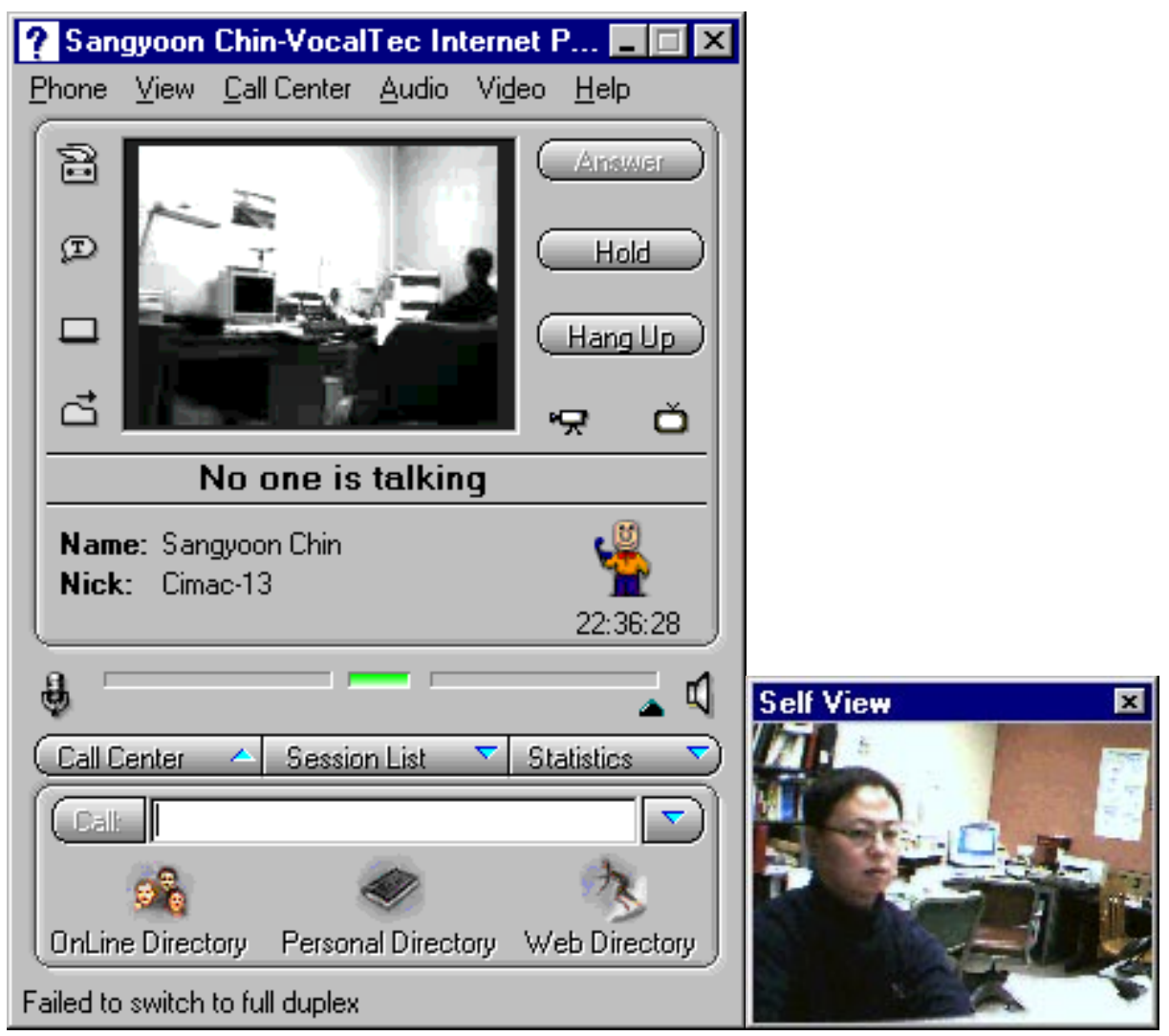

Figure 45. Internet Phone 4.0.

As mentioned previously, one important feature of videoconferencing software is whiteboarding. A whiteboard module is available with most commercial videoconferencing software, such as Internet Phone and NetMeeting. Remote users can share images and annotations on this common discussion board (Figure 46) and save the contents into the MFR database for later use and reference. (Refer to Capturing and Storing Multimedia Data in Chapter 3.) 


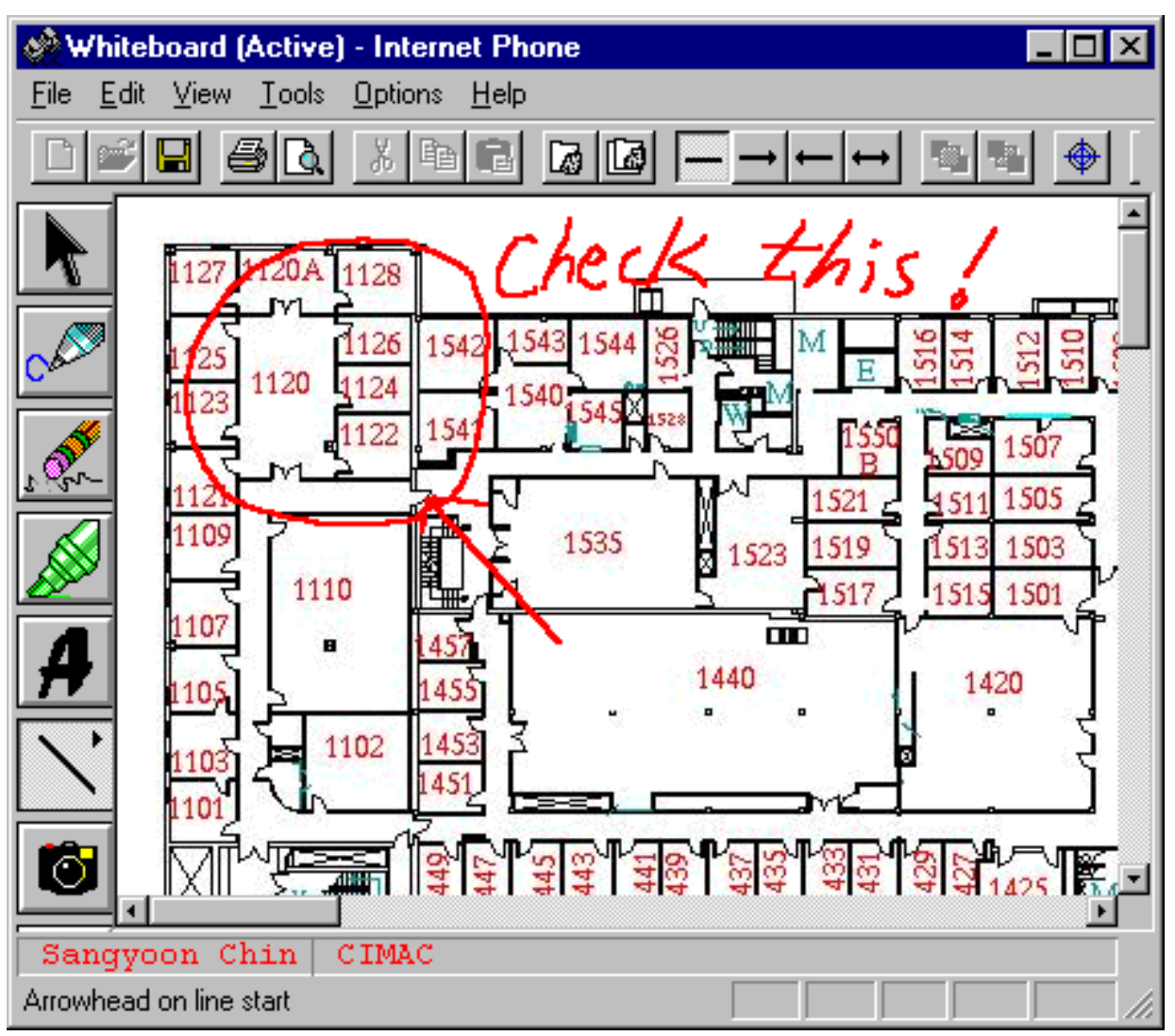

Figure 46. Using a whiteboard. 


\section{Retrieving Data Through a WWW Browser}

\section{WWW Address for the MFR Web}

Usually, the web address will be a full domain name or an IP address of your server unit. For example, you may type in the web address in the web browser as http://medcom1.ce.uiuc.edu or http://130.126.240.170.

\section{Using the MFR Web Browser}

- On the MFR home page (Figure 47), select MEDCOM Web Browser.

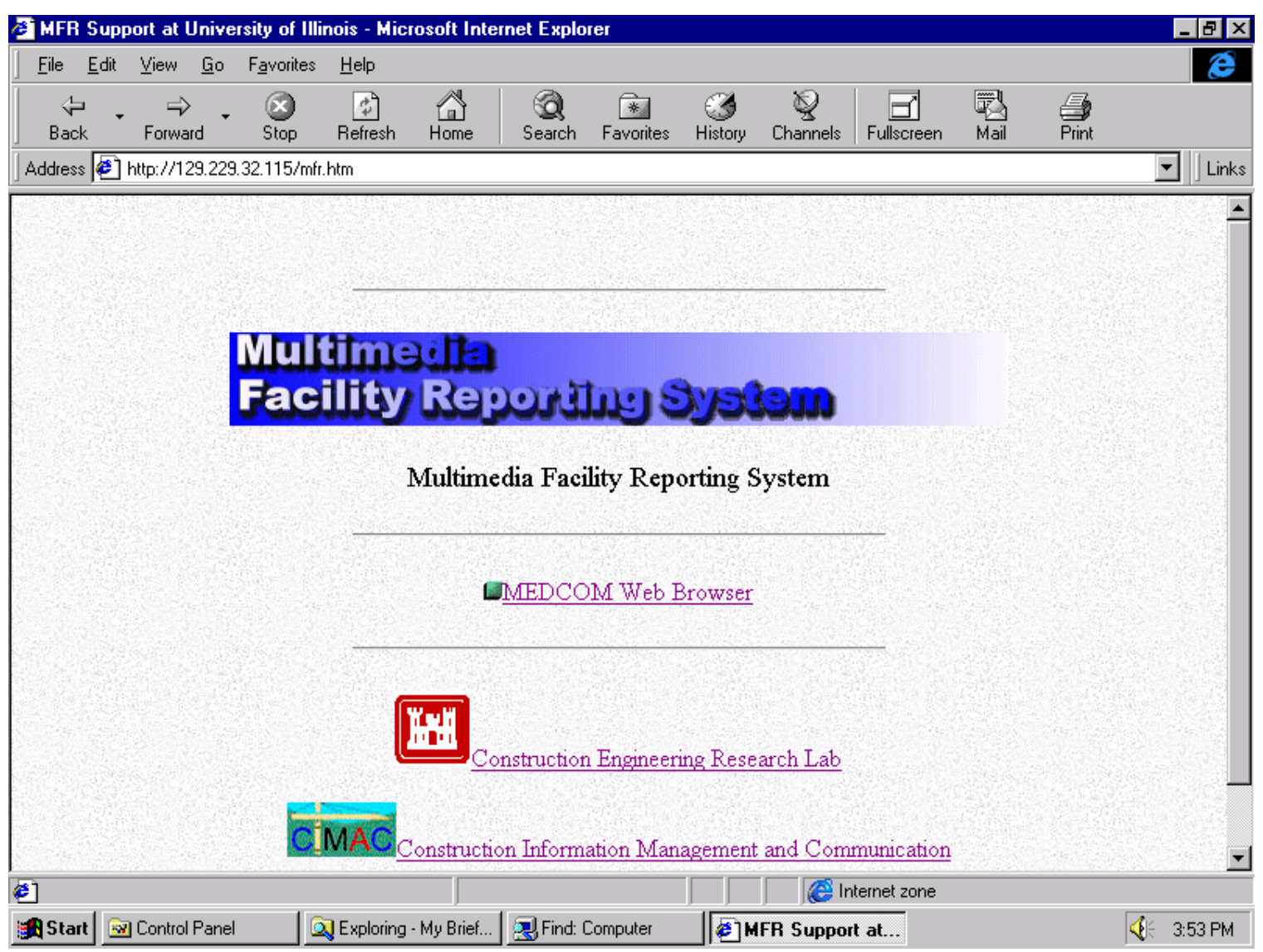

Figure 47. The home page of the MFR WWW server. 
- From the project list page, select the name of project you want to browse.

- From the issue list page (Figure 48), select a date for the specified issue.

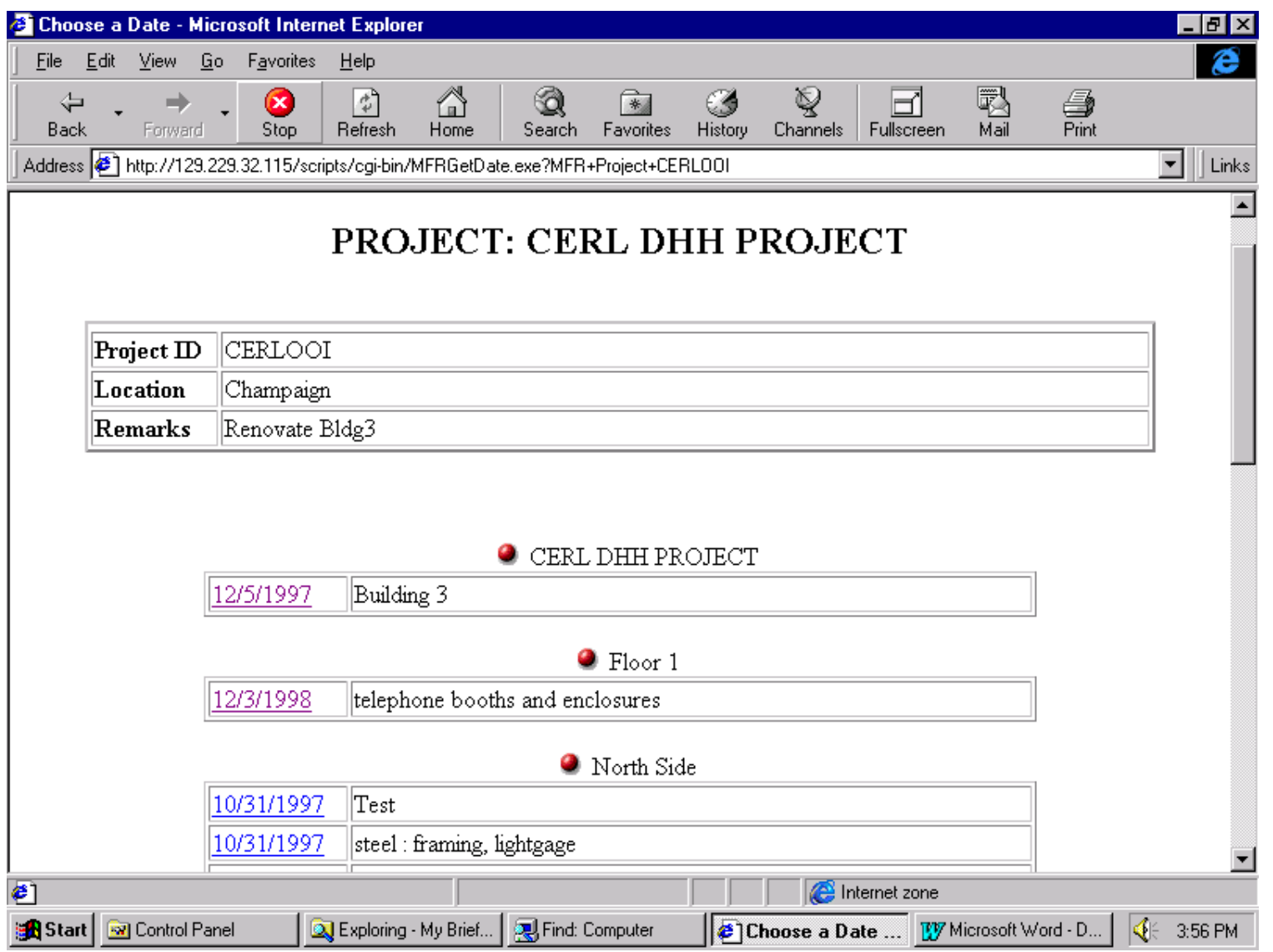

Figure 48. Issue List Page of MFR WWW. 
- Select the image or audio icon to be retrieved (Figure 49). If a video clip is available, you may select the video icon to retrieve and play the video (Figures 50 and 51).

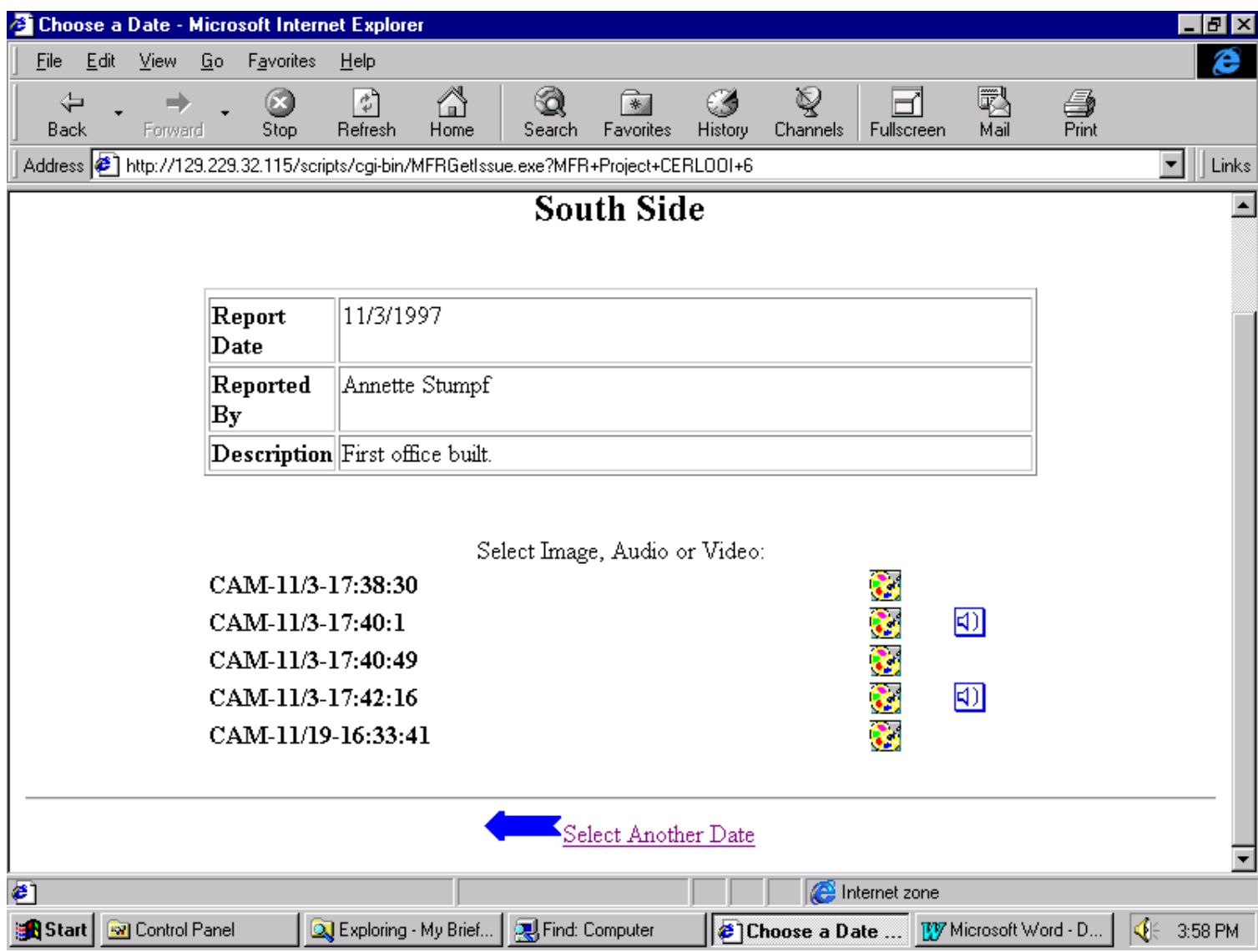

Figure 49. Data List Page of MFR WWW. 


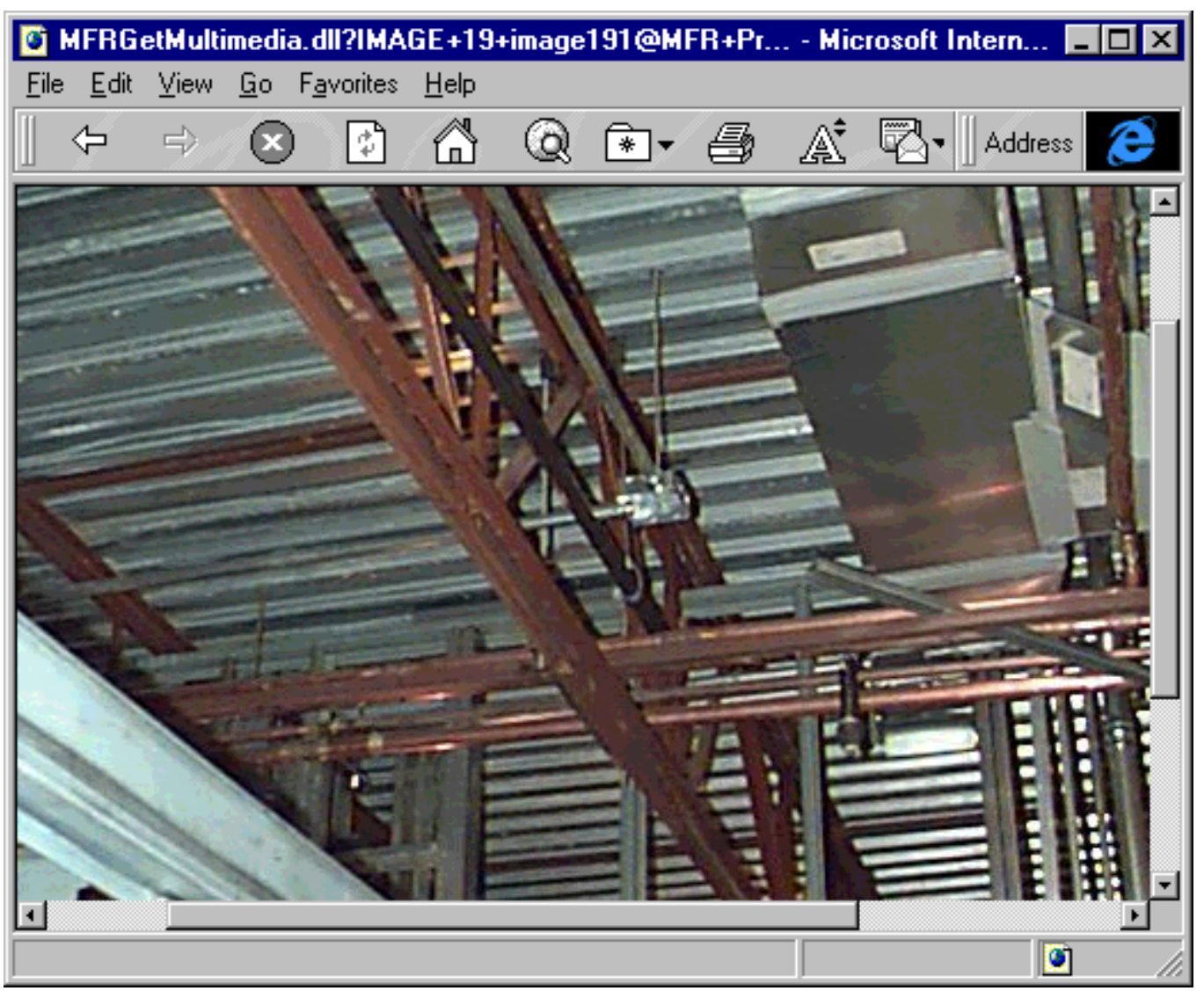

Figure 50. An image retrieved through MFR WWW.
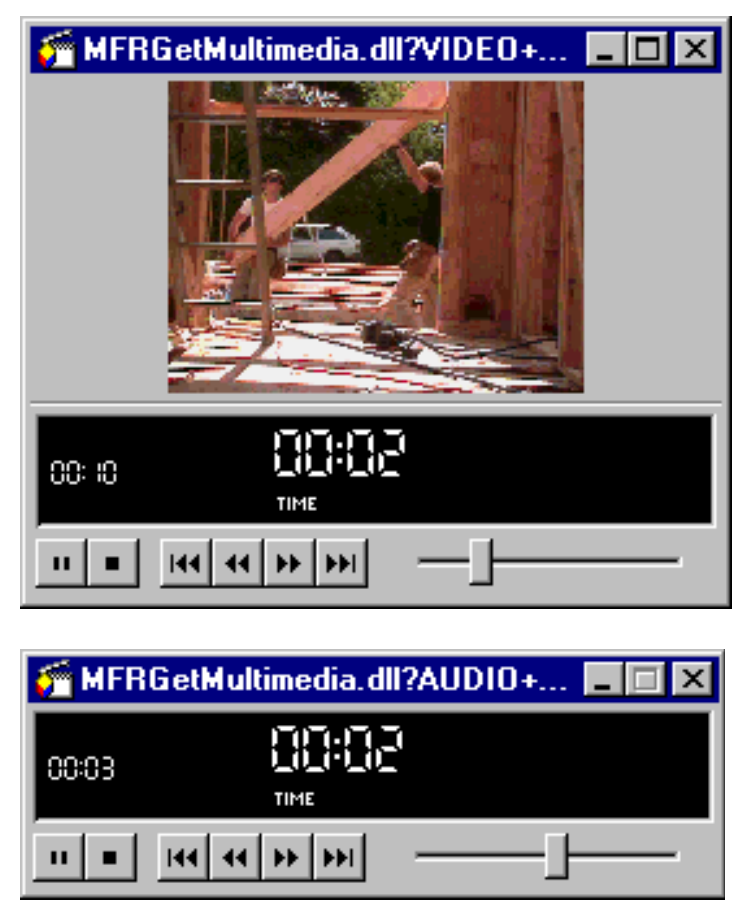

Figure 51. Video/audio clips retrieved through MFR WWW. 


\section{Digital Hardhat System Field Test and Results}

The DHH system field test was conducted at two different sites - Fort Worth District and USACERL-over a period of almost 2 years. Test participants included: Al Khatena, Milton Schmidt and Kurt C. Floyd (all from Fort Worth District), Annette L. Stumpf (USACERL), Dr. Liang Y. Liu, Dr. Sangyoon Chin and Chul-Soo Kim (all from the University of Illinois Civil Engineering Department). Lessons learned during this field test can be applied to teams who wish to (1) use multimedia to document project conditions, and (2) collaborate over a distance to work on projects together.

\section{Fort Worth District Field Test}

The DHH system was delivered on 1 and $2 \mathrm{~J}$ uly 1997 and tested for 2 days in Fort Worth and San Antonio, Texas. On the first day, the DHH system demonstrated the capability to capture and retrieve multimedia information using MFR WWW data retrieval on the Internet, and videoconference with Internet Phone Release 4.5. Also, tutorial sessions were held to teach the operation and system setup procedures for the DHH to Al Khatena (MEDCOM Support Team, Fort Worth District, Corps of Engineers). Other Fort Worth District participants included Kurt C. Floyd of the USACE Reinvention Center for District Support (CESWF-RC) and Milton Schmidt of the Cost Engineering Branch (CESWF-EC-CE).

On the second day, the $\mathrm{DHH}$ was tested at Brooke Army Medical Center (BAMC) at Fort Sam Houston in San Antonio. The second test investigated the outdoor performance of the mobile unit's display and the accessibility of the $\mathrm{DHH}$ WWW server from a remote location. Because of the limited time at the medical center, the videoconferencing capability was not tested. The mobile unit was tested at a construction site near the medical center. The test was conducted with the help of Roy Hirshak (Facility Manager, BAMC). 
Through the 2-day test, the DHH system performed successfully while testers observed the following features and benefits:

1. Capturing multimedia construction information can minimize wasted time and improve productivity in documenting site conditions. I mages captured using the DHH system can be annotated by the user to identify specific project concerns, reducing the need for text descriptions. The capability of adding audio comments also reduces project documentation time and improves the quality of site documentation.

2. Structured organization of site conditions based on a user-defined project breakdown allows easy and timely retrieval of information for fast and accurate decision-making and problem-solving.

3. The WWW server enabled remote users to retrieve site conditions in multimedia formats based on multiple key elements of project information, such as dates and project breakdown. With the password-protected WWW server in the DHH system, project information was accessible only to authorized participants from any location in the world. This feature allows remote users to view recent project conditions once project updates are posted to the WWW server.

4. Although not part of the Fort Worth field test, videoconferencing and whiteboarding using Internet Phone allow remote users to discuss, share, and mark up project information using the Internet. Videoconferencing enables users to communi cate in video and audio formats, while whiteboarding permits simultaneous sharing and editing of documents, images, and drawings between users. This feature enables collaboration between field engineers and coworkers at the District office or Headquarters by sharing multimedia project documents over the Internet. It also improves the productivity and accuracy for the resolution of imperative problems at construction sites or other projects.

5. Network communication: the wireless network was successfully connected to a network hub at the medical center, which gave access to the Internet so data could be shared with coworkers at Fort Worth District. If more time had been available, the videoconferencing capability of the system would have been tested. With the existing network connections throughout the medical center, it would be feasible to move the $\mathrm{DHH}$ equipment around the medical center to capture multimedia project data and to conduct videoconferences. Also, the $\mathrm{DHH}$ system can be configured so mobile users can 
transfer updated project records to the server using a modem or network connection. The network connection is much faster than a modem.

However, some issues need to be improved or resolved for better performance of the $\mathrm{DHH}$ system to fully meet users' needs. These possible improvements include:

1. Screen visibility of the color pen-based computer for outdoor use: The delivered pen-based computer has a DSTN VGA screen that supports up to 16-bit $\left(2^{16}\right)$ colors. The outdoor test of the pen-based computer showed that the DSTN screen did not have suitable visibility for outdoor use, although it was appropriate for indoor use.

2. Weight of the pen-based computer: The gross weight of the pen-based computer is somewhat heavy at $6 \mathrm{lb}$ including all the required accessories, while the computer unit itself weighs about $3.5 \mathrm{lb}$ for a 486/100 Mhz computer. For better mobility, the weight of the pen-based unit needs to be decreased. The recently marketed Pentium-level pen-based PCs weigh even more at $4 \mathrm{lb}$.

The neck strap on the pen-based computer was reconfigured after the test so that the user does not have to hold the computer in a horizontal position with his arm. Instead, the neck strap can be clipped on at diagonal corners to better support the computer.

One alternative could be the much lighter Handheld Personal Computers (HPCS), which operate on the Windows CE operating system. The HPC weighs around $1 \mathrm{lb}$.

3. Limited range of the wireless network communication: The maximum communication range between the pen-based computer and the wireless WavelAN antenna varies significantly depending on site conditions. In high-frequency areas, the communication range reaches up to 500 yd when no obstacles are directly between the antenna and the pen-based computer. However, when there are obstacles such as partitions, metal doors, and concrete block walls, the maximum communication range drops to 60 to 100 yd. This limit necessitated using the local storing feature, which allows the user to capture and store construction information locally in the pen-based computer. Later, when network communication is restored, the user can then transfer the local information to the server computer. 
4. User interface of MFR: After testing the $\mathrm{DHH}$, the customer requested several changes in the user interfaces of MFR. These requests were to: (a) enlarge several user input spaces, (b) simplify the operation procedure for capturing information, and (c) incorporate whiteboarding contents into the MFR database. A new version of MFR was developed and released to meet the users' needs. Input space for general project information was enlarged, capturing information was simplified by adding more toolbars, and whiteboarding contents can be captured and saved into the MFR database as a record of decisions made during the videoconference.

\section{Lessons Learned During the Fort Worth Field Test}

1. The impressive part of this experiment was the ability to collaborate between the field and the office, capture multimedia project data, and store it on an MFR project server. Other systems allow the user to videoconference, but this system allows multiple users to collect multimedia project data in an organized structured database and upload data to the server. Once the data is uploaded to the project server, anyone can access the data via the Web. This capability enables a virtual team to work together to document site conditions and resolve field problems.

2. Although MFR allows the user to create extensive project hierarchies, it was discovered that, because the customer at Fort Worth District manages J ob Order Contracts (J OCs), only simple project hierarchies were needed. MFR allows the user to develop simple or complex work breakdown structures. Digital images can be stored and indexed by date and description.

3. For all of the Fort Worth J OC projects, the Hospital Facility Manager and contractor walk through the facility and discuss the proposed work. Using the DHH system, this "Contractor Scope Validation Visit" could be conducted with Fort Worth District employees present as virtual team members. It is desirable to capture project information during this project scope definition. MFR was designed so that a project hierarchy can be built to document the scope of the project and capture before and as-built conditions of the facility. Once the project scope is determined, the contractor (or field engineer) could use the $\mathrm{DHH}$ to capture current conditions and add voice comments, drawings, cost estimates, schedules, etc. Periodic updates could be posted to the MFR Project Server to capture construction progress and final as-built conditions. If the contractor updates the project information in MFR 
periodically, Fort Worth J OC team members would al ways be able to see how the project was progressing.

4. Since a portion of the field test was conducted in a hospital, there was concern that wireless frequencies might interfere with lifesaving medical equipment. Areas in the hospital where the wireless network frequencies might disrupt pacemakers or other equipment were avoided. However, the steel and concrete structure prevented us from travelling a long distance from the antenna. In fact, the structure prevents doctors from using their cellular phones in many locations inside the building. BAMC plans to add an amplification system that will enable doctors to use cellular phones in appropriate areas of the medical facility. Direct connection of the MFR server to the hospital network prevents the wireless network frequencies from disrupting hospital equipment while improving access to other network resources such as printers.

5. Additional customer suggestions for improving the camera include a digital video camera that has auto zoom and auto focus. Also, a video camera that can be mounted on a flashlight with a pivot similar to a camera flash bracket would be useful in dark conditions. A camera mounted on an extension wand could be used to capture images or video of items that are very high or low. The Hitachi MPEGCAM stores video, stills, and sound on a removable 260 $\mathrm{Mb} \mathrm{PCMClA}$ hard disk you can insert directly into your computer. This camera is more expensive than many available, but would be very useful for recording what happened during contractor scope validation visits. Software conversion of MPEG video into AVI or incorporating the ability of MFR to utilize MPEG files directly could be an enhancement. Several "still" digital cameras now available will capture MPEG files to disk and record as much as $1 \mathrm{Mb}$.

6. Video cards are also available that allow analog video to be imported into digital files from which MFR can import them after they are converted to AVI files. Advanced users may feel comfortable with this application of MFR. Digital video cameras have not been tested, but there should be no reason that the user cannot use a digital camera with an IEER interface to a computer with a similarly appropriate interface. 


\section{USACERL Field Test and Lessons Learned}

USACERL also purchased a DHH system that was demonstrated and field tested many times during the past year, accomplishing the tasks described below. As researchers became more familiar with the system, shortcuts and improvements in both the software and user procedure were made. Also, a paradigm shift as to how to best implement the DHH technology at Fort Worth District occurred.

The following tasks were accomplished during the last portion of the field test:

1. Configured another computer at Fort Worth District so team members could collaborate with the mobile field unit. (The original configured computer had been put to another use.) MFR was loaded on a District server so project data would be available to team members when the mobile server was not available.

2. Conducted a usability test with the newest version of the MFR data capture software to see if the improvements really make DHH feasible for field use, or whether further improvements are necessary. The current version of MFR proved to be user friendly, but needed to be recompiled to work with updated Microsoft software and software drivers.

3. Conducted another field test to test the entire system (data capture, upload to server, and collaboration between office and field). The field test is described in the next section of this report.

4. Investigated how to "prepackage" the hardware so it is easier to move the DHH from site to site. It currently takes 10 to 20 minutes to set up the server and communication equipment. A rolling computer case was purchased for both $\mathrm{DHH}$ systems. The new case makes transporting the entire system easier, but it is still heavy. Additional useful equipment includes: several power strips, a flashlight, extra AAAA batteries, screwdriver, penbased computer stand and keyboard, configuration diagram and notes, equipment manuals, blank disks, emergency rescue disks, extra J az data cartridges, spare network cables and a terminator, telephone line tester, extra telephone cable, and an inline coupler (which allows you to connect two telephone cables together). One-gallon ziplock plastic bags were used to pack each system component with related cables to make system setup easier. There are also two different hubs; a large hub that works with both coaxial cables and 10baseT, and a pocket hub that works with only 10baseT. 
The hubs and a special hub-to-hub cable are necessary to connect the $\mathrm{DHH}$ server to an existing network hub. It would be a good idea to bring a spare pen for the pen-based computer if possible. For further discussion of this topic, see the section on Paradigm Shift.

5. Investigated whether additional equipment would make $\mathrm{DHH}$ much easier to use. For example, a PCMClA network card could be used to connect the pen-based data capture unit directly to a network at the remote location instead of transporting and setting up the wireless network equipment. If multimedia data capture equipment was located at each major customer location, the MFR database could be updated by contractor employees, and J OC project managers could view current project progress using the project WWW site. The project MFR server could be located at the District or at the customer location. Videoconferencing requires minimum equipment, so it could be conducted using either a network connection or a modem attached to the pen-based computer, laptop Windows NT server, or a personal computer set up at the customer location. If sound transmission is a problem (see NetMeeting comments below), then the parties videoconferencing can share data using the network or modem, while speaking on telephones or cellular phones.

\section{USACERL Lessons Learned}

1. Remote dial-in and project update: A series of tests were conducted to see how well a remote user could add a new project or update an existing project on the MFR server by dialing in to the MFR server with a modem. The experiment used two different MFR servers at Fort Worth District and a laptop computer at USACERL. A laptop computer was used as the mobile MFR server, running Windows NT Workstation as an operating system. The other computer was a District server running NT server software. Researchers were able to dial in to both Fort Worth servers using a laptop computer and a modem, logging in to the network using a special password created for the experiment. Projects were transferred and updated between Fort Worth and USACERL using all three computers involved in the test. The test proved that a roaming worker could capture multimedia project information using MFR and DHH and transfer data to and from a District server. However, researchers did have some difficulties getting the correct versions of certain .DLL files so the MFR server worked properly. (Necessary .DLL files are discussed on page 14 of this report.) 
2. Pen batteries wearing out: Researchers learned to keep a large supply of the "AAAA" batteries needed for the computer pen, and not to set the pen on top of the pen-based computer screen because it remains in communication with the computer. The batteries consistently wear out after a day of use, so the batteries are removed when the pen is not in use. The pen also seems to stop working once the computer batteries wear down past a certain point, and will start working again once the computer is plugged into an outlet.

3. The pen-based computer battery lasts for several hours if it is fully charged. It is useful to bring an extension cord when roaming with the pen-based computer in case the battery runs low. If the user can plug in the computer while building the initial project hierarchy, and when transferring images from a digital camera, it will reduce chances of the battery running out at a critical time. Digital camera batteries wear out quickly, so it is a good idea to plug the camera in when transferring images to a computer.

4. The modem and network connection cannot be used at the same time as the laptop MFR server. While running the wireless network, researchers were able to dial in to USACERL's network to access shared files and directories. However, when the modem was used, the connection from the mobile NT server (laptop) and the WaveLAN was broken. This occurrence has implications for how the mobile user can conduct videoconferences from the field to the office. The mobile user can use either a network connection or the modem to videoconference. It is impossible run the wireless network and use the modem on the laptop NT server to dial in to another computer to videoconference. This problem can be resolved because the PCMCIA 3Com Combo modem and network card will work with both the pen-based computer and the laptop Windows NT server if the proper drivers are selected and loaded. Another way to configure the system for videoconferencing is to connect the wireless network to the customer's network and videoconference over the Internet. Then the mobile user can carry the pen-based computer anywhere within range of the WaveLAN and videoconference with a person at another location. Again, telephones or cellular phones may be needed for satisfactory audio while videoconferencing.

5. When the wireless network was connected to USACERL's network, researchers could retrieve any project data available through the network (within range of the transmitter). It is possible to save much time by accessing specifications, drawings, details, correspondence, and other project information directly when resolving a problem. Both sound and video are transmitted reasonably well when the wireless network is not connected to 
USACERL's network and the pen-based computer is within range of the WaveLAN. Network noise prevented hearing audio transmissions during a live demonstration, however, even though the video was transmitted clearly. When the pen-based computer was carried the same distance from the server and was not connected to USACERL's network, the audio worked reasonably well. The quality of sound transmitted appears to be the biggest drawback when videoconferencing with a mobile pen-based computer. Communication can be improved if a telephone, cellular phone, or walkie-talkie is used to talk while video is transmitted through the wireless network connection.

\section{General Lessons Learned}

1. It is easier to use the pen-based computer keyboard to enter more complicated project hierarchies. With some advance planning, a hierarchy can be built before the user goes to the field and collects data. Building the hierarchy first will save time because it is typically easier to type in words than to select letters with the pen.

2. Data collection is simpler when the user has a general idea of what project information needs to be gathered and then plans a path through the site or building project. With such a plan, the user can move through the site or building and capture project information sequentially, storing it in an appropriate place in the project hierarchy.

3. The user needs to be comfortable using a voice recorder to capture voice comments that will be saved in the MFR database. Recorded comments can be played back and erased before the image is saved. Any comments added to a previously saved recording will be appended to the end of the audio file. Another way to annotate images with audio is to use a digital camera that allows the user to add voice comments to each image. Several new HPCs can capture audio comments also, and one features an integrated digital camera.

4. It is easier to focus the QuickCam lens during data capture once the penbased computer has been set on a table and the lens focused on a nearby object. The QuickCam Color II camera that was tested will adjust to lighting conditions if the user is patient and pauses for a moment before capturing the image. Final lens focus adjustments can be made after the camera has adapted to the lighting. Lighting conditions affect the quality and brightness of the captured image. In dark conditions, where a normal camera would require a flash, it is necessary to add light to the building component being captured with the digital camera. A flashlight is a good addition to the 
equipment being carried during data collection. Software adjustments can be made to adjust image size, quality, brightness, contrast, and hue.

5. The color screen on the pen-based computer that was tested nicely displayed CADD drawings, color images, and other graphics. Each user can use a different colored pen to markup drawings while whiteboarding. The transflective display would be much better for outdoor use, but a color display improves legibility with color images or color-coded drawings or documents.

6. The color image captured by the Connectix QuickCam Color II was significantly improved once updated QuickCam Color II drivers were downloaded from the Connectix Web site and installed (http://www.logitech.com/us/ cameras/index.html). It is a good idea to check manufacturers' Web sites for updated drivers periodically.

7. The audio and video quality available during videoconferencing using Internet Phone 4.0 was not very satisfactory, so software was upgraded to Internet Phone 5.0. The sound was much better but still limited by the sound capabilities of the current equipment. The video did not appear to improve after the upgrade. Next, Microsoft NetMeeting was downloaded from Microsoft's Internet site and tested. NetMeeting videoconferencing capabilities seemed to be much better than Internet Phone Release 5.0. The image captured by the QuickCam Color II was significantly improved and the audio quality improved somewhat. A switch was made to NetMeeting software for videoconferencing. Further experiments were conducted using NetMeeting to videoconference with the internal network, through a firewall, and using a modem. Additional NetMeeting comments are listed in the next section.

8. Video quality: Installing a new Connectix QuickCam VC camera on the penbased computer was attempted but it was very incompatible with the MFR software. MFR and video drivers had to be removed and reinstalled before the DHH would work properly again. QuickCam VC video drivers are nonstandard, and not recommended for use with MFR software. QuickCam VC cameras are optimized for videoconferencing, and capture a lower resolution image than do QuickCam Color II cameras. They also refresh the image more frequently during videoconferencing with NetMeeting than do QuickCam Color II cameras, and they are less expensive. 


\section{NetMeeting Lessons Learned}

1. The rate of transmission of audio, video, whiteboards, and shared applications depends on available bandwidth. Several factors affect the speed and quality of transmission: (a) how fast the connection is between participants and (b) how busy the connection is. If participants are using the Internet or a network, and it is a busy time of day, then the available bandwidth is reduced, video frames are refreshed less frequently, and there will be a delay in receiving sound and images. Use of a slow modem will also reduce refresh rates and cause a delay in the sound transmission. Sound quality is affected by both hardware (soundcard, microphone, speakers, network card, and/or modem) and available bandwidth. Each videoconferencing computer should have full duplex audio capabilities on both the sound card and modem.

2. If the meeting is conducted using a slow modem, with inadequate sound capabilities, or during peak Internet usage, it may be desirable for the meeting participants to turn off unneeded video transmission. If the sound quality is still less than desirable, many users actually use telephones to converse while sharing applications or transmitting video one way (from the field to the office).

3. The USACERL research team routinely conducts videoconferences with a coworker in California using NetMeeting. The remote worker logs into USACERL's network using a toll-free 800 line and a $28.8 \mathrm{kbps}$ modem. Audio transmission is slightly delayed, and seems distracting, so the telephone is used to talk. Transmission of two-way video without audio speeds up NetMeeting and works very well. Currently under investigation is the use of a remotely controlled videocamera for use in a team collaboration room. The remote user wants to be able to control the camera zoom, tilt, and pan, so he/she can more actively participate in the meeting. The QuickCam VC digital videocamera currently used does not capture high resolution images in a conference room, and the remote user cannot control the camera view.

4. NetMeeting and firewall: It was learned that, if someone who is not behind a firewall hosts the meeting, all others who are behind a firewall can participate. A NetMeeting conference was successfully conducted with eight participants in different locations, but the meeting host had to be someone who did not have a firewall around his network. A special telephone conference call was used to talk while sharing the documents during the meeting. Researchers have not successfully conducted a NetMeeting where 
all meeting participants are behind the firewall, but Microsoft's Web site has instructions for configuring NetMeeting for use with a firewall. Testing of this capability is ongoing.

5. NetMeeting caused a general protection fault several times when using twoway audio and video, while using two computers running Windows NT 4.0, and sharing a large application over an internal network. In that case, it would have been better to shut off the video transmissions and use the telephones while sharing the application. Microsoft's support Web page described problems running Windows NT 4.0 and NetMeeting. (For updated information, search for product updates and support information at http://www.support.microsoft.com.)

\section{Shortcuts and Time Savers}

1. One way to save time when capturing multimedia project data is to take photographs using a digital camera and add them to the MFR project database later. For legal documentation, use a digital camera with a date and time stamp to identify when the picture was taken. To save time figuring out where the picture was taken, the user could use a camera with a voice annotation feature to help identify what is important about the photo and where it was taken. Another possibility is to use a digital camera that stores images on a 3.5-in. disk. Each disk could be labeled with appropriate information and saved in the project folder once selected images are added to the MFR project database. Another digital camera allows the user to mark images with a special pen before saving them, and to add voice comments. Many new digital cameras capture high resolution images, and have features such as autofocus, zoom, flashes, date/time stamp, voice annotation, or PCMCIA memory cards to store the images. PCMCIA cards can be inserted directly into a computer to transfer the images instead of using a cable.

2. Another timesaver when working on a network is to use the DHCP settings (dynamic I nternet Protocol [IP] addresses) that allow the server to assign IP addresses. Using DHCP settings enables the user to move the wireless network (or computer) between different subnets without reconfiguring network settings. This method allows the mobile user to relocate within a building and still access project files from servers or computers on the network. Several network settings still must be changed at each location, and the user needs to be able to log into the network server. When the USACERL DHH equipment was configured in this manner, the equipment 
could be moved with only minor network changes, but there were problems hearing audio while videoconferencing because of network traffic.

3. If the mobile user is going to capture data in several locations within a building complex, it is convenient to have the equipment on a cart with wheels. Then the equipment can be relocated easily and stored in a locked room overnight. The pen-based computer should be plugged in overnight to recharge the batteries.

4. It is possible to save much time by accessing specifications, drawings, details, correspondence, and other project information directly off the network when resolving a problem. Mobile users could access this information from the mobile server via the wireless network, or from their District server.

\section{Paradigm Shift}

The DHH system has evolved after experimentation by project team members at Fort Worth District, Brooke Army Medical Center, the University of IIlinois, and USACERL. The University of Illinois originally developed the Multimedia Reporting System (MRS) with the DHH system so that several international construction companies could collaborate overseas on large construction projects. MRS software enables users to capture multimedia daily log information at a construction project site. The equipment configuration typically consists of an MRS server (a laptop running Windows NT workstation and MRS software) inside a construction trailer at the site, a WaveLAN wireless network, several pen-based computers, and accessories. A wireless network allows users to roam the construction site within range of the wireless network to capture multimedia data or videoconference with coworkers. If the user walks out of range of the wireless network, data can be stored directly on the pen-based computer and uploaded to the project server later.

Computers capable of videoconferencing are used at each physical location where project team members gather to discuss and resolve project issues. The videoconferencing stations are connected by the fastest available connection, which could be a modem, network or ISDN line. The MRS project server is kept in the same location throughout the project duration.

USACERL worked with the University to develop spin-off technology for Corps of Engineers projects. The Multimedia Facility Reporting system (MFR) was custom designed for Corps of Engineers projects, and includes features 
developed for MRS. When the DHH equipment was first configured for the Fort Worth District field test, researchers tried the following paradigm: the mobile user would transport the DHH system (a laptop computer configured as the Windows NT server, a wireless network and hub, a pen-based computer, and accessories) to the project site. After setting up the equipment, the mobile user could carry the pen-based computer to any location on the project site that was within range of the wireless antenna, which could be extended a fixed distance from the WaveLAN. This configuration enables the mobile user to collect multimedia project data and upload the data to the server. Once the project data were uploaded to the server, others would be able to access project data using the WWW. The mobile user could also use a modem on the MFR server or pen-based computer to videoconference with coworkers using a specially configured personal computer at their home office. The videoconferencing computer at the District office has a modem, but no network card (for security reasons).

It proved to be more difficult to transport and configure the DHH system and wireless network than anticipated. It takes approximately 10 minutes for an experienced person to set up all the equipment. However, connecting to an unfamiliar network may take longer and require local expertise and a "hub-tohub" network cable. Using this DHH paradigm presents several challenges: (1) the mobile user must be able to set up and troubleshoot computers comfortably, (2) the mobile user has to understand network configuration to be able to adapt to both coaxial and 10 BaseT networks, (3) the rolling case holding the DHH system equipment is heavy to carry, and does not fit in overhead compartments on small planes, and (4) the MFR project web server is unavailable when the user is traveling or has turned off the computer.

If the mobile user is comfortable setting up the $\mathrm{DHH}$ equipment within a new network environment when visiting a project location, the following method will save time. The mobile user should request a network login, IP address information, network connection, and any special cables required from the Information Management team at the project location. Both the pen-based computer and MFR server should be set up to use dynamic IP addresses if possible, because it will be much easier to connect the wireless network and server to the new network, and to relocate them within the facility. This capability would allow the mobile user to connect to various network connections within the facility and access resources such as printers and project Web servers via the Internet. The user can then capture project information, transfer updated information to the server, and videoconference with coworkers at the District office using the Internet. Another option is to use a modem in either the 
pen-based computer or mobile MFR server to dial into a District computer to videoconference. A third option is to use the modem to dial into a local Internet Service Provider (ISP) and use the Internet to access data and to videoconference.

The mobile user could carry less equipment and still complete all the desired tasks if the equipment is configured in one of the following ways:

1. The mobile user could bring the MFR Project server (laptop) and a digital camera. The user could then capture images with the camera (with voice annotations and date/time stamp if possible), and then upload them to a MFR project database on the server. Videoconferencing could be done with the District using either a modem or network connection.

2. The mobile user could bring just the pen-based computer and perhaps a camera and do the same tasks that were described previously. The user would need to transfer the newly captured multimedia data to the MFR server upon returning to the District office.

Without the wireless network, the mobile user would be able to roam while videoconferencing only when using a modem that works with a cellular telephone, and a fully charged computer battery. A second cellular telephone might be desirable for improved audio, since transmitting both audio and video reduces the sound quality considerably. It would be less awkward to carry the pen-based computer for videoconferencing than the laptop. Testing a cellular modem was not part of this field test.

The wireless network paradigm is still valid at a large construction or project site where the server can be set up in a fixed location for the duration of the data collection. A system similar to the one being tested at Fort Worth district is in use by three international construction companies. They have the servers set up in construction project trailers, and the people collecting the data with the pen-based computers are able to roam around the site and access data off the server. This is the paradigm first envisioned for using DHH with the Fort Worth Medical Command (MEDCOM) support team, but they have so many projects scattered around a large geographic area that the current equipment would have to be relocated frequently.

However, an MFR project server can be located at a customer facility where many projects are being done. For example, an MFR server could be located at $B A M C$, and the contractor could be required to update the project database with 
current project information as part of the contract. Then the MEDCOM Support Team at Fort Worth District would be able to view multimedia current project information directly over the Internet by accessing the Web site. Distributed team members could also conduct videoconferences to discuss project scope and resolve issues using the techniques described previously. If the project server was in an appropriate location, such as the penthouse of a tall structure, an antenna could be mounted on a tower to extend the range of the wireless network. Mobile users would then be able to roam quite far outside the facility while still accessing the network and videoconferencing over the Internet.

Until customers are equipped with $\mathrm{DHH}$ or similar systems, the simplest paradigm for using this technology is to set up an MFR project server on the District network. Mobile users could carry the minimum equipment and dial into the network server to collaborate with coworkers and update the project database on the MFR server. This configuration was tested, and researchers were able to share project information and files on the network. They were also able to transfer multimedia project information both ways between the mobile computer and District server. After experimentation, it was sometimes quicker to carry a digital camera to photograph construction, and then insert the images in the MFR project database.

Some users noted that the pen-based computer was heavy and awkward to carry. The MFR software could be modified to run on a lighter HPC. They are so light and portable that it would be easy to move around the project site and capture multimedia information. It is not clear how much data the HPC could capture before its memory is full and the data would have to be transferred to the project server. Also, although HPCs can capture images, record voice annotations, and e-mail multimedia messages, they are not currently capable of video-conferencing.

Mobile videoconferencing capabilities are developing and improving at a rapid pace. As long as the equipment and software complies with the existing videoconferencing standards, users with various configurations will be able to videoconference with each other. This capability has made mobile videoconferencing dramatically more accessible to the public, and it will catch on rapidly. USACERL's tests indicate that it is sometimes difficult to transmit audio clearly between two people using desktop or laptop computers to videoconference. A computer with inadequate sound capabilities (full duplex audio is best) will be frustrating to use. One way to avoid this problem is to use the Internet to collaborate and transmit data (for example using NetMeeting software) and a telephone conference call for voice communication. For maxi- 
mum mobility, a worker in the field could use one cellular telephone to talk, and another cellular telephone and modem to transmit the video images and data. The speed of data transmission will depend on the type of cellular telephone service and the modem speed. Some images may take a while to transmit, perhaps up to 30 seconds; however, remote team members can still have a meaningful conversation about the topic, resolve problems, and make decisions, all the while avoiding travel. Most of the applications for $\mathrm{DHH}$ under consideration do not require live video transmission of moving objects (like people talking), so this delay can be accommodated. 


\section{Summary and Future Development of the Digital Hardhat Technology}

\section{Summary of the Technology}

Depending on user requirements, existing equipment available, and the chosen communication path (ISDN, Internet, Intranet, or modem), required equipment for the DHH system may include:

- a pen-based computer, software, and accessories, with data-sharing and conferencing capabilities

- multimedia data-management software needed with the pen-based computer (to capture images, text, sound, video and to share with other users using a Web server)

- a Windows NT server, software, and hardware for a wireless local area network (LAN)

- a desktop collaboration station (or hardware to convert an existing computer) for use at the District or Field Office

- the newest version of DHH uses a pal mtop computer running Windows CE, a digital camera, and a modem or wireless LAN. This advance in technology is less expensive and easier to transport than the pen-based computer. The Windows CE-based equipment will be ready to field test soon.

Since computers and software keep improving, USACERL selects the best commercially available equipment and software that is compatible and will fulfill the project requirements. MFR software was developed by the University of Illinois for the Fort Worth DHH field test. Several international construction firms are using construction daily log and inspection software called Multimedia Reporting System (MRS) with DHH to collaborate overseas on large construction projects. 
The DHH enables dispersed users to capture and communicate multimedia field data to collaboratively solve problems, and to collect and share information. This system runs on a pen-based computer using Windows 95 to collect multimedia information (text, sound, video, and images). Special MFR software allows the field representative to save multimedia information into a projectspecific database, which is then accessible to others through the WWW. Current technology and typical communication lines allow users to transmit high resolution images from the field to the office. The project information collected using DHH will help document site conditions, progress, and problems in an organized manner so the information can be easily retrieved as needed by any project participant. The remote user can also access other electronic project information (such as CADD drawings, specifications, or change orders) via the network connection or modem.

The $\mathrm{DHH}$ equipment can be configured in several ways depending on available communication lines and project goals. For live image conferencing from remote field locations, a modem or wireless network connection can be used. (Wireless networks require more knowledgable users, additional equipment, and cost more than setting up a dial-in account on an existing server.) Using a modem or wireless network, the remote user can conduct a live "image conference" with team members while roaming around the site within range of the wireless network or cellular phone. If mobility is not necessary, the remote worker can use a communication station (network connection, phone, ISDN line, etc.) and image conference with co-workers. Available software allows both parties to share and markup images, video, text, documents and to share Microsoft Windows-based software applications.

If necessary, the remote user can also use digital cameras or the pen-based computer and video camera to capture the desired project information, then load the images with voice comments into the MFR software on the server at a later time. Once the data are transferred to the server, other people can immediately view the multimedia project information on the Web. This important software feature of MFR allows remote users to communicate important project information asynchronously.

\section{Future Development of the Technology}

Based on the test results of the DHH system, the following areas are recommended for research, focusing on the improvement of screen visibility, system mobility, and wireless communication. 
1. Screen visibility: To improve screen visibility for outdoor use, it is recommended that other screen types such as TFT and transflective monochrome be tested. Another option is to buy or construct a sun shade for the color pen-based computer so it can be used outdoors. This solution may not be effective in direct sunlight, however.

2. System mobility: To improve the mobility of the DHH system, it is necessary to reduce its total weight, which is currently about $6 \mathrm{lb}$. An alternative is to use HPCs (weighing about $1 \mathrm{lb}$ ), which run on the Windows CE operating system. Recent developments in the HPC industry tend to overcome the limitations of the old HPCs by adding Java technology, and making multimedia devices available with prices (around $\$ 500$ to $\$ 700$ ) much lower than pen-based computers (around $\$ 5,000$ ). However, the MFR program would have to be rewritten to run on HPCs. Team members from the University of Illinois have been using HPCs to capture and communicate multimedia project information on another project. HPCs now available on the market are capable of:

- using the Windows CE 2.0 operating system

- using modems to transfer data, send email messages, and connect to the Internet

- running popular software applications such as Pocket Word $\AA_{\text {, }}$ Pocket PowerPoint Viewer ${ }^{\circledR}$, Pocket Excel ${ }^{\circledR}$, Pocket Internet Explorer ${ }^{\circledR}$, Pocket Outlook $^{\mathrm{TM}}$ (in-box, calendar, contacts, tasks), Voice Recorder, and fax software.

Additionally, one HPC unit is designed to integrate images captured by a specially designed Digital PCMCIA camera. HPCs have full-color displays, full-featured keyboards, and stylus pens, and can synchronize data with a desktop PC.

3. Wireless communication: The maximum communication range of the wireless network (both $2.4 \mathrm{GHz}$ and $900 \mathrm{MHz}$ ) significantly depends on site conditions, and the test results showed far less range than the manufacturer's specifications. Using modems and cellular telephones could eliminate the range limitation because, through cellular tel ephones, the penbased computer can be connected to commercial Internet service providers' networks, which are available almost everywhere in the United States. However, the preliminary test results of analog cellular telephone 
connections showed data transfer rates varying from $4 \mathrm{kbps}$ to $28.8 \mathrm{kbps}$. A more consistent transfer rate could be accomplished by using a cellular digital packet data (CDPD) type of cellular telephone and digital modem. This type of device supports up to a $19.2 \mathrm{kbps}$ transfer rate, which provides a reasonably good performance of audio communication and whiteboarding with remote users. 


\section{Conclusions and Recommendations}

\section{Conclusions}

The results of the DHH system test show the following:

- The DHH system improves the documentation of site conditions by integrating multimedia and database technologies.

- Structured organization of project information provides easy and timely retrieval for fast and accurate decision making and problem solving.

- Easy availability of multimedia project information reduces frequent travel and telephone expenses between District offices and construction sites.

- Video conferencing and whiteboarding on the Internet improved the collaboration of project participants by sharing construction information in multimedia formats.

Although problems still exist, it has been proven that the DHH system can enhance project documentation and collaboration.

Benefits of using the pen-based computer with a wireless network (within range of the transmitter) include the user's ability to access any project data available through the network. It is possible to save much time by accessing specifications, drawings, details, correspondence, and other project information directly when resolving a problem. Host organizations that allow the mobile user to log on to the network to access printers and the Internet will enable the user to transmit data back to his/her home District. This type of accommodation of mobile workers may become more common as the Corps transitions to a virtual workplace. Telecommuters and virtual teams can use tools such as $\mathrm{DHH}$ to become a large part of successful Corps of Engineers projects in the future.

It is expected that the data-sharing capabilities and improved communication offered by the Digital Hardhat will result in a reasonable payback period if the 
costs of avoided travel and extended meetings are considered. Immediate reductions in travel cost will be the most obvious benefit; however, costs associated with more quickly resolved issues, reduced construction claims, and fewer delays will be the ultimate benefit of this technology. Improved communication between personnel involved in project planning, design, and construction throughout the life of the project is expected to improve the quality of the completed facility.

Immediate reductions in travel cost will be the most obvious benefit; however, costs associated with more quickly resolved issues, reduced construction claims, and fewer delays will be the ultimate benefit of this technology. Potential applications of $\mathrm{DHH}$ include: military engineering, real estate support for facility evaluations, emergency operations, split-based operations, collaboration between the field and District for new construction, remodeling and Civil Works projects, and field support for international projects.

\section{Recommendations}

It is strongly recommended that the issues and alternatives discussed in Chapter 5 be further examined and implemented. Other possibilities recommended for study include:

- Videoconferencing:

- further test videoconferencing between mobile and desktop computers

- investigate connecting room videoconferencing systems to desktop videoconferencing systems

- Connectivity standards: Many Corps projects are situated in remote locations, and do not have high speed connectivity to District offices. Alternative communication methods should be investigated to improve collaboration and reduce congestion on current communication links.

- investigate use of CDPD communication links

- investigate use of satellite-based communication links

- consider using a local Internet Service Provider (ISP) and a fast modem 
- Collaboration:

- further test remote control, application sharing, chat systems, whiteboarding, and videoconferencing using various communication links

- investigate recent developments in emerging productivity tools (i.e., Web browser-based systems), which are heading toward platform-independent, J ava-enabled Web browsers that work with Windows, Macintosh, Unix, and lightweight network systems. They can provide terminal emulation and mediate information exchange between various clients (such as Netscape Communicator or Microsoft Internet Explorer 4.0), but these productivity tools do not currently handle audio or videoconferencing.

- Digital photographs as legal documentation:

- Study available recommendations on use of digital photographs as legal documentation. Review procedures for capturing, storing, documenting, and securing digital images. Investigate use of digital cameras and compare the level of security of available for different cameras. (For instance, Kodak DC50 and DC120 cameras offer "Level 2" security ratings on photos, which is better than the "Level 1" security rating for other cameras.) Compare ease of use, resolution, file size and type, camera features, memory, and transfer of images from camera to computer for the digital cameras under consideration.

- Multimedia video/tel econferencing standards:

- Define videoconferencing operability over ISDN, Internet (IP - Packet Switched N etworks) or POTS and between ISDN and IP networks.

As of October 1996, several standards had been ratified by the International Telecommunication Union (ITU). The ITU-T T.120, H.320, $\mathrm{H} .323$, and H.324 standards comprise the core technologies for multimedia teleconferencing. The T.120 standard addresses Real Time Data Conferencing (Audiographics), the H.320 standard addresses ISDN Videoconferencing, the H.323 standard addresses Video (Audiovisual) Communication on Local Area Networks, and the H.324 standard addresses High Quality Video and Audio Compression over POTS modem connections. Standards, however, are not static. It is expected that these 
standards will be enhanced to incorporate new functionality and capabilities.

The best way to determine how effectively $\mathrm{DHH}$ technology can enhance collaboration between remote team members, improve project documentation, and reduce travel is to use the system on actual projects. The $\mathrm{DHH}$ hardware, software, and configuration have evolved into an easy-to-use system that is now ready for field use. The Army Corps of Engineers vision requires use of virtual teams. This technology should be rigorously field-tested at this time so recommendations can be made and implementation costs budgeted for Corpswide use in appropriate situations. 


\section{Appendix A: Database Description}

\section{Relationship Diagram}

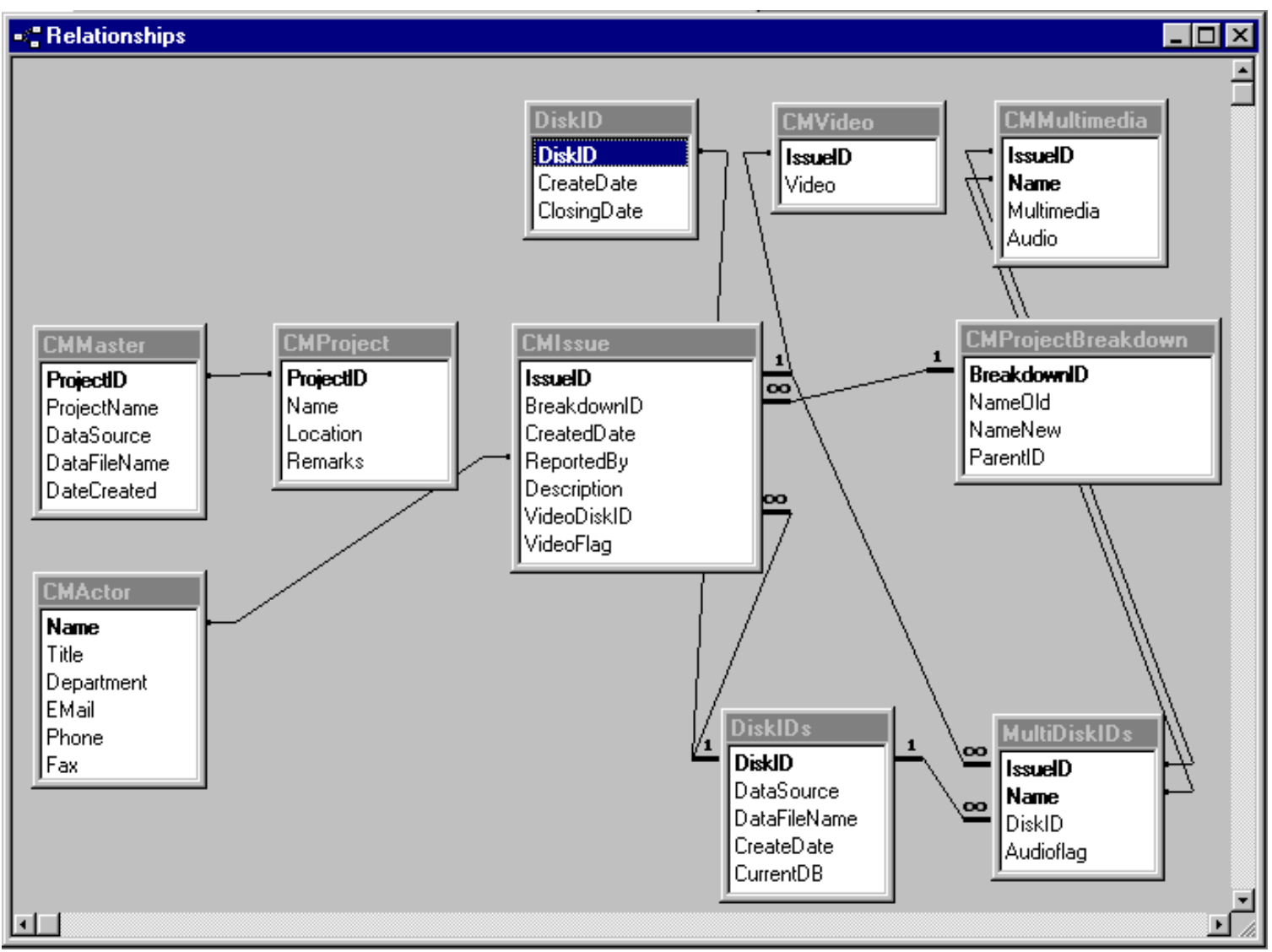

Figure A1. Database Relationship Diagram. 


\section{Database Structure}

Master Database

- File Name: MFRMaster.MDB

Table A1. Master Database.

\begin{tabular}{|l|c|l|c|c|c|c|}
\hline $\begin{array}{c}\text { Table } \\
\text { Name }\end{array}$ & $\begin{array}{c}\text { Primary } \\
\text { Key }\end{array}$ & Field Name & Data Type & $\begin{array}{c}\text { Data Size/ } \\
\text { Data Format }\end{array}$ & Required & $\begin{array}{c}\text { Allow Zero } \\
\text { Length }\end{array}$ \\
\hline \hline CMMaster & $\hat{a}$ & Project ID & Text & 20 & Yes & No \\
& & Project Name & Text & 255 & Yes & No \\
& & Data Source & Text & 34 & Yes & No \\
& & DataFileName & Text & 200 & Yes & No \\
& & DateCreated & Date/Time & Short Date & No & - \\
\hline CMActor & $\hat{a}$ & Name & Text & 30 & Yes & No \\
& & Title & Text & 50 & No & Yes \\
& & Department & Text & 50 & No & Yes \\
& & Email & Text & 50 & No & Yes \\
& & Phone & Text & 20 & No & Yes \\
& & Fax & Text & 20 & No & Yes \\
\hline
\end{tabular}

\section{Project Database}

- File Name: MFRProject.MDB

Table A2. Project Database.

\begin{tabular}{|c|c|c|c|c|c|c|}
\hline $\begin{array}{l}\text { Table } \\
\text { Name }\end{array}$ & $\begin{array}{c}\text { Primary } \\
\text { Key }\end{array}$ & Field Name & Data Type & $\begin{array}{c}\text { Data Size/ } \\
\text { Data Format }\end{array}$ & Required & $\begin{array}{c}\text { Allow Zero } \\
\text { Length }\end{array}$ \\
\hline CMProject & $\overline{\overline{\mathrm{a}}}$ & $\begin{array}{l}\text { ProjectID } \\
\text { Name } \\
\text { Location } \\
\text { Remarks } \\
\end{array}$ & $\begin{array}{c}\text { Text } \\
\text { Text } \\
\text { Text } \\
\text { Memo } \\
\end{array}$ & $\begin{array}{c}50 \\
255 \\
255 \\
- \\
\end{array}$ & $\begin{array}{l}\text { Yes } \\
\text { Yes } \\
\text { No } \\
\text { No } \\
\end{array}$ & $\begin{array}{l}\text { No } \\
\text { No } \\
\text { Yes } \\
-\end{array}$ \\
\hline CMIssue & â & $\begin{array}{l}\text { IssuelD } \\
\text { BreakdownID } \\
\text { CreatedDate } \\
\text { ReportedBy } \\
\text { Description } \\
\text { VideoDiskID } \\
\text { VideoFlag } \\
\end{array}$ & $\begin{array}{c}\text { Auto Num. } \\
\text { Number } \\
\text { Date/Time } \\
\text { Text } \\
\text { Memo } \\
\text { Number } \\
\text { Number }\end{array}$ & $\begin{array}{c}\text { Long Integer } \\
\text { Long Integer } \\
\text { Short Date } \\
30 \\
- \\
\text { Long Integer } \\
\text { Integer }\end{array}$ & $\begin{array}{l}- \\
\text { Yes } \\
\text { Yes } \\
\text { Yes } \\
\text { No } \\
\text { No } \\
\text { No } \\
\end{array}$ & $\begin{array}{c}- \\
- \\
- \\
\text { No } \\
- \\
- \\
- \\
\end{array}$ \\
\hline $\begin{array}{l}\text { CMProject- } \\
\text { Breakdown }\end{array}$ & â & $\begin{array}{l}\text { BreakdownID } \\
\text { NameOld } \\
\text { NameNew } \\
\text { ParentID }\end{array}$ & $\begin{array}{c}\text { Auto Num. } \\
\text { Text } \\
\text { Text } \\
\text { Number }\end{array}$ & $\begin{array}{l}\text { Long Integer } \\
30 \\
30 \\
\text { Long Integer }\end{array}$ & $\begin{array}{l}- \\
\text { No } \\
\text { No } \\
\text { Yes }\end{array}$ & $\begin{array}{l}- \\
\text { Yes } \\
\text { Yes } \\
-\end{array}$ \\
\hline DiskIDs & â & $\begin{array}{l}\text { DiskIDs } \\
\text { DataSource } \\
\text { DataFileName } \\
\text { CreateDate } \\
\text { CurrentDB }\end{array}$ & $\begin{array}{c}\text { Auto Num. } \\
\text { Text } \\
\text { Text } \\
\text { Date/Time } \\
\text { Number }\end{array}$ & $\begin{array}{c}\text { Long Integer } \\
34 \\
200 \\
\text { Short Date } \\
\text { Integer }\end{array}$ & $\begin{array}{l}- \\
\text { Yes } \\
\text { No } \\
\text { No } \\
\text { Yes }\end{array}$ & $\begin{array}{l}\text { - } \\
\text { No } \\
\text { Yes } \\
- \\
-\end{array}$ \\
\hline $\begin{array}{l}\text { MultiDisk- } \\
\text { IDs }\end{array}$ & $\begin{array}{l}\text { â } \\
\hat{a}\end{array}$ & $\begin{array}{l}\text { IssuelD } \\
\text { Name } \\
\text { DiskID } \\
\text { AudioFlag }\end{array}$ & $\begin{array}{c}\text { Number } \\
\text { Text } \\
\text { Number } \\
\text { Number }\end{array}$ & $\begin{array}{c}\text { Long Integer } \\
30 \\
\text { Long Integer } \\
\text { Integer }\end{array}$ & $\begin{array}{l}\text { Yes } \\
\text { Yes } \\
\text { Yes } \\
\text { Yes }\end{array}$ & $\begin{array}{c}- \\
\text { No } \\
- \\
-\end{array}$ \\
\hline
\end{tabular}




\section{Multimedia Database}

- File Name: MFRMultimedia.MDB

Table A3. Multimedia Database.

\begin{tabular}{|l|c|l|c|c|c|c|}
\hline $\begin{array}{c}\text { Table } \\
\text { Name }\end{array}$ & $\begin{array}{c}\text { Primary } \\
\text { Key }\end{array}$ & Field Name & Data Type & $\begin{array}{c}\text { Data Size/ } \\
\text { Data Format }\end{array}$ & Required & $\begin{array}{c}\text { Allow Zero } \\
\text { Length }\end{array}$ \\
\hline \hline DiskID & $\hat{a}$ & DiskID & Number & 50 & Yes & No \\
& & CreateDate & Date/Time & 255 & Yes & No \\
& & ClosingDate & Date/Time & 255 & No & Yes \\
\hline CMMulti- & $\hat{a}$ & IssuelD & Number & Long Integer & - & - \\
Media & & Name & Text & 30 & Yes & No \\
& & Multimedia & Ole Object & - & No & - \\
& & Audio & Ole Object & - & No & - \\
\hline CMVideo & \multirow{a}{a}{} & IssuelD & Number & Long Integer & - & - \\
& & Video & Ole Object & - & No & - \\
\hline
\end{tabular}




\section{Appendix B: Project File and Data Source Naming Conventions}

\section{Master Database}

- Data Source Name: MFR Master Database

- File Name: MFRMaster.mdb

The data source and file name for the Master Database should al ways be as above and should never change. The above setup must be done before first-time running of MFR.

\section{Project Database}

- Data Source Name: MFR Project PROJ ECTID

- File Name: MFR-PROJ ECTID.MDB

Example: When the project's ID is CS970411, the data source name will be 'MFR Project CS970411', and the file name will be assigned as MFRCS970411.mdb.

\section{Multimedia Database}

- Attached Multimedia File Name: MFR-PROJ ECTID-M00.mdb

A multimedia file is linked to a project database file, and it is not necessary to have a separate data source name.

Example: 'MFR-CS970411-M00.mdb' for the project CS970411. 
- Archived Data Source Name: MFR MM PROJ ECTID MXX

- Archive File Name: MFR-PROJ ECTID-MXX.MDB

A project will have a multiple number of archived multimedia files. They will be serially numbered as files are produced by the archiving function of MFR.

Example: The first archive file's data source and name for the project CS970411 would be 'MFR MM CS970411 M01' and 'MFR-CS970411-M01.mdb', respectively. 


\section{Appendix C: Installation Procedures}

The DHH System uses several different hardware and software resources, which include network, modem, video, audio, database interfaces, image file formats, etc. to name a few. Therefore, a complete system setup for the DHH includes several steps, and it will not be an easy task. A person with a strong background in PC hardware as well as Windows operating systems should perform the following setup. Ask your network administration or Information Management support staff for help if you are unfamiliar with Windows NT.

\section{Steps for Setting Up a New PC as an MFR Server}

1. Operating System Installation

The operating system must be installed first. For NT4, use the three Microsoft NT4 setup diskettes and the Microsoft NT4 installation compact disk (CD) to install the NT4 operating system, the peer web server for NT workstation, and the web server module and RAS (RAS is necessary on the server only for remote access dial-up from the remote to the server and its associated connected network).

2. $\mathrm{PCMCIA}$ Socket

Configure the PCMCIA socket so that the operating system detects it. This configuration is done by clicking the PC Card (PCMCIA) icon inside Control Panel.

3. Network and Modem Setup

Network and modem setup are described in detail beginning on page 58 in this appendix. 
4. RAS (Remote Access Service) Setup

Select Control Panel - Network - Services - Add - Remote Access Service. Copy files from the Windows NT CD. RAS setup is described in detail beginning on page 61.

5. Audio Device Setup

Select Control Panel - Multimedia - Devices - Audio Devices - Add. Select Windows Sound System and add driver from the Windows NT CD.

6. Install Adaptec SCSI Card and J AZ Drive

It is preferred to set the $\mathrm{AZ}$ drive as drive $\mathrm{D}$.

7. Enlarge Virtual Memory Size

Select Control Panel - System - Performance - (Virtual Memory) Change - Set initial size to 100MB and maximum size to 150MB, then click Set.

8. U pdate the operating system using Microsoft NT4 Service Pack 3. Once you have a working upgraded operating system installed that recognizes all devices, proceed to Step 9.

9. Install Open Database Connectivity and Data Access Object

Install Microsoft Office 97's ACCESS and accompanied DAO. MFR97 has been tested with ODBC ACCESS driver version 3.50.342800.

10. Install the latest version of Microsoft Internet Explorer Browser. Versions 3.2 through 4.72 have been tested, but version 4.72 or above is recommended for use with MFR97 in conjunction with Microsoft Office 97.

11. Install the MFR program.

12. Map the $X$ : drive.

Map \\mobile2 $\backslash$ MFR Database directory as X: drive (where "mobile2" is the name of the remote computer and MFR Database directory is the shared MFR folder "database" that contains the database). 


\section{Network Setup}

\section{Modem Installation and Setup}

- Load Modems Properties.

From Control Panel, click the Modems icon to load Modems Properties dialog box (Figure C1).

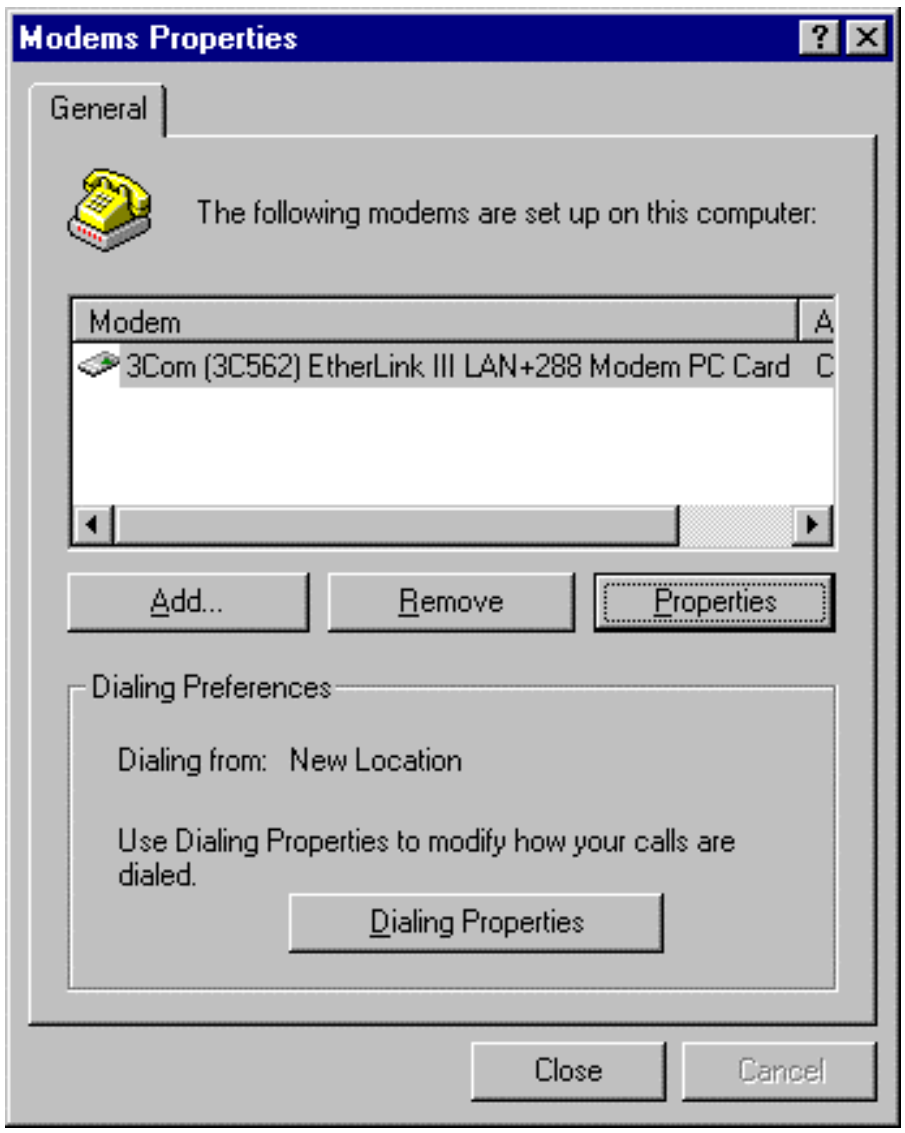

Figure C1. Modems properties.

- Install modem drivers.

Click Add and then select the name of the installed modem from the list (not shown) and click OK. Follow driver installation procedure as directed.

- Set modem speed. 
After modem drivers are installed, select the modem from the modem list. Then click the Properties... button. Set Maximum speed at the highest number (see Figure C2).

Note: This procedure is not absolutely essential. You may skip this and check back later if you have modem speed-rel ated problems.

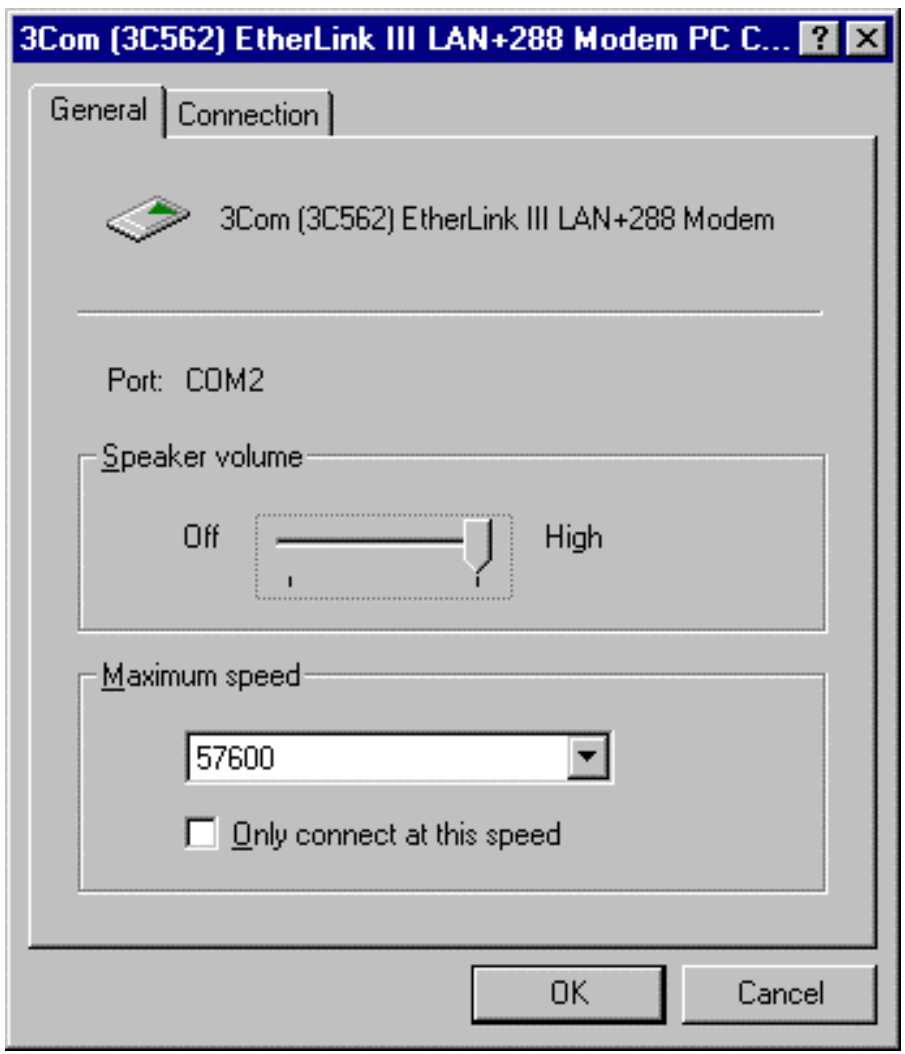

Figure C2. Modem maximum speed setting.

- Set Connection properties

Select the Connection tab (Figure C3) and check if all the boxes appear as follows. 


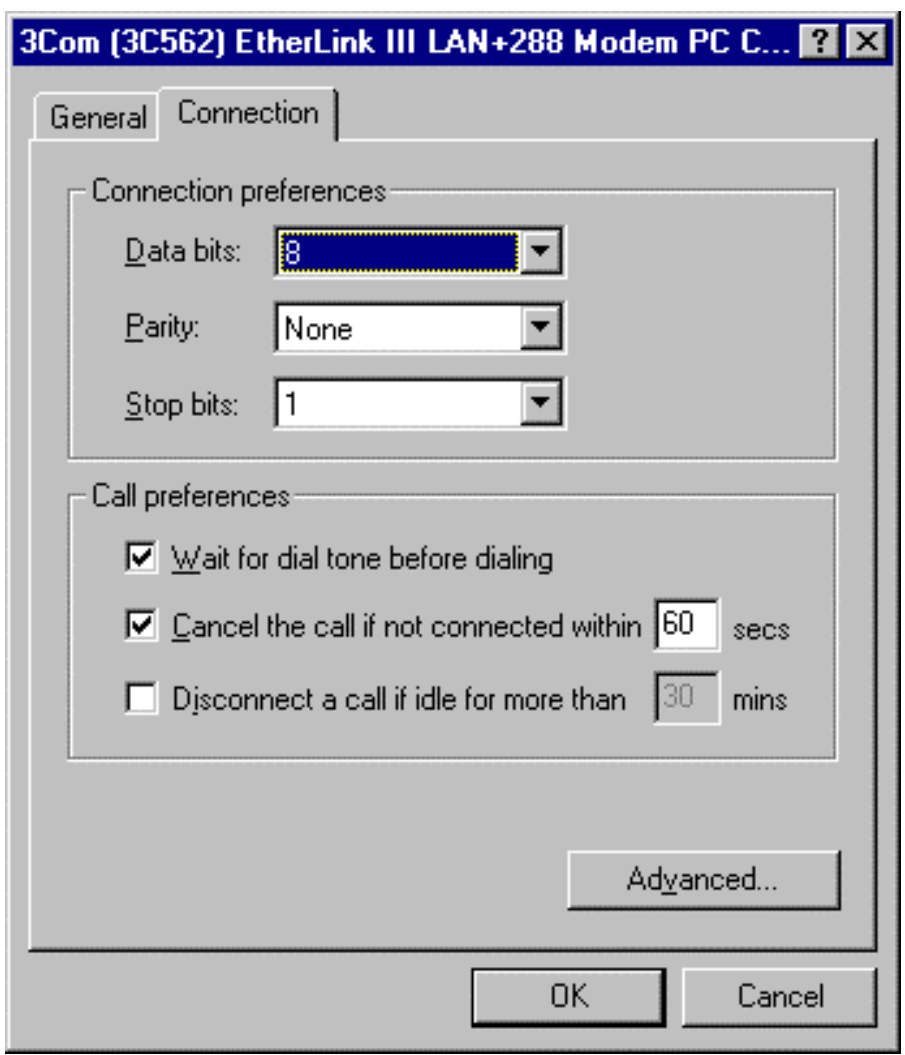

Figure C3. Connection properties of modem.

- Set Advanced properties.

Click on the Advanced... button. The dialog box shown in Figure C4 should appear.

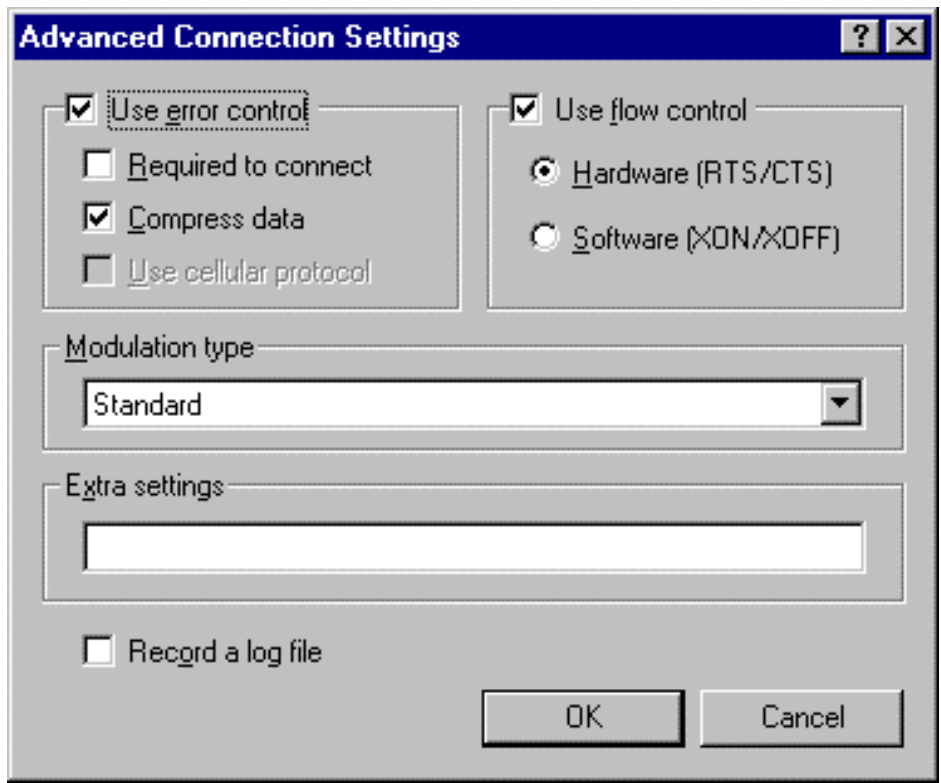

Figure C4. Advanced connection settings. 


\section{Network and Remote Access Service (RAS) Setup for the MFR Server}

- Load Network setup dialog.

In Control Panel, double click the Network icon to load the network setup dialog box (Figure C5).

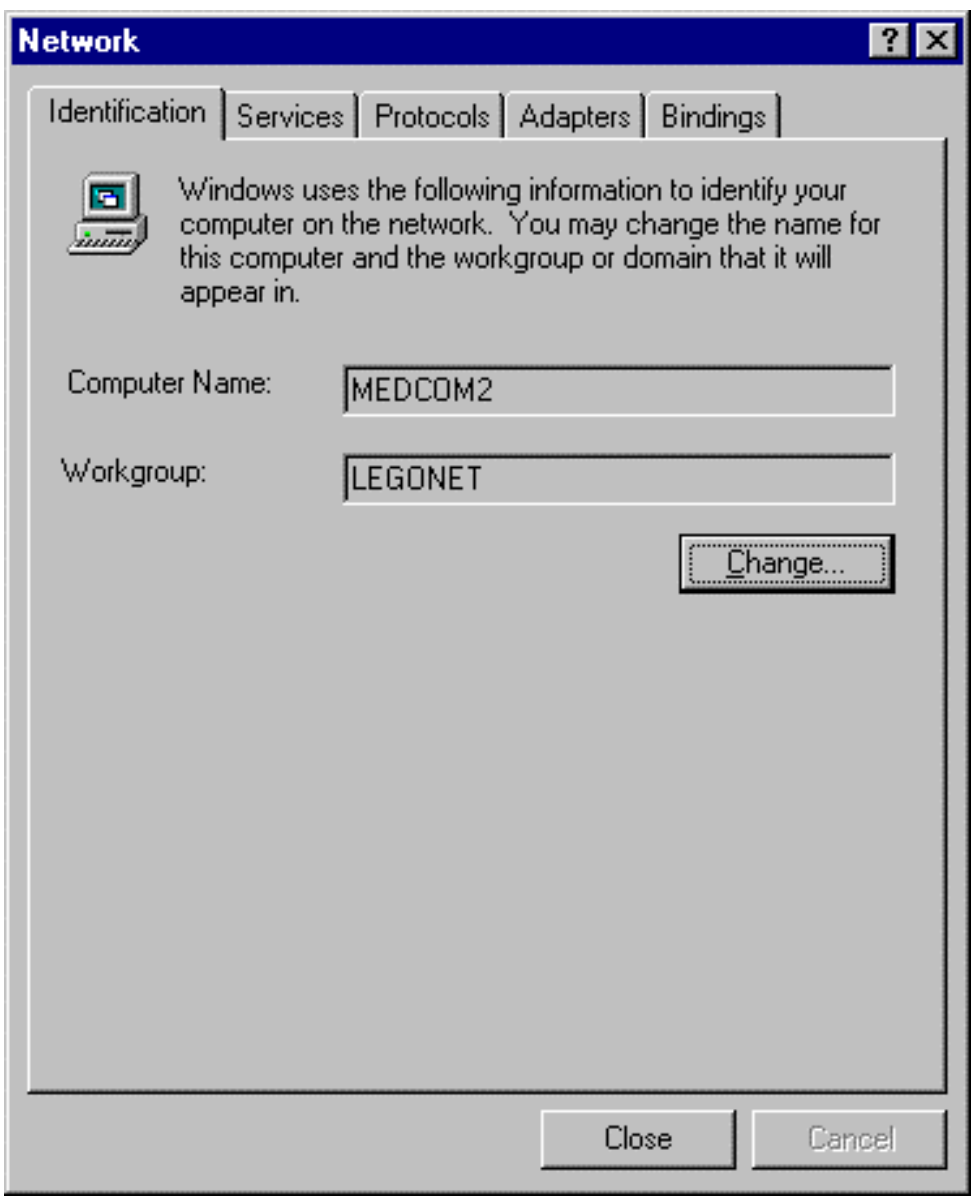

Figure C5. Network configuration main dialog box.

You may change your computer name and work group by clicking Change... and editing in the dialog box that then appears.

- Adding the network adapter.

First install drivers for your network adapter. (This assumes that you have already installed a network adapter in the computer.) Select the Adapters tab and click on Add (Figure C6). 


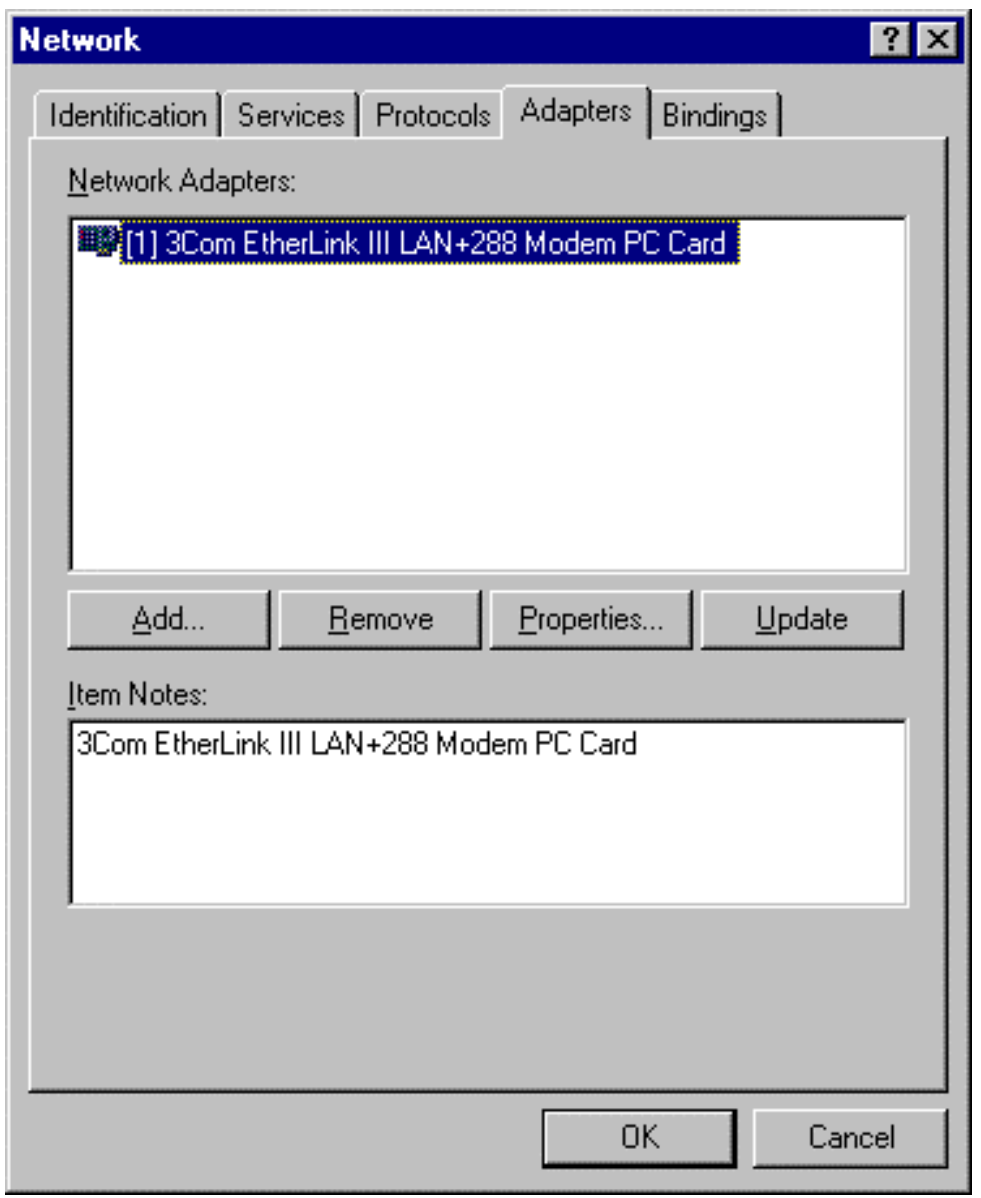

Figure C6. Network adapter configurations.

Select the network driver from the list in the Select Network Adapter dialog box (not shown), or select Have Disk... if you want to install it from the manufacturer's disk. 
- Add protocols.

Select the Protocols tab and click Add... (Figure C7). Select TCP/IP Protocol and click OK button. Click Add again and sel ect NetBE UI Protocol and then, OK. The resulting dialog box should appear as shown in Figure C7.

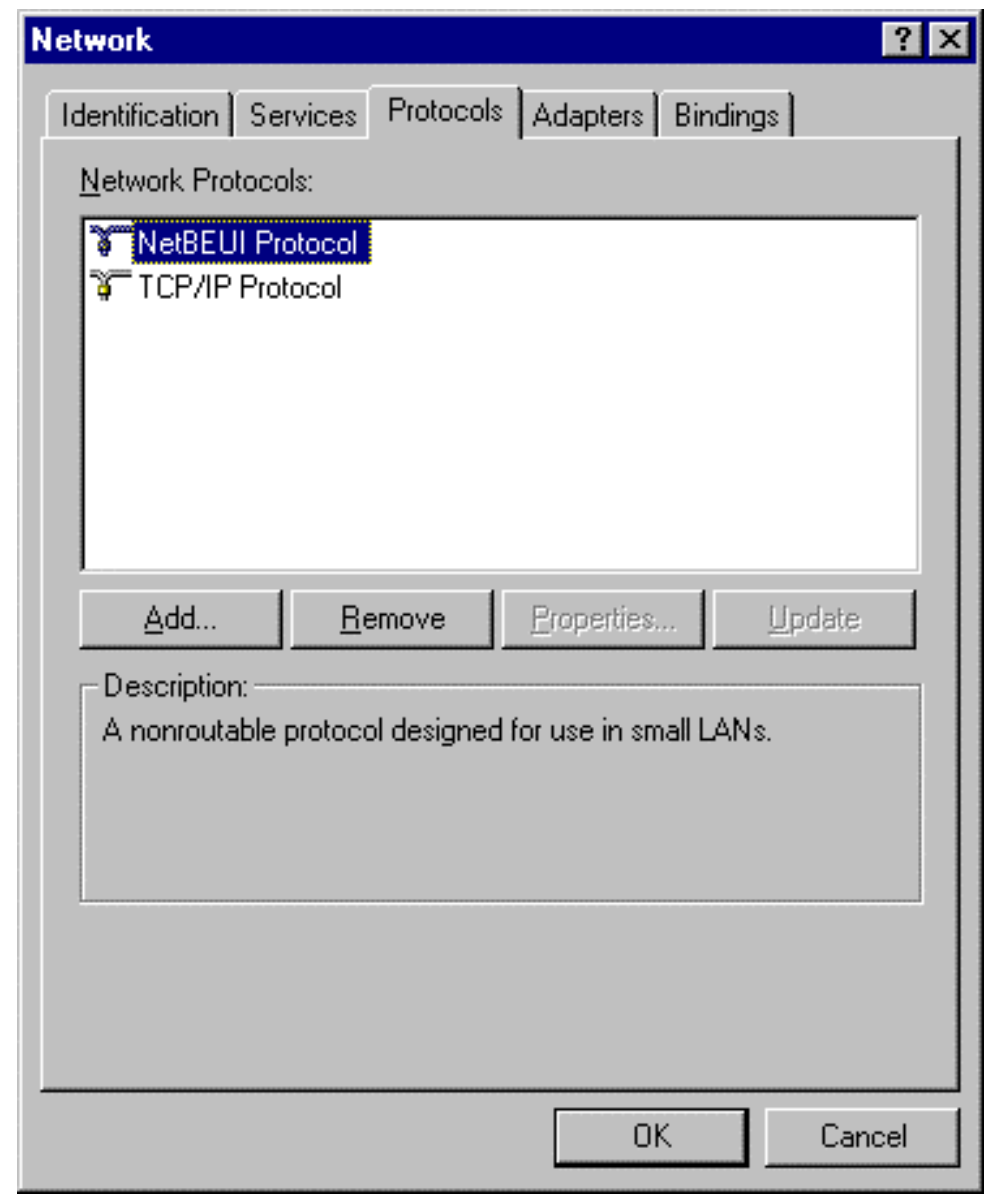

Figure C7. Network protocols dialog box.

- $\quad$ Setup TCP/IP Protocol properties.

From the Network Protocols list in the above dialog box, select TCP/IP Protocol and click Properties... . A Microsoft TCP/IP Properties dialog box will appear (Figure C8). 


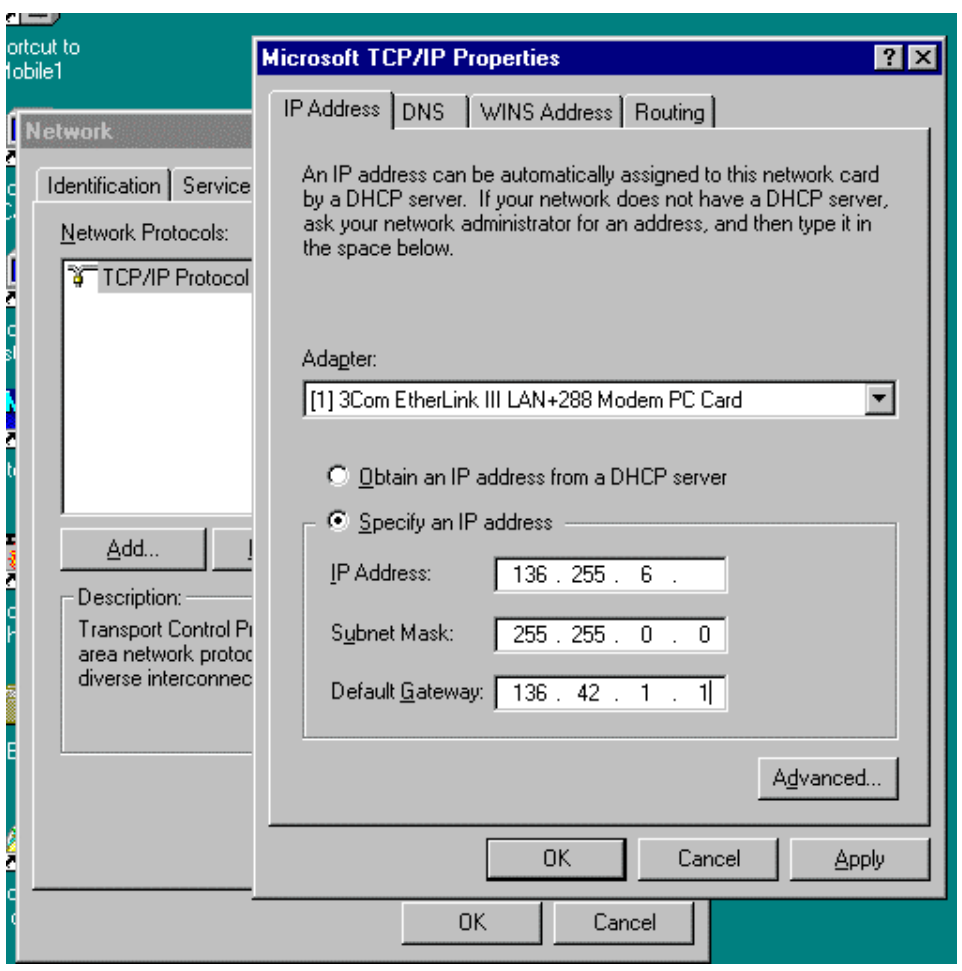

Figure C8. IP Address input dialog box.

As shown in Figure C8, select Specify an IP address and fill in IP Address, Subnet Mask and Default Gateway boxes. Your network administrator will provide appropriate numbers for your computer.

Note: Your Adapter combo box may show a different adapter from the one listed in theabove dialog box.

- $\quad$ Set DNS (Domain Name Server) properties.

Select the DNS tab and fill in all the boxes as shown in Figure C9. Acquire appropriate information from you network administrator. 


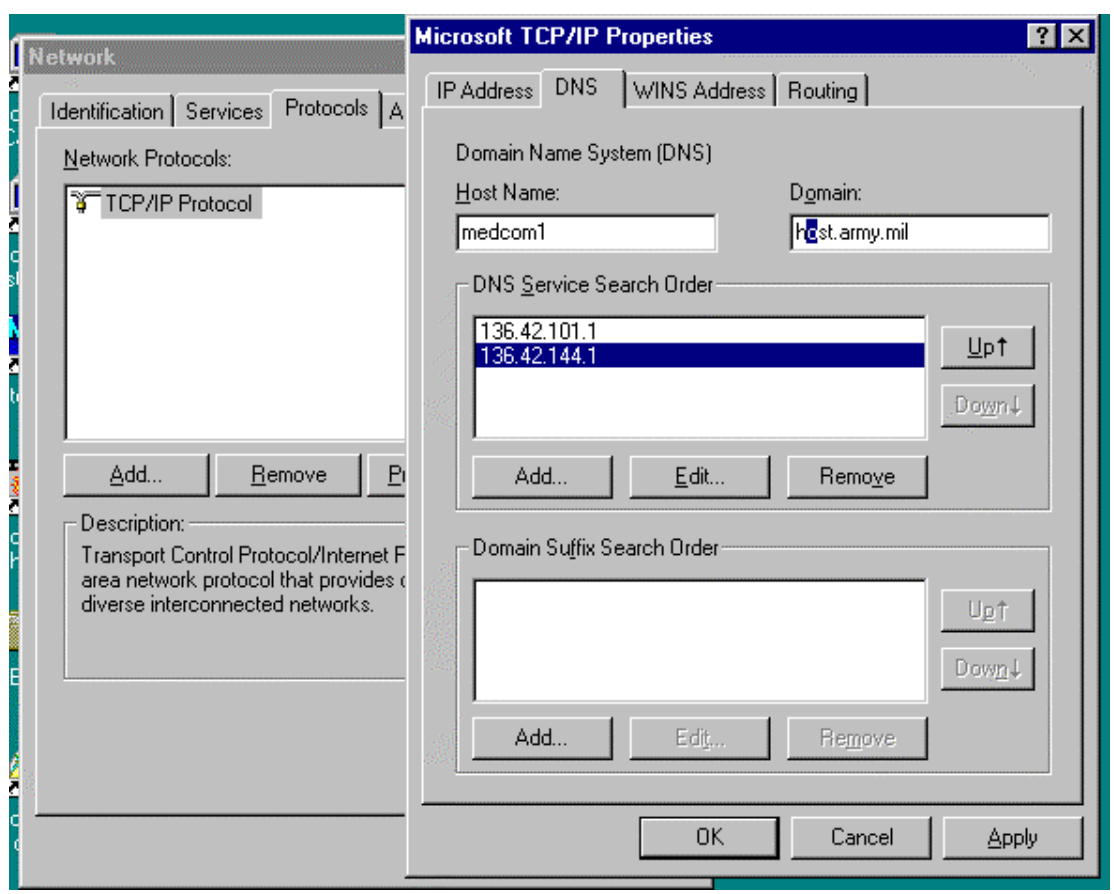

Figure C9. DNS setup.

- $\quad$ Check WINS Address.

Check if WI NS Address properties are set as in Figure C10. All the properties are default values and may not have to be changed. 


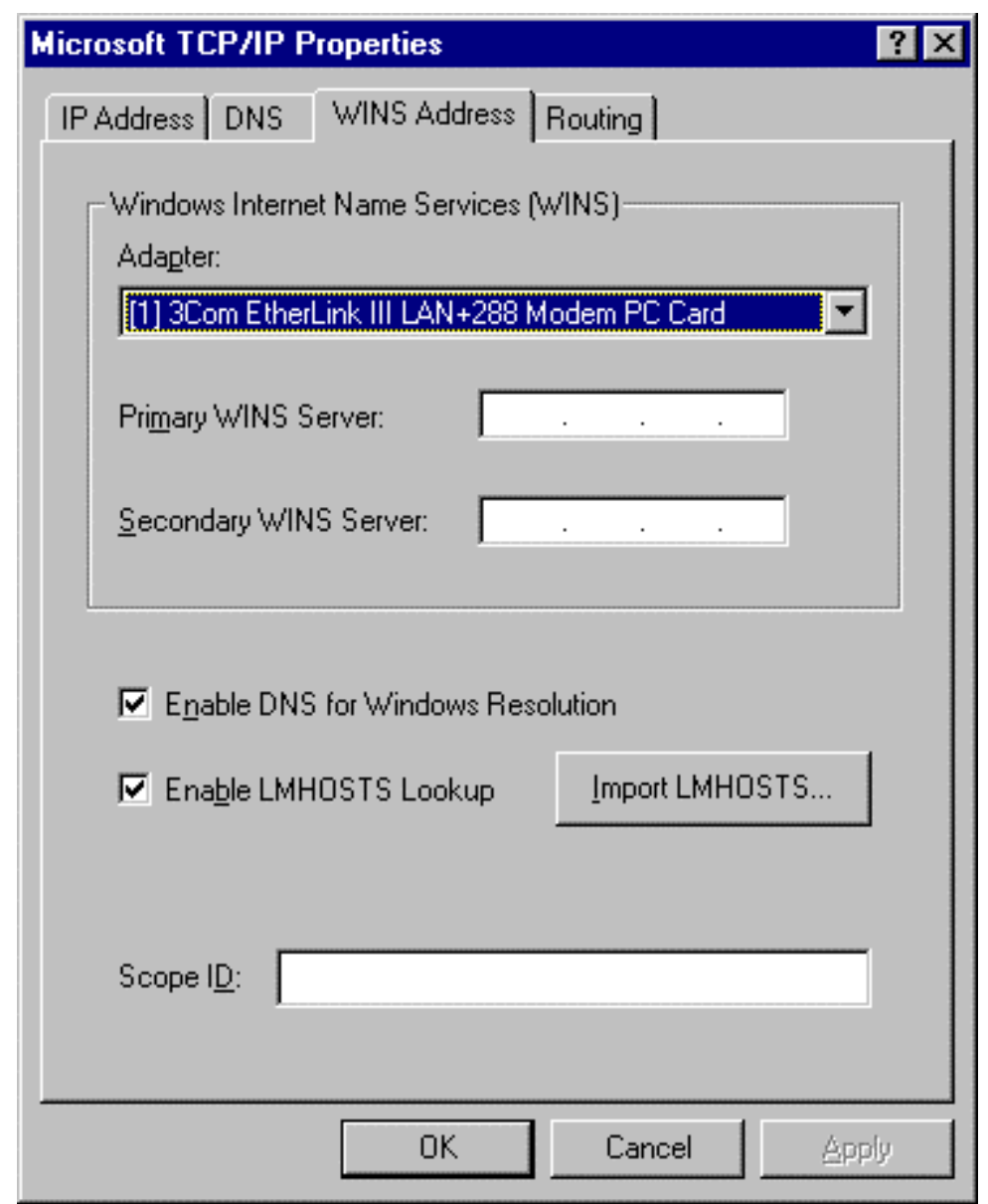

Figure C10. WINS Address dialog box.

- Set Routing properties.

Make sure the Enable IP F orwarding box is checked on the Routing tab (Figure C11). This step is required for RAS. 


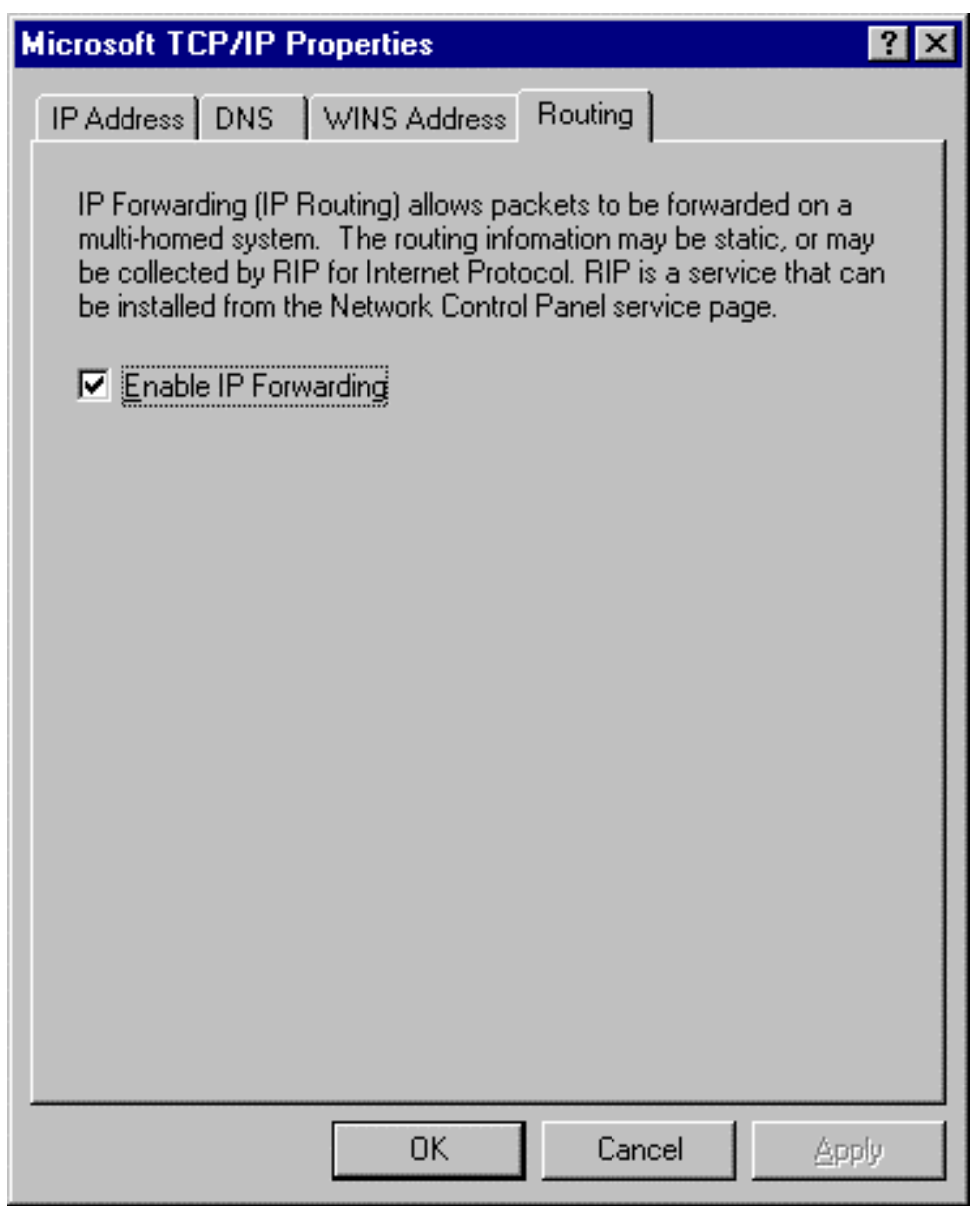

Figure C11. Enable IP Forwarding.

Click OK to close TCP/P Properties dialog box.

- Add RAS

Select the Services tab and click on the Add button (Figure C12). From the Select Network Service dialog box (not shown), select Remote Access Service, and click OK. 


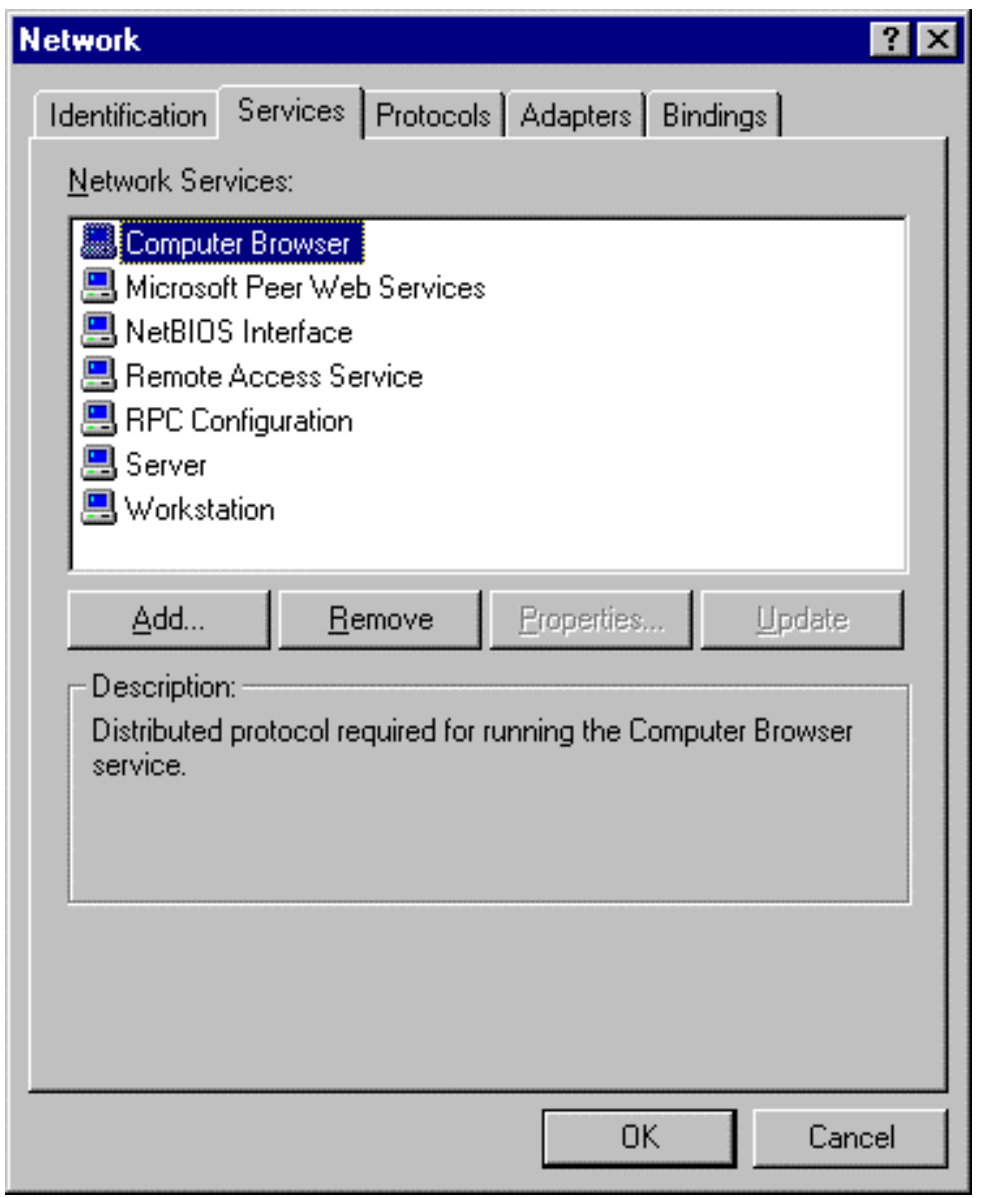

Figure C12. Network Services dialog box.

- Set RAS properties.

After RAS is installed, select Remote Access Service and click the Properties... button. Select the name of the installed modem from the list (shown in Figure C13), then click the Configure... button.

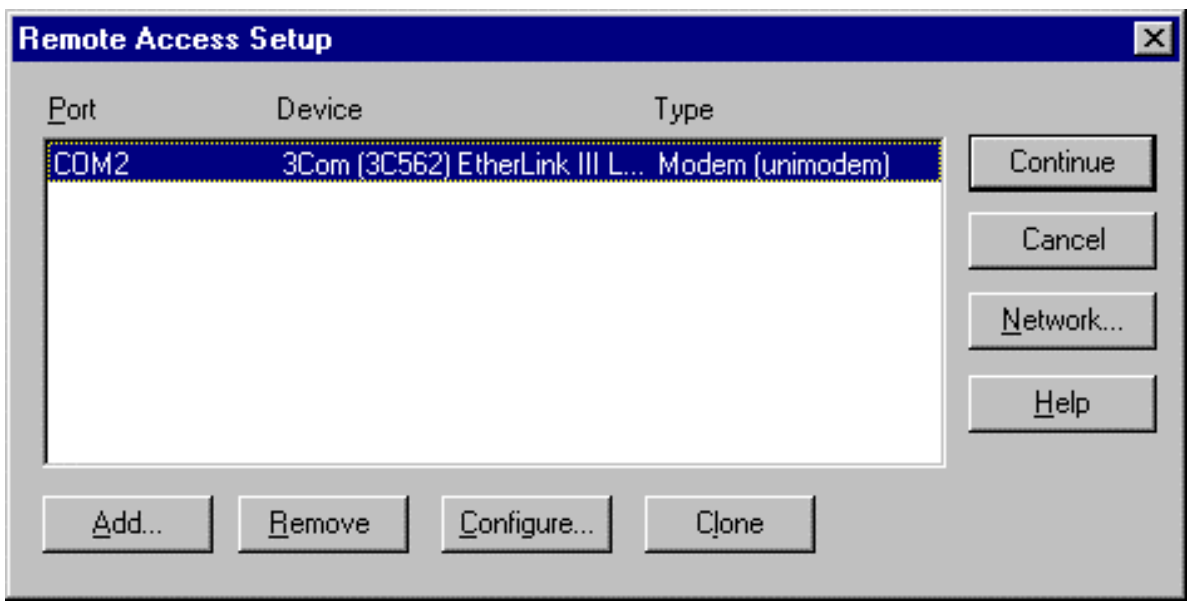

Figure C13. Remote Access Setup dialog box. 
- $\quad$ Set Port Usage.

From the Configure Port Usage dialog box, select the radio button before Dial out and Receive calls (Figure C14). Click OK.

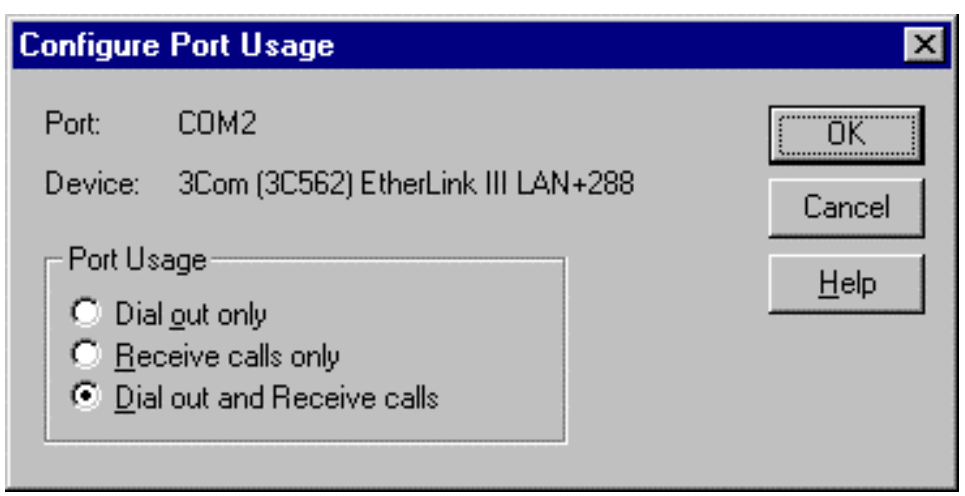

Figure C14. Set Dial out and Receive calls.

- Network Configuration setup.

From the Remote Access Setup dialog box, select the Network... button. When the Network Configuration dialog box appears (Figure C15), make appropriate changes. Make sure NetBEUI and TCP/IP boxes in Server Settings are checked. 


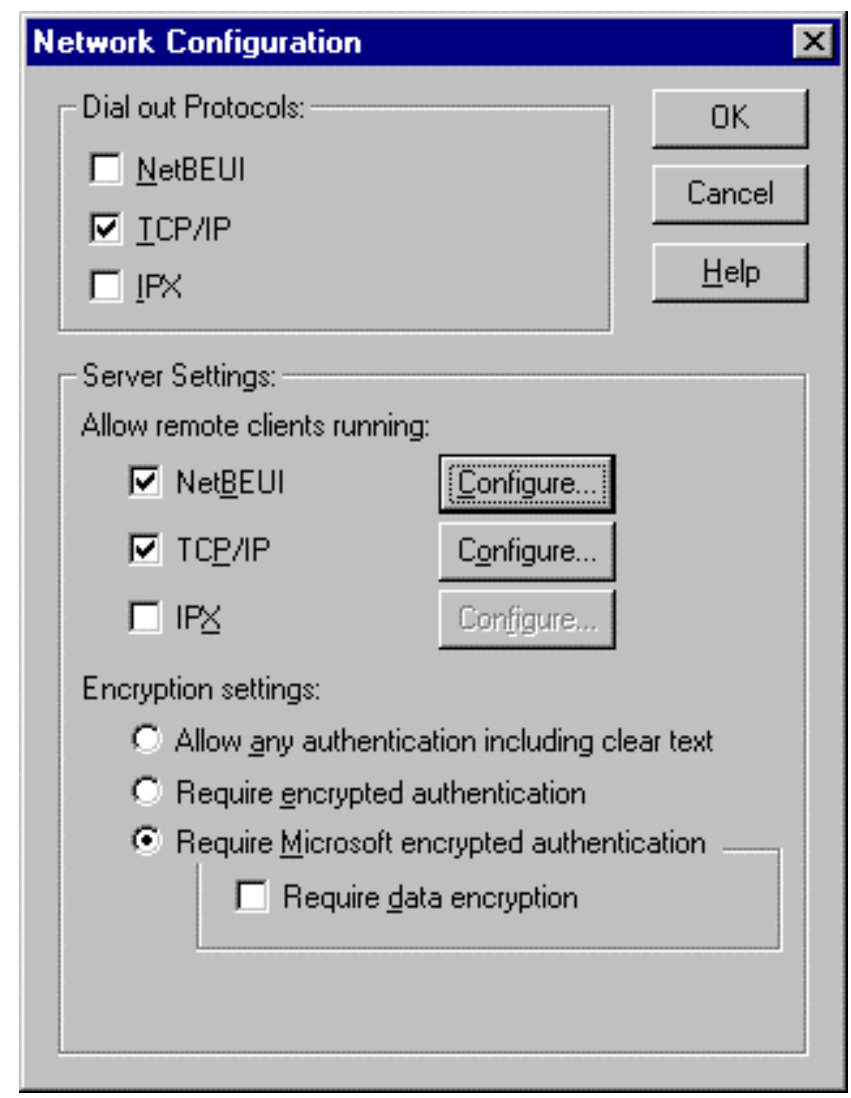

Figure C15. Allow remote clients running NetBEUI.

- Set NetBEUI configuration.

Click Configure... next to NetBEUI from the Network Configuration dialog box. Select Entire network (see Figure C16). Click OK.

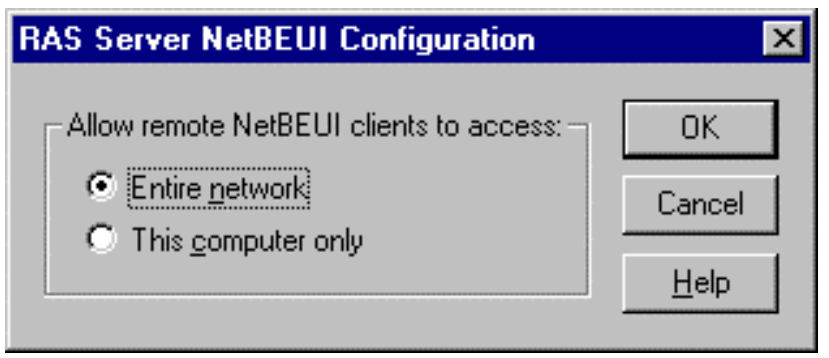

Figure C16. Allow remote NetBEUI clients to access the entire network.

- RAS Server TCP/IP Configuration.

Select Configure... next to TCP/IP from the Network Configuration dialog box (Figure $\mathrm{C} 15$ ). Select the Entire network and Use static address pool radio buttons (Figure $\mathrm{C} 17$ ). Also check the Allow remote clients to ... box. 
In the Begin and End boxes, enter IP addresses reserved for RAS. Request hel $p$ from your network administrator to set up these properties.

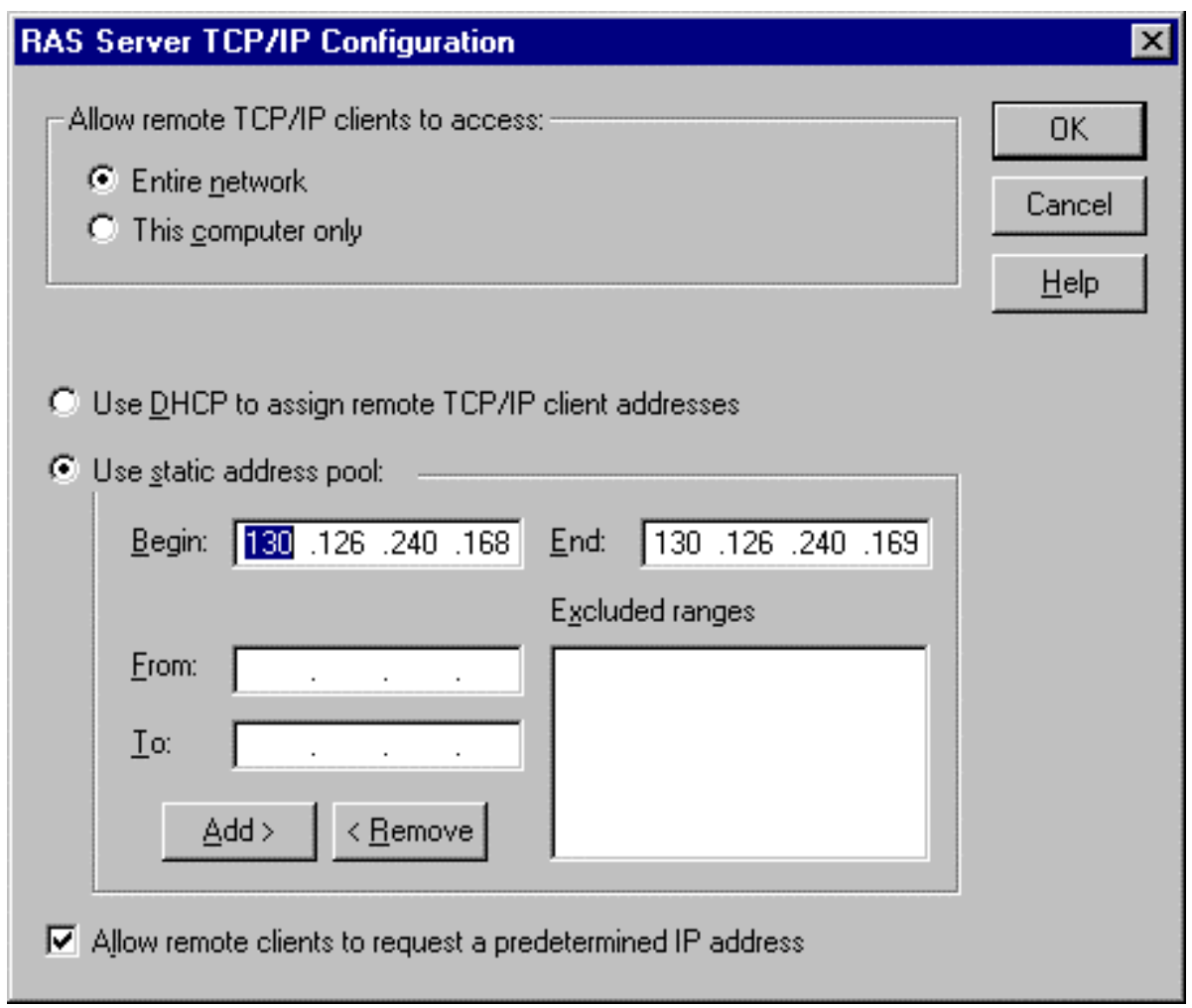

Figure C17. Assign static address pool.

- Restart your system.

After setting all the properties, exit network setup by clicking a series of OK buttons. You will be prompted for a system restart. Click OK and restart your system.

- Test.

From a remote computer that is not connected to any network system, dial in the server with the appropriate user name and password (in NT, use User Manager to set up a user account). If you are able to list the computer names and workgroups within your network system in your Windows Explorer, the setup succeeded. 


\section{Distribution}

Chief of Engineers 20314-1000

ATTN: CEHEC-IM-LH (2)

ATTN: CEHEC-IM-LP (2)

ATTN: CERD-L

ATTN: CERE-C (3)

U.S. Army Engineer District, Fort Worth

ATTN: CWSWF-PM-J (MED) (10)

Defense Technical Information Center 22060-6218

ATTN: DTIC-O (2)

20

$11 / 98$ 